UNIVERSIDADE DE SÃO PAULO

FACULDADE DE ECONOMIA, ADMINISTRAÇÃO E CONTABILIDADE DEPARTAMENTO DE ADMINISTRAÇÃO

PROGRAMA DE MESTRADO PROFISSIONAL EM EMPREENDEDORISMO

DESENVOLVIMENTO DE VEÍCULOS COMERCIAIS NO BRASIL:

UM ESTUDO SOBRE PARÂMETROS DE SUCESSO

EM GERENCIAMENTO DE PROJETOS DE PRODUTOS

Paschoal Federico Neto

Orientador: Prof. Dr. Antonio Cesar Amaru Maximiano

SÃo PAULO 
Prof. Dr. Marco Antonio Zago

Reitor da Universidade de São Paulo

Prof. Dr. Adalberto Américo Fischmann

Diretor da Faculdade de Economia, Administração e Contabilidade

Prof. Dr. Roberto Sbragia

Chefe do Departamento de Administração

Prof. Dr. Martinho Isnard Ribeiro de Almeida

Coordenador do Programa de Mestrado Profissional em Empreendedorismo 


\title{
DESENVOLVIMENTO DE VEÍCULOS COMERCIAIS NO BRASIL: UM ESTUDO SOBRE PARÂMETROS DE SUCESSO EM GERENCIAMENTO DE PROJETOS DE PRODUTOS
}

\author{
Dissertação apresentada ao Programa de \\ Mestrado Profissional em Empreendedorismo \\ do Departamento de Administração da \\ Faculdade de Economia, Administração e \\ Contabilidade da Universidade de São Paulo \\ como requisito parcial para obtenção do título \\ de Mestre em Ciências.
}

Orientador: Prof. Dr. Antonio Cesar Amaru Maximiano

\section{Versão Corrigida}

(versão original disponível na Biblioteca da Faculdade de Economia, Administração e Contabilidade)

\section{SÃO PAULO}


Federico Neto, Paschoal

Desenvolvimento de veículos comerciais no Brasil: um estudo sobre parâmetros de sucesso em gerenciamento de projetos de produtos.

Dissertação apresentada e aprovada em 20.09.2016 no Programa de Mestrado Profissional em Empreendedorismo do Departamento de Administração da Faculdade de Economia, Administração e Contabilidade da Universidade de São Paulo como requisito parcial para obtenção do título de Mestre em Ciências.

Comissão Julgadora:

Prof. Dr. Antonio Cesar Amaru Maximiano FEA-USP Presidente

Prof. Dr. Marcelo Caldeira Pedroso FEA-USP Membro

Prof. Dr. Flavio Hourneaux Junior $\quad$ FEA-USP Membro

Prof. Dr. Jefferson Leando Anselmo PROMON - Membro

Federico Neto, Paschoal

Desenvolvimento de veículos comerciais no Brasil: um estudo sobre parâmetros de sucesso em gerenciamento de projetos de produtos / Paschoal Federico Neto. - São Paulo, 2016.

$128 \mathrm{p}$.

Dissertação (Mestrado) - Universidade de São Paulo, 2016.

Orientador: Antonio Cesar Amaru Maximiano.

1. Administração de projetos 2. Gerenciamento de projetos 3. Sucesso 4 . Indicadores de sucesso 5 . Fatores críticos de sucesso 6 . Indústria automobilística. II. Título. 
Dedico este trabalho à minha amada esposa Vera Cristina Miotto Federico e aos meus filhos Beatriz Miotto Federico e Pedro Miotto Federico, por todo apoio e incentivo que me deram e dão, compreendendo meu desejo de desenvolvimento e aperfeiçoamento pessoal e acadêmico-profissional. 


\section{AGRADECIMENTOS}

Gostaria de agradecer a todos que, direta ou indiretamente, muito colaboraram com minha formação neste mestrado e na elaboração desta dissertação.

Ao meu orientador, Prof. Dr. Antonio Cesar Amaru Maximiano, meus profundos agradecimentos por todo auxílio e dedicação prestados ao longo deste meu mais recente projeto pessoal. Conheci-o há cerca de 20 anos e felizmente pude reencontrá-lo e aprender com suas magníficas aulas sobre Gerenciamento de Projetos. A amizade, no lado pessoal, e o respeito por sua competência profissional só aumentaram.

Agradecimentos especiais aos professores Dr. Martinho Isnard Ribeiro de Almeida, coordenador do Mestrado Profissional em Empreendedorismo (MPE), Dr. Marcelo Caldeira Pedroso, Dr. Fabio Lotti Oliva e Dr. Antonio Geraldo da Rocha Vidal, com quem, além de assistir excelentes aulas, tive a oportunidade de ser o primeiro representante discente na Comissão de Coordenação do Programa (CCP) no ano de 2015 (turmas 2014/15) e com isto conviver, aprender e tentar ajudá-los nos esforços pelo aprimoramento do curso e afirmação dos Encontros dos Mestrados Profissionais em Administração EMPRAD (FEA/USP, 2014).

Agradeço aos demais professores com quem pude aprender sobre os mais diversos temas da Administração, entre eles Dr. Silvio Aparecido dos Santos, Dra. Renata Giovinazzo Spers e Dra. Ana Cristina Limongi-França. Agradeço ainda, pelo convívio produtivo, à Dra. Patrícia V. de C. Krakauer, à Dra. Jane Marques e ao Dr. Emerson A. Maccari. Agradecimentos especiais à Sra. Fabiana de Cassia Caseiro, que sempre apoia a todos. Agradeço ao Dr. Flavio Hourneaux Junior e Dr. Jefferson Leando Anselmo por integrarem a comissão julgadora.

Agradeço também aos colegas e agora novos amigos Andrea A. M. Resende, Antonio S. Nasser Filho, Artur T. Vilas Boas, Bruno M. Madureira, Débora Rodrigues, Eduardo Bonilha, Fábio O. Hyraiama, Gabriel S. de Paiva, Gisele Jacociuk. B. de Souza, Irina Bullara, Karina Kikuti, Lívia L. Baptista, Marco A. Bottacin, Marcus V. Vivone, Milton Francesconi, Míriam Martin, Renata M. Rocha, Sidirley Fabiani e Stéfani Paranhos, integrantes desta que foi a primeira turma (2014) do MPE da Faculdade de Economia, Contabilidade e Administração (FEA) da Universidade Estadual de São Paulo (USP).

Por fim, meus agradecimentos a todos os colegas e amigos profissionais que aqui simbolicamente represento pelo Sr. Carlos E. Brevilieri, com quem tive a oportunidade de trocar muitas ideias durante a elaboração desta dissertação. 
"Da prática à teoria!"

Prof. Dr. Martinho Isnard Ribeiro de Almeida 


\section{RESUMO}

Esta dissertação tem como objetivo pesquisar a importância de parâmetros de sucesso no processo de gerenciamento do desenvolvimento de veículos comerciais em uma empresa estabelecida no Brasil, quarto maior mercado mundial. O referencial teórico tem como base os cinco critérios de avaliação de resultados de projetos descritos no Modelo Diamante de Shenhar e Dvir e os dez fatores críticos de sucesso (FCS) que formam o Modelo de Processo de Implantação de Projetos (PIP) de Pinto e Slevin. Para isto, foi feito um estudo de caso em uma grande montadora tradicional, por meio de um questionário dirigido a participantes de gerenciamento de projetos de produtos. A pesquisa revelou resultados como: (i) o perfil do participante de projetos de veículos comerciais, principalmente engenheiros com grande experiência profissional; (ii) as características principais dos produtos desenvolvidos, como inovação, tecnologia, complexidade e prazo restrito; (iii) a comparação de priorização dos critérios de sucesso segundo as opiniões dos entrevistados e segundo o que pensam ser o que sua empresa adota e (iv) a priorização dos FCS segundo suas próprias opiniões. Nestes dois últimos resultados, obtiveram-se achados que, por um lado, confirmam o referencial teórico e, por outro lado, mostram algumas diferenças como (i) o paradoxo de alguns altos executivos considerarem que a empresa adota critérios diferentes da sua própria priorização e (ii) a relação de importância dos FCS com o perfi do entrevistado e suas principais necessidades próprias para o desenvolvimento de projetos. Por fim, esta pesquisa traz colaborações para a academia, para as empresas e para a sociedade por meio da proposta do Mestrado Profissional em Empreendedorismo da Faculdade de Economia, Administração e Contabilidade da Universidade de São Paulo (FEA-USP), que busca temas de pesquisa baseado no universo profissional, embasa os conceitos teóricos com a metodologia acadêmica e aplica a pesquisa novamente no campo profissional. Isto aproxima a Universidade ao mundo empresarial e colabora com uma melhora sustentável de produtividade da sociedade brasileira.

Palavras Chave: $\quad$ Administração de Projetos, Gerenciamento de Projetos, Sucesso, Indicadores de Sucesso, Fatores Críticos de Sucesso, Indústria Automobilística. 


\begin{abstract}
This dissertation aims to research the importance of success parameters in the management process of commercial vehicles' development in one company established in Brazil, world's fourth largest market. The theoretical framework was based on five criteria of project evaluation results, described in the Diamond Model designed by Shenhar and Dvir, and in ten critical success factors (CSF) that integrate the Projects Implementation Process (PIP) modeled by Pinto and Slevin. For this purpose, a case study in a large traditional automaker was done through a questionnaire addressed to participants of product management projects. This research showed results such as: (i) the profile of commercial vehicles projects' participants, which are mainly engineers with large professional experience; (ii) the developed products main characteristics, as innovation, technology, complexity and limited term; (iii) the comparison of success criteria prioritization according to the their own opinions and what they think their company adopts and (iv) the prioritization of CSF according to their own opinions. In the latter two results, research has gathered interesting findings that, on one hand, confirm the theoretical framework and, on the other hand, show some differences as (i) the paradox of some senior executives who consider that the company adopts different criteria than their own prioritization and (ii) the importance of CSF relationship with the respondents' profiles and their own main needs for development projects. Finally, this research brings contributions to academy, to business and to society through the proposal of the Professional Master's Degree in Entrepreneurship of the School of Economics, Business and Accounting of the University of São Paulo (FEA-USP), which seeks to research themes based on the professional world, underlies theoretical concepts with academic methodology and applies research findings again into the professional field. This brings the University closer to the business world and collaborates with a sustainable improvement of Brazilian society's productivity.
\end{abstract}

Keywords: Project Administration, Project Management,

Success, Success Indicators, Critical Success Factors, Automotive Industry. 


\section{SUMÁRIO}

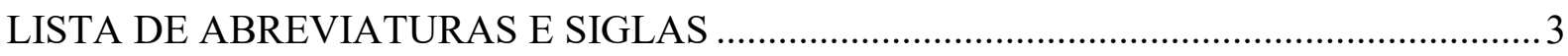

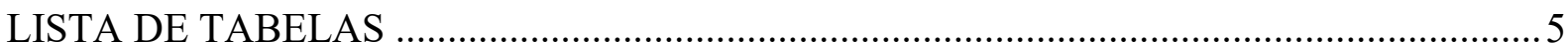

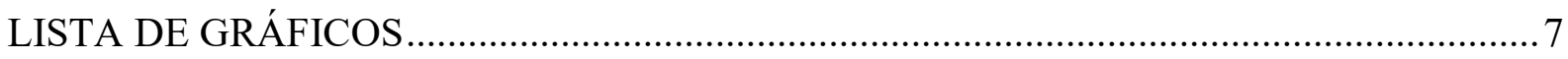

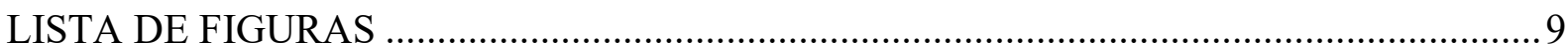

1 INTRODUÇÃ

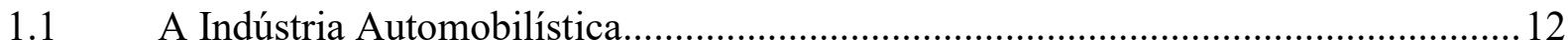

1.2 Oportunidade de Estudo, Objetivos e Questão Principal da Pesquisa ....................... 17

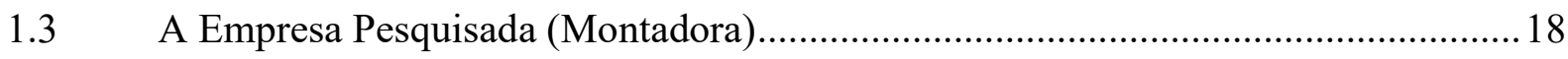

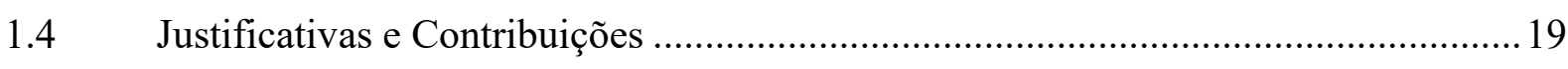

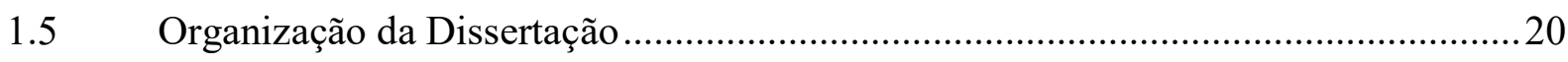

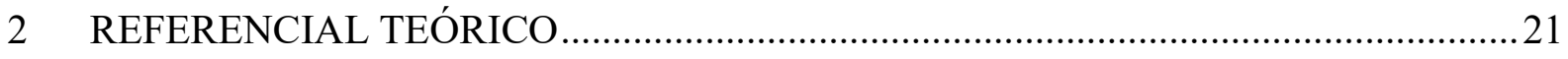

2.1 Processos Funcionais e Projetos de Novos Produtos .............................................21

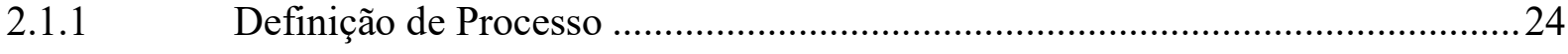

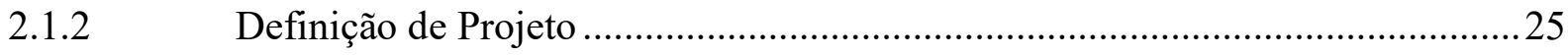

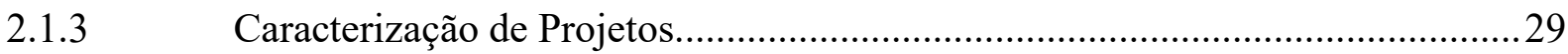

2.2 Parâmetros de Sucesso em Gerenciamento de Projetos.............................................. 34

2.2.1 Critérios de Avaliação de Sucesso do Resultado do Projeto...............................34

2.2.2 Fatores Críticos de Sucesso na Execução do Gerenciamento de Projetos ..........41

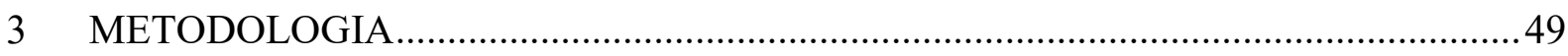

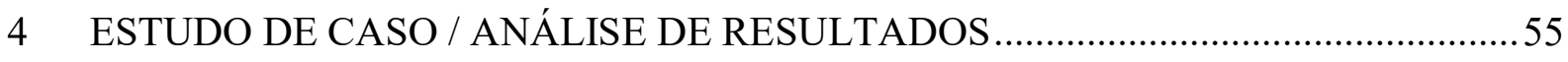

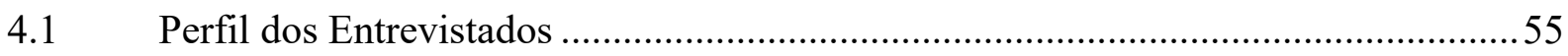

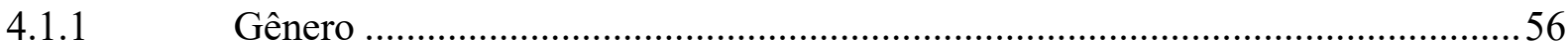

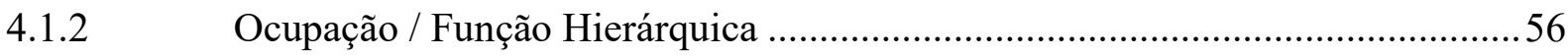

4.1.3 Atividade Funcional na Organização ..............................................................57

4.1.4 Tempo de Experiência Profissional .............................................................5

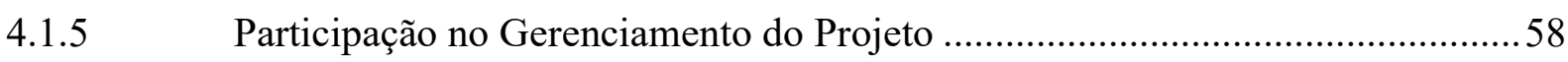

4.2 Caracterização dos Projetos Referenciados pelos Entrevistados ...............................58

4.2.1 Novidade dos Veículos em Relação ao Mercado ................................................59 
4.2.2 Tecnologia dos Veículos ou de seus Principais Sistemas Importantes .............. 60

4.2.3 Complexidade de Fornecimento de Sistemas Importantes ............................... 60

4.2.4 Tempo Disponível para Desenvolvimento do Projeto ......................................... 61

4.3 Classificação dos Critérios de Sucesso do Resultado do Projeto.............................. 61

4.3.1 Priorização segundo a opinião dos entrevistados............................................ 62

4.3.2 Priorização adotada pela empresa, segundo os entrevistados ........................... 72

4.4 Classificação dos Fatores Críticos de Sucesso para a Execução do Projeto ............. 82

4.4.1 Priorização dos FCS em Função do Perfil do Entrevistado ................................ 89

4.4.2 Priorização dos FCS em Função das Características dos Projetos..................... 93

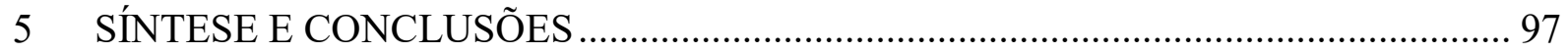

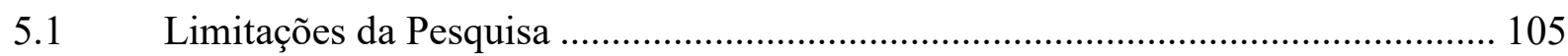

5.2 Contribuições para a Academia, para as Empresas, para a Sociedade.................... 106

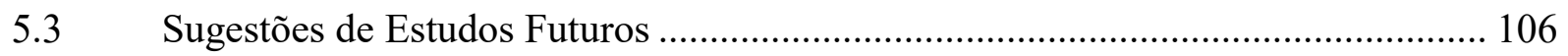

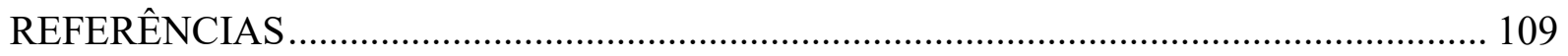

APÊNDICES 


\section{LISTA DE ABREVIATURAS E SIGLAS}

ABNT Associação Brasileira de Normas Técnicas

ANFAVEA Associação Nacional dos Fabricantes de Veículos Automotores

CAPES Coordenação de Aperfeiçoamento de Pessoal de Nível Superior

CCP Comissão de Coordenação do Programa

CPG Comissão de Pós Graduação

CRUESP Conselho de Reitores das Universidades Estaduais Paulistas

EFQM European Foundation for Quality Management

EMPRAD Encontro dos Mestrados Profissionais em Administração

FCS Fator(es) Crítico(s) de Sucesso

FEA Faculdade de Economia, Administração e Contabilidade

FIA Fundação Instituto de Administração

FNQ Fundação Nacional da Qualidade

IBAMA Conselho Nacional do Meio Ambiente

ICB4 Individual Competence Baseline $-4^{\text {th }}$ Version

IPMA International Project Management Association

JUSE Union of Japanese Scientist and Engineer

MDIC Ministério do Desenvolvimento, Indústria e Comércio Exterior

MEC Ministério da Educação

MPE Mestrado Profissional em Empreendedorismo

NIST National Institute of Standards and Technology

OGC Office of Government Commerce

$\mathrm{PMBOK}{ }^{\circledR} \quad$ Project Management Body of Knowledge (Registered)

PMI Project Management Institute

PIP Processo de Implantação de Projeto (Project Implementation Profile)

PRINCE Projects in Controlled Environments

PROCONVE Programa de Controle de Poluição do Ar por Veículos Automotores

SIBi Sistema Integrado de Bibliotecas

SINDIPEÇAS Sindicato Nacional da Indústria de Componentes para Veículos Automotores USP Universidade de São Paulo 


\section{LISTA DE TABELAS}

Tabela 1 - Principais grupos fabricantes de veículos comerciais e suas marcas mundiais ...... 12

Tabela 2 - Principais grupos / marcas de veículos comerciais no mercado brasileiro ............. 16

Tabela 3 - Influência das estruturas organizacionais nos projetos .......................................22

Tabela 4 - Áreas de Resultados relacionadas a Critérios de Avaliação de Sucesso..................37

Tabela 5 - Áreas de Resultados relacionadas a Fatores Críticos de Sucesso ...........................46

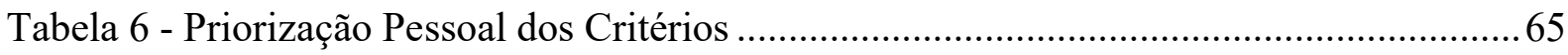

Tabela 7 - Priorização Pessoal em função do Nível Hierárquico ..............................................66

Tabela 8 - Priorização Pessoal em função da Área Funcional ................................................67

Tabela 9 - Priorização Pessoal em função do Tempo de Experiência Profissional...................67

Tabela 10 - Priorização Pessoal em função da Participação no Projeto ....................................68

Tabela 11 - Priorização Pessoal em função da Novidade............................................................69

Tabela 12 - Priorização Pessoal em função da Tecnologia ....................................................... 70

Tabela 13 - Priorização Pessoal em função da Complexidade ....................................................70

Tabela 14 - Priorização Pessoal em função do Tempo.............................................................. 71

Tabela 15 - Comparação de Priorização de Critérios: Pessoal x Empresa.................................74

Tabela 16 - Comparação de Priorização Pessoal x Empresa, por Nível Hierárquico .............. 75

Tabela 17 - Comparação de Priorização Pessoal x Empresa, por Área Funcional.................... 76

Tabela 18 - Comparação de Priorização Pessoal x Empresa, por Experiência Profissional .... 77

Tabela 19 - Comparação de Priorização Pessoal x Empresa, por Participação no Projeto ...... 78

Tabela 20 - Comparação de Priorização Pessoal x Empresa, por Novidade.............................79

Tabela 21 - Comparação de Priorização Pessoal x Empresa, por Tecnologia ........................... 80

Tabela 22 - Comparação de Priorização Pessoal x Empresa, por Complexidade ..................... 80

Tabela 23 - Comparação de Priorização Pessoal x Empresa, por Tempo ............................... 81

Tabela 24 - Priorização dos Fatores Críticos de Sucesso (FCS) …............................................ 88

Tabela 25 - Priorização dos FCS em função do Nível Hierárquico .......................................... 89

Tabela 26 - Priorização dos FCS em função da Área Funcional..............................................90

Tabela 27 - Priorização dos FCS em função do Tempo de Experiência Profissional ..............91

Tabela 28 - Priorização dos FCS em função da Participação no Projeto .................................. 92

Tabela 29 - Priorização dos FCS em função da Novidade ....................................................... 93

Tabela 30 - Priorização dos FCS em função da Tecnologia.....................................................94

Tabela 31 - Priorização dos FCS em função da Complexidade ................................................95

Tabela 32 - Priorização dos FCS em função do Tempo ............................................................96 


\section{LISTA DE GRÁFICOS}

Gráfico 1 - Produção brasileira de veículos comerciais 2011-2015 _...................................... 15

Gráfico 2 - Períodos de tempo das dimensões de sucesso...................................................... 40

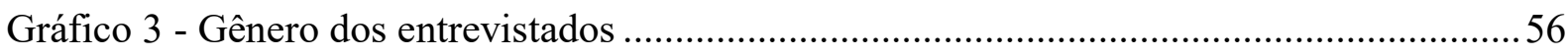

Gráfico 4 - Ocupação / Função Hierárquica ...........................................................................56

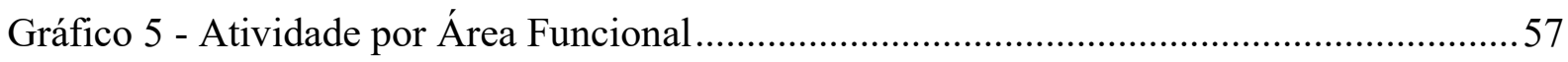

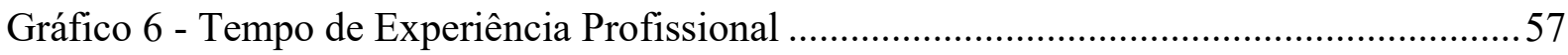

Gráfico 7 - Participação no Gerenciamento de Projeto .............................................................58

Gráfico 8 - Novidade dos produtos em relação ao mercado...................................................59

Gráfico 9 - Tecnologia dos veículos ou de seus sistemas importantes....................................60

Gráfico 10 - Complexidade do fornecimento de sistemas importantes....................................60

Gráfico 11 - Tempo disponível para desenvolvimento do projeto .........................................61

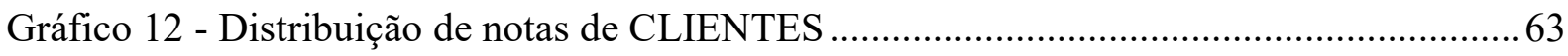

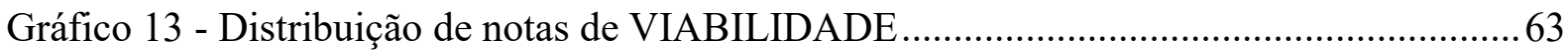

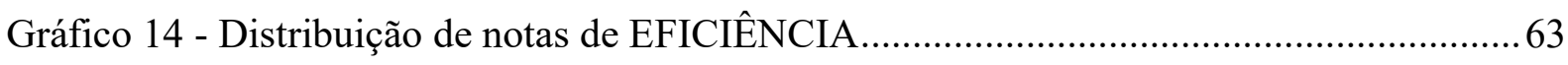

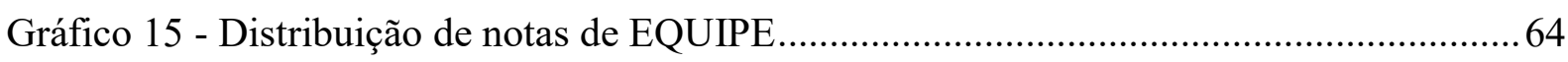

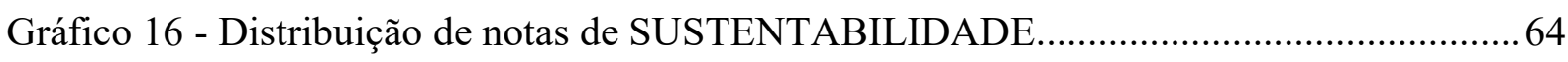

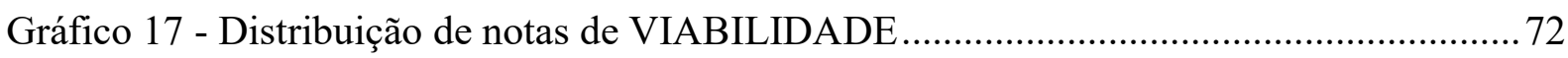

Gráfico 18 - Distribuição de notas de CLIENTES ................................................................. 72

Gráfico 19 - Distribuição de notas de EFICIÊNCIA............................................................... 73

Gráfico 20 - Distribuição de notas de SUSTENTABILIDADE.............................................. 73

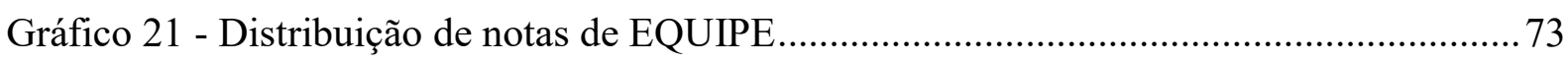

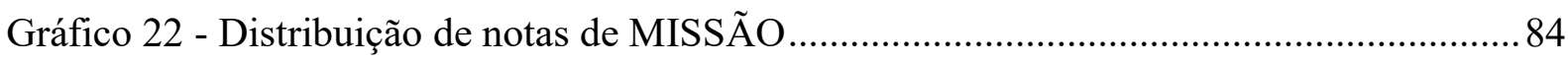

Gráfico 23 - Distribuição de notas de PLANEJAMENTO E CRONOGRAMA ......................84

Gráfico 24 - Distribuição de notas de CONSULTA A CLIENTES ......................................... 84

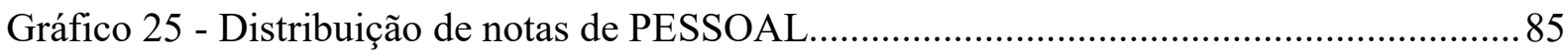

Gráfico 26 - Distribuição de notas de APOIO DA ALTA DIREÇÃO .....................................85

Gráfico 27 - Distribuição de notas de ACEITAÇÃO DE CLIENTES...................................... 85

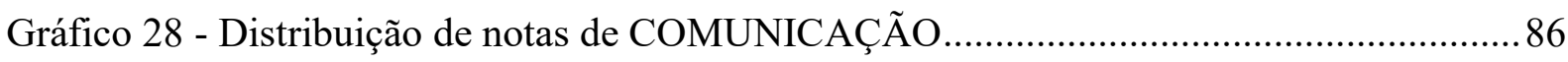

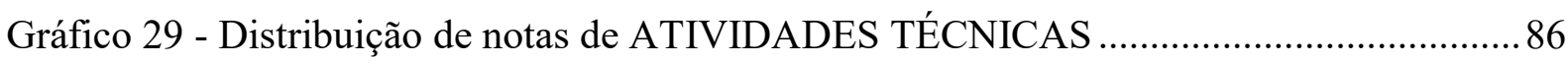

Gráfico 30 - Distribuição de notas de ACOMPANHAMENTO E FEEDBACK ......................86

Gráfico 31 - Distribuição de notas de SOLUÇÃO DE PROBLEMAS.................................... 87 


\section{LISTA DE FIGURAS}

Figura 1 - Classificação das indústrias (pela utilização da gestão de projetos) 22

Figura 2 - Características que definem o grau de dificuldade e o risco do projeto segundo

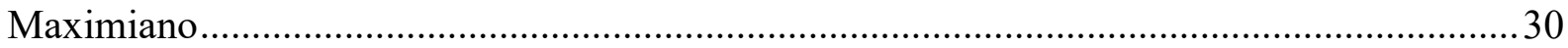

Figura 3 - Exemplo de Modelos I4 Pró-Valor ${ }^{\circledR} /$ Único .......................................................... 32

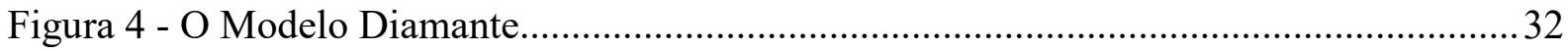

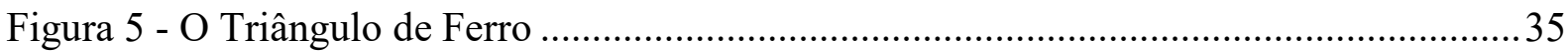

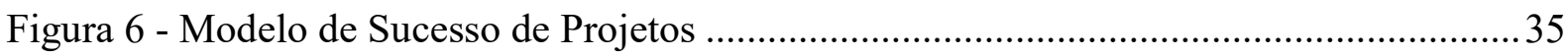

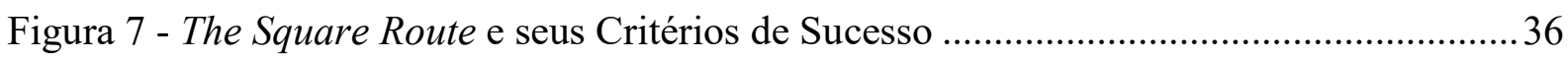

Figura 8 - Cinco níveis de sucesso do projeto segundo Bannerman ....................................... 38

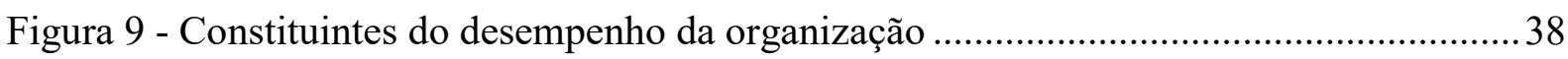

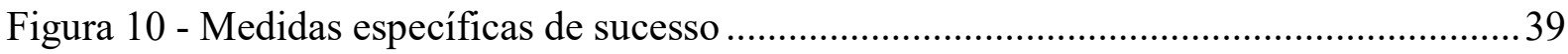

Figura 11 - Importância relativa das dimensões de sucesso: Uma questão de tempo ..............40

Figura 12 - Importância relativa das dimensões de sucesso depende do projeto ......................41

Figura 13 - Modelo de Dez Fatores Críticos do Processo de Implantação de Projeto ..............45

Figura 14 - Fatores Críticos de Sucesso / Fracasso segundo Bellassi e Tukel ..........................46

Figura 15 - Fatores Críticos de Sucesso mapeados conforme Modelo Formal de Sistemas ....47

Figura 16 - Fluxo de atividades / Metodologia de pesquisa ..................................................50 


\section{INTRODUÇÃO}

Com base na experiência profissional do autor, de mais de 30 anos de trabalho em setor de desenvolvimento de produtos de veículos comerciais, o objetivo da elaboração desta dissertação é pesquisar sobre a importância dos parâmetros de sucesso deste processo e buscar identificar os fatores críticos de sucesso (FCS) para a execução do processo de gerenciamento de desenvolvimento de produtos e os critérios de avaliação de sucesso dos resultados de projetos, por meio do estudo de caso em uma empresa tradicional da indústria brasileira de veículos comerciais.

A indústria automobilística, devido aos crescentes equacionamentos ambientais e também buscando aproveitar o desenvolvimento tecnológico de outras áreas de interface (eletrônica embarcada, por exemplo), tem trabalhado com projetos cada vez mais complexos, integrando sistemas modulares importantes na elaboração de seus veículos.

Os grupos participantes da indústria automobilística, em especial os de veículos comerciais que elaboram produtos de natureza profissional (bens de investimento), tem tido a necessidade de se destacar no mercado, desenvolvendo produtos sobre plataformas mundiais, cada vez mais específicos às diferentes aplicações locais de seus clientes.

No Brasil, este cenário também se verifica e o quarto maior mercado de veículos do mundo (ANFAVEA, 2016a) tem muitas experiências que podem e devem ser registradas e compartilhadas, para que a sociedade possa usufruir destes conhecimentos aqui desenvolvidos.

Em função disto, este trabalho busca então analisar e divulgar lições aprendidas sobre os principais parâmetros de sucesso no gerenciamento do processo de desenvolvimento de veículos comerciais brasileiros, de modo a poder contribuir para o avanço e registro do conhecimento, para a disseminação de práticas da iniciativa privada e colaborar com empreendedores, mesmo os de outros segmentos. 


\subsection{A Indústria Automobilística}

A indústria automobilística contemporânea nasceu há cento e trinta (130) anos, em 1886, quando Karl Benz inventou o primeiro automóvel do mundo (Benz Patent Motorwagen) movido com um motor de combustão interna e configurado com três rodas. No mesmo ano, Gottlieb Daimler apresentava sua carruagem motorizada, considerada então o primeiro automóvel de quatro rodas do mundo (DAIMLER, 2015). A partir daí, diversos fabricantes de veículos, em diversos continentes, lançaram-se ao mercado, produzindo automóveis e veículos comerciais (caminhões e ônibus).

Atualmente, observando-se o mercado mundial de veículos comercias, pode-se perceber que existem cerca de quarenta (40) marcas principais, das quais aproximadamente dois terços (2/3) pertencem a um seleto rol de sete (7) grandes grupos de fabricantes, estes notadamente europeus e norte-americanos (vide Tabela 1).

Tabela 1 - Principais grupos fabricantes de veículos comerciais e suas marcas mundiais

\begin{tabular}{|c|c|c|c|c|c|c|c|c|c|c|}
\hline & \multicolumn{2}{|c|}{ Principais Grande Grupos } & \multicolumn{7}{|c|}{ Principais Marcas } & \multirow[t]{2}{*}{ Alianças } \\
\hline & \multirow{4}{*}{ Europeus } & Daimler & Mercedes-Benz & Freightliner & Western Star & Thomas Built & Fuso & Setra & BharatBenz & \\
\hline & & Volvo & Volvo & Renault & Mack & Prevost & Nova & UD & Eicher & \\
\hline & & MAN (VW) & MAN & Neoplan & VW & Scania & & & & \\
\hline & & CNH (FIAT) & Iveco & Iveco Bus & Heuliez & Iveco Astra & Magirus & & & \\
\hline & \multirow{3}{*}{$\begin{array}{l}\text { Norte } \\
\text { Americanos }\end{array}$} & Paccar & Peterbilt & Kennworth & DAF & & & & & \\
\hline & & Navistar & International & IC-Bus & Neostar & & & & & \\
\hline & & Ford & Ford & (Cargo) & & & & & & \\
\hline \multirow{11}{*}{ : } & \multirow{5}{*}{ Chineses } & DFCV & Dongfeng & & & & & & & Volvo \\
\hline & & CFGC & FAW & & & & & & & \\
\hline & & CNHTC & Sinotruk & & & & & & & MAN \\
\hline & & FOTON & Aumark & (Auman) & & & & & & Daimler \\
\hline & & Shaanxi & Schacman & & & & & & & \\
\hline & \multirow{2}{*}{ Indianos } & Tata & Tata & & & & & & & \\
\hline & & Ashok-Leyland & Leyland & & & & & & & \\
\hline & \multirow{2}{*}{ Japoneses } & ISUZU & Isuzu & & & & & & & \\
\hline & & Toyota & Hino & & & & & & & \\
\hline & \multirow{2}{*}{ Russos } & KAMAZ & Kamaz & & & & & & & Daimler \\
\hline & & GAZ & Gaz & & & & & & & \\
\hline & Brasileiro & AGRALE & Agrale & & & & & & & \\
\hline
\end{tabular}

Fonte: Elaborado pelo autor

Esta relativa concentração atual de fabricantes é devida à tendência cada vez maior de os produtos exigirem grandes investimentos para seu desenvolvimento e produção, o que dificulta a sobrevivência de empresas de menor porte e menores recursos. Fatores como economia de escala, novas e cada vez mais restritivas legislações de emissões de gases 
atmosféricos, emissões de ruído, normas de segurança veicular e mesmo o advento da eletrônica embarcada, ilustram alguns dos diversos motivos que levam os produtos a terem alta tecnologia e complexidade, comparativamente aos primeiros veículos produzidos.

Para serem viáveis, portanto, as montadoras de veículos comerciais adotam um modelo de desenvolvimento de produtos semelhante ao modelo das indústrias aeroespacial e aeronáutica, que atuam como integradoras de sistemas modulares importantes como propulsão, trens de pouso, navegação e outros (GUERRA, 2011). No caso da indústria automobilística, estes sistemas, tais como trens de força, sistemas de dirigibilidade e outros, podem ser produzidos por empresas do próprio grupo a que pertencem (“holding”) ou serem fornecidos por empresas fabricantes, especializadas em sistemas veiculares (sistemistas).

Da mesma forma que as montadoras de veículos, também as empresas sistemistas passaram por um movimento de concentração, e pelos mesmos motivos, atualmente existem no mundo cerca de 20 grandes grupos, notadamente europeus e norte-americanos (STATISTA, 2016; PWC, 2015).

O desafio dos grandes fabricantes mundiais de veículos comerciais passa então a ser o desenvolvimento com sucesso de produtos inovadores e com alta tecnologia e complexidade, diferenciados sobre plataformas mundiais (de modo a aumentarem-se escalas e diminuírem-se custos) e adaptados aos desejos dos diferentes clientes locais (KOTABE; HELSEN, 2000).

“Tão global quanto possível, tão local quanto necessário" (DAIMLER, 2012) é uma frase que traduz os princípios da Daimler para seus veículos comerciais, mas que poderia ser atribuída a qualquer competidor deste mercado.

No Brasil, a indústria automobilística foi iniciada no governo do presidente Juscelino Kubitschek nos anos de 1950 (ANFAVEA, 2016a; SÃO PAULO, 2014). Esta história se desenvolveu de forma local, crescente e competitiva, sendo que atualmente o Brasil é o oitavo maior produtor mundial de veículos e o quarto maior mercado interno (vide Quadro 1), mesmo considerando-se a crise econômica vivida pelo país a partir de 2014, que provocou fortes reduções de aproximadamente 21\% em 2014/2013 e 45\% em 2015/2014 nos volumes de veículos produzidos (vide Gráfico 1). 
O cenário do início do ano de 2016 permanece de crise, havendo uma redução de aproximadamente $36 \%$ no primeiro trimestre 2016/2015 (ANFAVEA, 2016b).

Quadro 1 - Indústria automobilística brasileira em grandes números

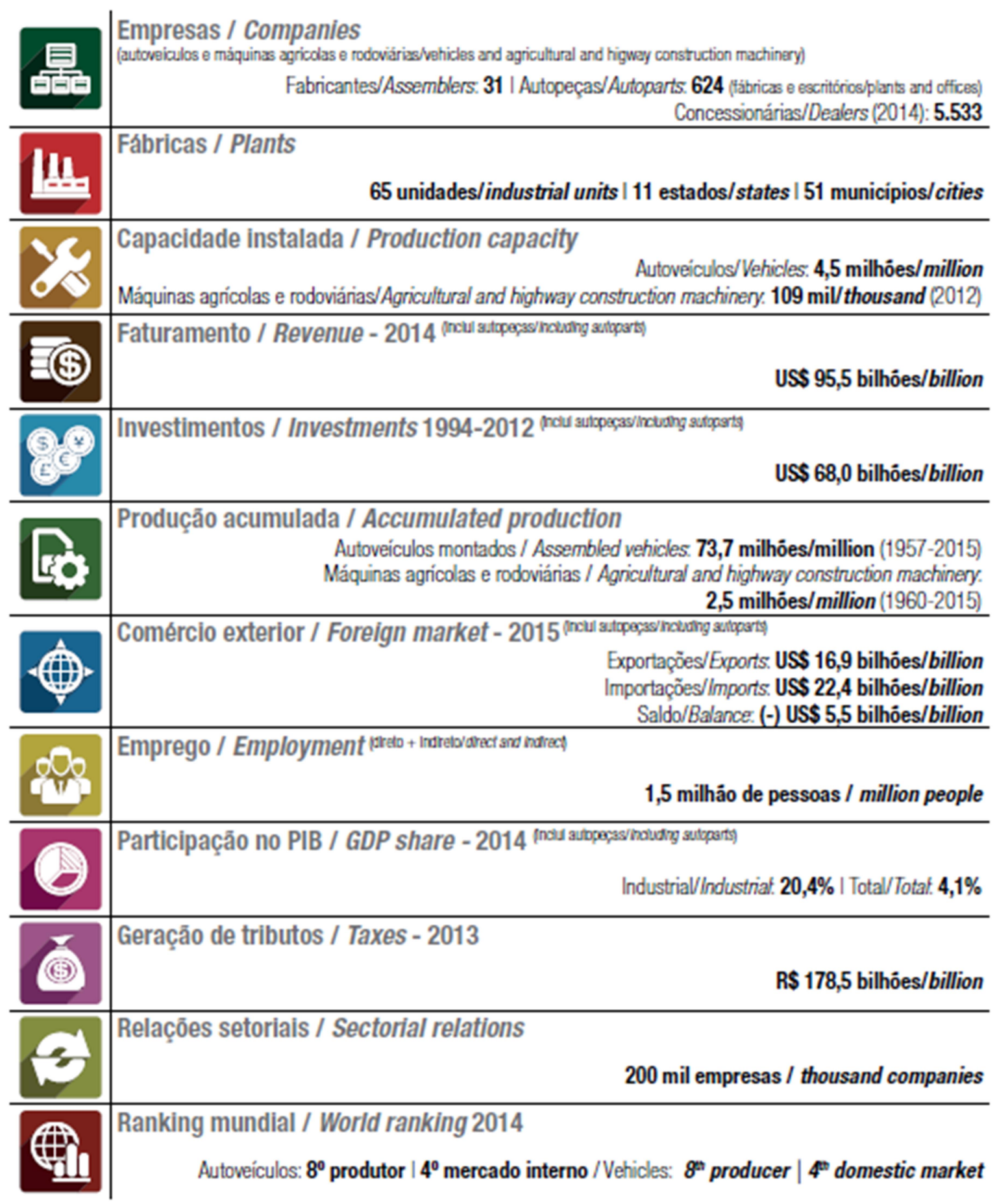

Fonte: Anuário ANFAVEA (2016a) 
Gráfico 1 - Produção brasileira de veículos comerciais 2011-2015

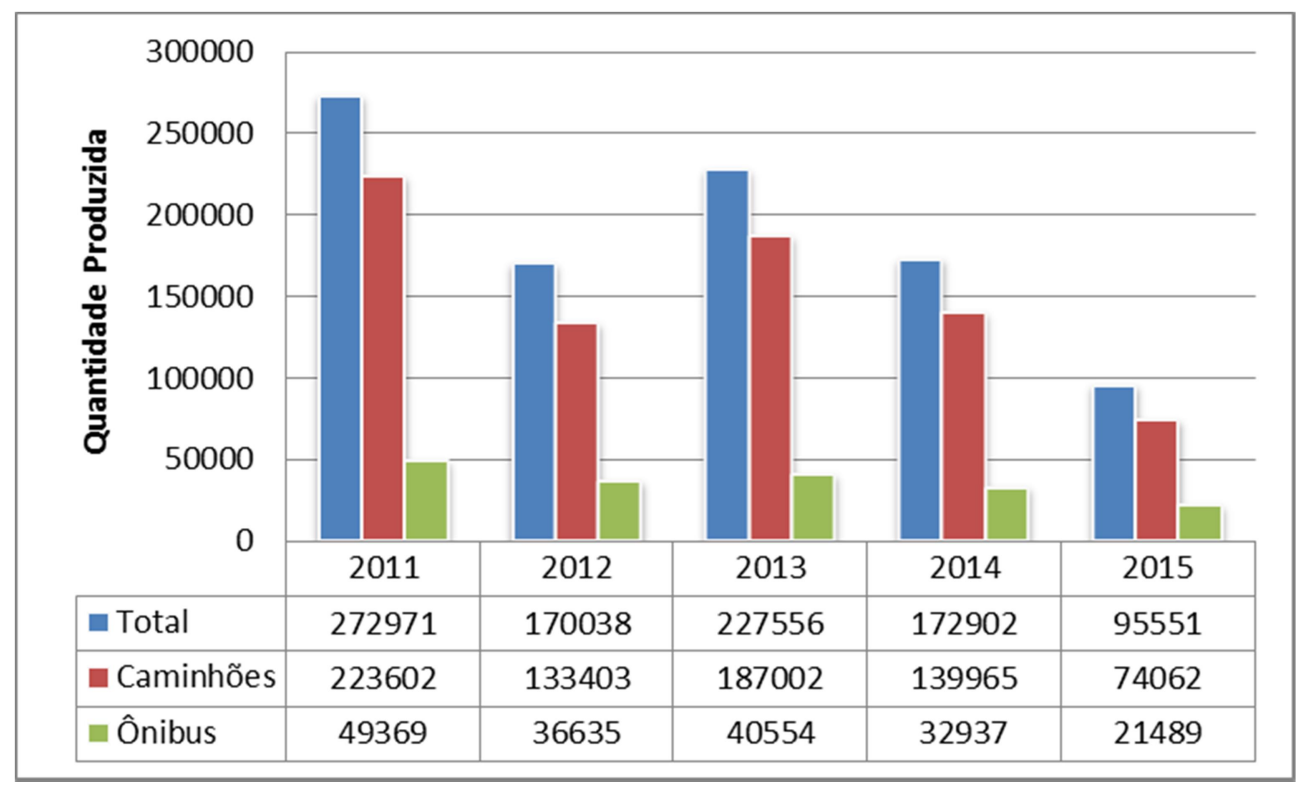

Fonte: Elaborado pelo autor com dados de ANFAVEA (2016c)

Até recentemente, estavam presentes no mercado brasileiro marcas tradicionais de veículos comerciais de origem europeia, norte-americana e brasileira.

$\mathrm{Na}$ última década, e antes da crise atual, outros grupos internacionais buscaram internacionalização rumo ao Brasil e América do Sul. Devido à introdução de novas legislações em 2012 sobre emissões de poluentes atmosféricos PROCONVE P7 (IBAMA, 2016) e, principalmente, de incentivo à inovação tecnológica e adensamento da cadeia produtiva de veículos Inovar-Auto (MDIC, 2016), cinco novos grupos anunciaram a intenção de instalar fábricas em território brasileiro, algumas já realizadas (vide Tabela 2).

A vinda destes novos fabricantes de veículos comerciais é de certa forma facilitada pelo fato de praticamente todos os grupos sistemistas mundiais terem fábricas já instaladas no Brasil. O Sindicato Nacional da Indústria de Componentes para Veículos Automotores informa um número de cerca 500 associados entre grandes, médias e pequenas empresas (cerca de 260 para o segmento de veículos comerciais), que suprem as montadoras e o mercado de reposição de aproximadamente 41 milhões de veículos do mercado nacional, como também exportam para cerca de 180 países (SINDIPEÇAS, 2016). 
Todo este contexto dá a dimensão da atratividade e da competitividade do mercado brasileiro, em condições econômicas normais.

Tabela 2 - Principais grupos / marcas de veículos comerciais no mercado brasileiro

\begin{tabular}{|c|c|c|c|c|}
\hline \multicolumn{3}{|c|}{ Principais Grande Grupos } & \multirow{2}{*}{\multicolumn{2}{|c|}{$\begin{array}{l}\text { Principais Marcas } \\
\text { Mercedes-Benz }\end{array}$}} \\
\hline \multirow{6}{*}{ 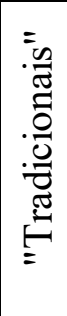 } & \multirow{4}{*}{ Europeus } & Daimler & & \\
\hline & & Volvo & Volvo & \\
\hline & & MAN (VW) & Scania & MAN \\
\hline & & CNH (FIAT) & Iveco & \\
\hline & Norte Americano & Ford & Cargo & \\
\hline & Brasileiro & AGRALE & Agrale & \\
\hline \multirow{5}{*}{$\begin{array}{l}\text { zo } \\
0 \\
\text { o } \\
\text { Z }\end{array}$} & \multirow{2}{*}{ Norte Americanos } & Paccar & DAF & \\
\hline & & Navistar & International & \\
\hline & \multirow{3}{*}{ Chineses } & FOTON & Aumark & \\
\hline & & CNHTC & Sinotruk & \\
\hline & & Shaanxi & Schacman & \\
\hline
\end{tabular}

Fonte: Elaborado pelo autor com informações de ANFAVEA 2016

Em relação ao corpo de Engenharia, praticamente todos os "tradicionais" fabricantes de veículos comerciais têm estruturas funcionais específicas no Brasil, que são responsáveis pelo desenvolvimento de projetos dos produtos das diferentes marcas para serem aplicados localmente e em mercados de países em desenvolvimento semelhante ao sul-americano. Muitos destes produtos são desenvolvidos exclusivamente no Brasil, mesmo para aplicações específicas fora deste continente.

Da mesma forma, praticamente todos os "tradicionais" sistemistas também tem corpo de Engenharia no Brasil de modo a dar suporte às Engenharias dos fabricantes de veículos comerciais. 


\subsection{Oportunidade de Estudo, Objetivos e Questão Principal da Pesquisa}

Diante deste cenário de alta concentração de fabricantes e sistemistas de alta tecnologia e complexidade de produtos, observa-se uma oportunidade de se estudar, pesquisar e registrar os parâmetros de sucesso mais importantes da prática do desenvolvimento de projetos de veículos comerciais inovadores.

O objetivo principal deste trabalho é, portanto, pesquisar sobre a importância dos Fatores Críticos de Sucesso (FCS) para a execução do Processo de Gerenciamento do Desenvolvimento de Produtos e a importância dos Critérios de Avaliação de Sucesso dos Resultados de Projetos, por meio de estudo de caso em uma empresa "tradicional" da indústria automobilística brasileira de veículos comerciais.

Assim é que a principal questão de pesquisa é:

\section{- Quais são os Fatores Críticos de Sucesso (FCS) mais importantes para a execução do processo de desenvolvimento de veículos comerciais brasileiros?}

Como objetivo secundário, serão analisadas as seguintes questões:

- Quais são os critérios de avaliação do resultado mais importantes de um projeto bem sucedido de veículos comerciais brasileiros? A percepção dos participantes de times de projetos sobre a hierarquia destes critérios é semelhante à que eles pensam ser a valorizada pela empresa em que trabalham?

- Quais as características de projeto de desenvolvimento de veículos comerciais brasileiros?

- Qual o perfil do participante de processos de gerenciamento de projetos de desenvolvimento de veículos comerciais brasileiros? 


\subsection{A Empresa Pesquisada (Montadora)}

Para responder a estas questões, buscou-se examinar o Processo de Gerenciamento de Desenvolvimento de Produtos de uma empresa "tradicional" do segmento de veículos comerciais da indústria automobilística brasileira, que será a partir de agora denominada montadora.

Como praticamente todas as tradicionais montadoras instaladas no Brasil a partir do governo Juscelino Kubitschek, esta multinacional tem como sede local uma grande planta industrial que abriga os três processos principais de Desenvolvimento, Produção e Vendas de Produtos.

Sua estrutura organizacional é desenhada em função de suas principais unidades de negócios, e as atividades de gerenciamento de projetos de produtos são definidas em forma matricial à estrutura funcional, com tarefas e responsabilidades claramente definidas por meio de matrizes de responsabilidades internas.

Desde os anos 1990, a empresa sempre apresentou faturamento anual na ordem de dezena de bilhões de Reais (em valor presente) e quantidade de funcionários na ordem de milhares de pessoas.

A montadora é líder de mercado em seu segmento de atuação, sendo vários de seus produtos os mais vendidos das respectivas categorias.

A montadora sempre esteve entre as dez (10) maiores empresas do setor automobilístico, e entre as 50 maiores em geral do Brasil, nos diferentes índices de anuários de jornais e revistas especializados em economia.

A empresa atende a todos as exigências de certificação de qualidade de processos internacionais existentes no segmento automobilístico e é competente de forma a certificar todos os seus produtos perante os requisitos dos diversos países para os quais exporta.

A empresa tem um guia próprio de gerenciamento de desenvolvimento de veículos comerciais que é utilizado internacionalmente em todas as suas subsidiárias. 


\subsection{Justificativas e Contribuições}

Como resultado deste trabalho, são analisadas as lições aprendidas sobre a importância dos Fatores Críticos de Sucesso (FCS) para a execução de projetos de veículos comerciais brasileiros, assim como da importância dos critérios de análise de sucesso dos resultados do projeto, e busca sugerir melhorias práticas e novas pesquisas teóricas.

A pesquisa traz esclarecimentos sobre o desenvolvimento de produtos de veículos comerciais em mercados altamente crescentes e competitivos, como o brasileiro, respeitando suas características econômicas e culturais. Neste sentido, mostra a principais características dos produtos desenvolvidos por uma empresa do mercado brasileiro, assim como o perfil do participante do seu processo de gerenciamento de projetos de produtos.

Este trabalho contribui, portanto, de diferentes formas para o mundo acadêmico, para a iniciativa privada e para a sociedade como um todo:

Para a Academia, ele contribui com a validação de conceitos teóricos sobre os parâmetros de sucesso de projetos em mercados em desenvolvimento, pela verificação de um caso prático, vivido em uma grande montadora de veículos comerciais brasileira.

Para a Iniciativa Privada, mais propriamente a Indústria Automobilística, ele joga luz sobre os principais fatores críticos de sucesso (FCS) na realização de projetos de produtos e os principais critérios de avaliação de resultados de projetos, fundamentados em conceitos teóricos. As observações e conclusões aqui estudadas contribuem para que os responsáveis por desenvolvimento de produtos desta indústria, e de outras com perfis semelhantes, reflitam e possam de alguma maneira aperfeiçoar seus processos internos.

Para a Sociedade, ele propicia aos atuais e novos empreendedores dos diversos segmentos de mercado, a visão da prática embasada na teoria, sobre o cuidado necessário na realização de projetos, através dos fatores críticos de sucesso durante o gerenciamento do projeto e dos critérios de avaliação de sucesso dos resultados finais do projeto. 


\subsection{Organização da Dissertação}

Esta dissertação está estruturada de forma a tratar os diferentes assuntos detalhada e sequencialmente. Sendo assim, a dissertação está subdividida em quatro principais capítulos, além da introdução.

No capítulo 2 é feita uma revisão bibliográfica sobre o referencial teórico existente, que busca fundamentar os conceitos sobre Processos Funcionais e Projetos de Novos Produtos e Parâmetros Sucesso em Gerenciamento de Projetos, o que servirá de embasamento para a discussão dos resultados da pesquisa;

No capítulo 3 é apresentado o fluxo de atividades para elaboração dos trabalhos, bem como a metodologia utilizada para a pesquisa de campo. No caso em questão, uma pesquisa qualitativa, de estudo de caso, com a utilização da técnica entrevista por meio de questionário enviado por mídia eletrônica.

No capítulo 4 é mostrado o Estudo de Caso propriamente dito, realizado em uma grande montadora brasileira. São comentados os resultados da pesquisa, caracterizando o perfil do profissional brasileiro que trabalha com projetos de desenvolvimento de veículos comerciais, a caracterização dos projetos em que os entrevistados que responderam à pesquisa participaram e os principais resultados das análises dos parâmetros de sucesso do gerenciamento de projeto, a saber, os critérios de avaliação de sucesso do resultado de um projeto, segundo a opinião dos entrevistados e o que eles entendem a montadora em que trabalham adotar, e os fatores críticos de sucesso (FCS) para a execução de um projeto.

No capítulo 5 são apresentadas as principais conclusões, a partir da síntese dos resultados, e abordadas as principais lições aprendidas, no tocante às limitações do estudo, às contribuições para academia, para as empresas e para a sociedade, assim como sugestões de estudos futuros. 


\section{REFERENCIAL TEÓRICO}

O objetivo deste capítulo é dar uma visão da abordagem teórica referente ao tema da dissertação comentando principalmente os seguintes aspectos:

i. Processos Funcionais e Projetos de Novos Produtos:

Definição de processo / Excelência na gestão de processos;

Definição de projeto / Gerenciamento de projetos / Excelência na gestão de projetos; Caracterização de Projetos.

ii. Parâmetros de Sucesso em Gerenciamento de Projetos:

Critérios de avaliação de sucesso do resultado do projeto;

Fatores críticos de sucesso (FCS) na execução do gerenciamento do projeto.

Estes conceitos teóricos embasam as análises que são apresentadas no capítulo 4.

\subsection{Processos Funcionais e Projetos de Novos Produtos}

Segundo Maximiano (2014, p. 19-20), as empresas em geral dividem-se em dois grandes grupos no que se refere a projetos: (i) empresas que executam predominantemente processos e atividades funcionais como rotina e eventualmente realizam projetos internos com a função de atender seus projetos estratégicos (ex.: indústria, comércio e serviços); (ii) empresas que executam predominantemente projetos e vendem produtos e serviços resultantes sob encomenda (ex.: construção civil, cinema, etc.). Estas últimas também executam eventualmente outros projetos internos com a função de atender seus objetivos estratégicos.

Kerzner (2006) dá às indústrias três classificações: (i) orientadas a projetos, (ii) híbridas e (iii) não orientadas a projetos (vide Figura 1), em função da utilização de gestão de projetos e afirma que "[...] atualmente, a gestão de projetos é exaltada pelas áreas de Marketing, de Engenharia e de Produção, e não mais apenas pelo departamento de projetos.” (p. 18). 


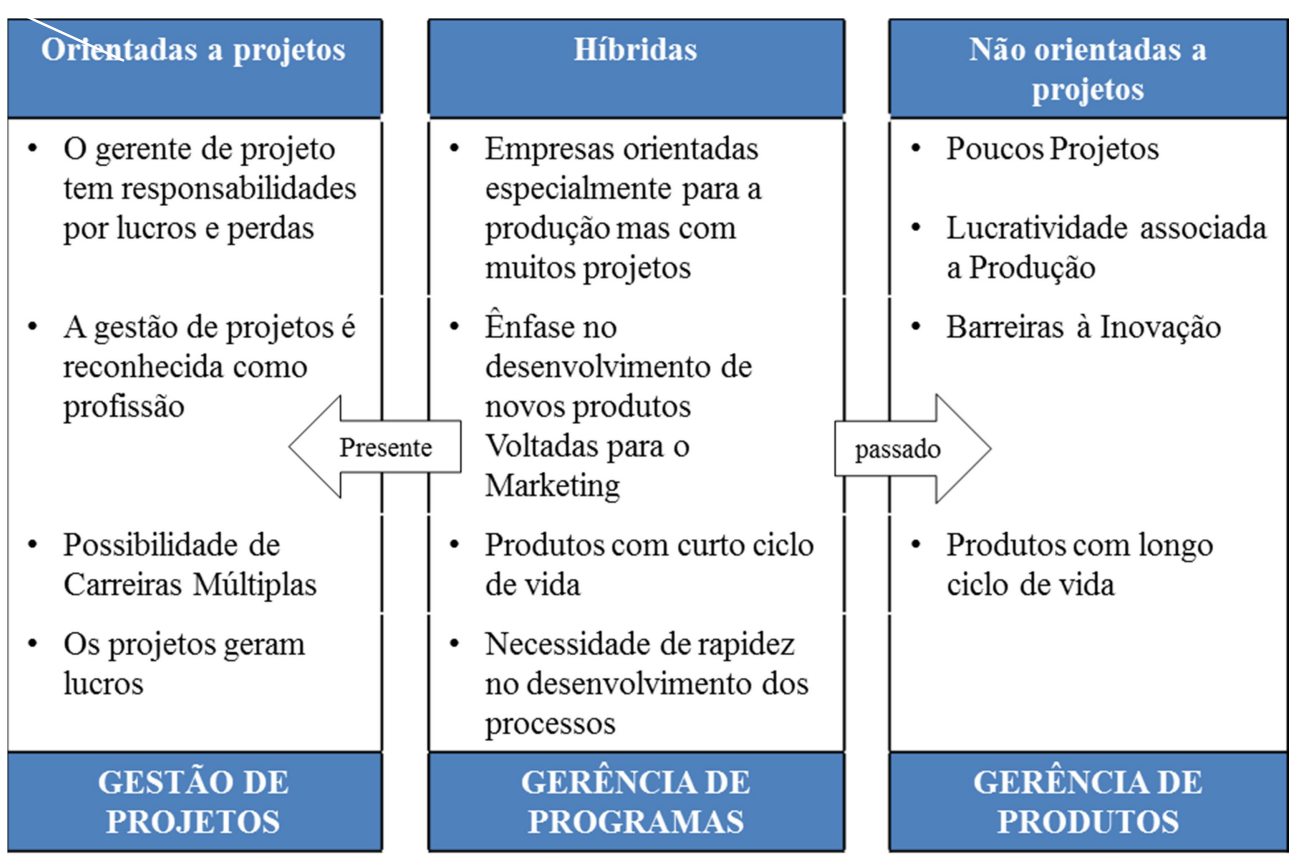

Figura 1 - Classificação das indústrias (pela utilização da gestão de projetos)

Fonte: Kerzner (2006)

O Guia PMBOK ${ }^{\circledR}$ (PMI, 2014b, p. 21-26) classifica as estruturas organizacionais em seis tipos: (i) funcional; (ii) matricial fraca; (iii) matricial balanceada; (iv) matricial forte; (v) projetizada e (vi) composta (mista) mostrando a influência das estruturas organizacionais nos projetos conforme a Tabela 3 .

Tabela 3 - Influência das estruturas organizacionais nos projetos

\begin{tabular}{|c|c|c|c|c|c|}
\hline \multirow{2}{*}{$\begin{array}{l}\text { Estrutura da } \\
\text { organização } \\
\text { do projeto }\end{array}$} & \multirow{2}{*}{ Funcional } & \multicolumn{3}{|c|}{ Matricial } & \multirow{2}{*}{ Projetizada } \\
\hline & & fraca & balanceada & forte & \\
\hline $\begin{array}{l}\text { Autoridade do } \\
\text { gerente de projetos }\end{array}$ & $\begin{array}{l}\text { Pouca ou } \\
\text { nenhuma }\end{array}$ & Baixa & $\begin{array}{l}\text { Baixa a } \\
\text { moderada }\end{array}$ & $\begin{array}{l}\text { Moderada } \\
\text { a alta }\end{array}$ & $\begin{array}{c}\text { Alta a } \\
\text { quase total }\end{array}$ \\
\hline $\begin{array}{l}\text { Disponibilidade } \\
\text { de recursos }\end{array}$ & $\begin{array}{l}\text { Pouca ou } \\
\text { nenhuma }\end{array}$ & Baixa & $\begin{array}{l}\text { Baixa a } \\
\text { moderada }\end{array}$ & $\begin{array}{l}\text { Moderada } \\
\text { a alta }\end{array}$ & $\begin{array}{c}\text { Alta a } \\
\text { quase total }\end{array}$ \\
\hline $\begin{array}{l}\text { Quem gerencia o } \\
\text { orçamento do projeto }\end{array}$ & $\begin{array}{l}\text { Gerente } \\
\text { funcional }\end{array}$ & $\begin{array}{l}\text { Gerente } \\
\text { funcional }\end{array}$ & Misto & $\begin{array}{c}\text { Gerente } \\
\text { do projeto }\end{array}$ & $\begin{array}{c}\text { Gerente } \\
\text { do projeto }\end{array}$ \\
\hline $\begin{array}{l}\text { Papel do gerente } \\
\text { do projeto }\end{array}$ & $\begin{array}{l}\text { Tempo } \\
\text { parcial }\end{array}$ & $\begin{array}{l}\text { Tempo } \\
\text { parcial }\end{array}$ & $\begin{array}{l}\text { Tempo } \\
\text { integral }\end{array}$ & $\begin{array}{l}\text { Tempo } \\
\text { integral }\end{array}$ & $\begin{array}{l}\text { Tempo } \\
\text { integral }\end{array}$ \\
\hline $\begin{array}{l}\text { Equipe administrativa } \\
\text { de gerenciamento } \\
\text { de projetos }\end{array}$ & $\begin{array}{l}\text { Tempo } \\
\text { parcial }\end{array}$ & $\begin{array}{l}\text { Tempo } \\
\text { parcial }\end{array}$ & $\begin{array}{l}\text { Tempo } \\
\text { integral }\end{array}$ & $\begin{array}{l}\text { Tempo } \\
\text { integral }\end{array}$ & $\begin{array}{l}\text { Tempo } \\
\text { integral }\end{array}$ \\
\hline
\end{tabular}

Fonte: Guia PMBOK ${ }^{\circledR}($ PMI, 2014b) 
Nas grandes organizações automobilísticas, três macroprocessos organizacionais normalmente estão presentes: (i) Desenvolvimento de Produtos, (ii) Produção e (iii) Vendas. Estes macroprocessos são tradicionalmente desdobrados em diversos outros processos organizacionais como, por exemplo:

i. Pesquisa de Inovações, Conceituação, Projeto do Produto, Simulação Numérica, Documentação, Prototipagem, Testes, Homologação, etc..

ii. Planejamento, Industrialização, Suprimentos, Logística, Montagem, Qualidade, Revisão Final, Liberação, etc..

iii. Marketing, Pesquisa de Mercado, Vendas, Relacionamento com Clientes, Pós-vendas, Remanufatura, etc..

Para dar suporte a estes macroprocessos e seus desdobramentos, existem ainda outros processos auxiliares importantes, comumente denominados de (iv) "processos de suporte" ou "processos transversais", como por exemplo: Compras, Recursos Humanos, Relações Institucionais e Jurídicas, Recursos Financeiros, etc..

Com o objetivo de executarem estes processos com maestria, normalmente as organizações automobilísticas estruturam-se funcionalmente segundo grandes áreas comumente denominadas como: Desenvolvimento de Produtos, Produção, Vendas, Finanças, Compras, Recursos Humanos e outros (dependendo da necessidade específica da organização). Acontece que estes processos, apesar de suas peculiaridades específicas, não são estanques entre si e, portanto, as áreas funcionais obrigatoriamente precisam interagir de forma a executá-los com sinergia.

Desta forma, a indústria automobilística poderia ser classificada segundo Kerzner (2006) como uma empresa híbrida na utilização da gestão de projetos, e segundo o Guia PMBOK® (PMI, 2014b) como uma estrutura organizacional matricial.

Cabe aqui registrar que, a área de Desenvolvimento de Produtos de uma montadora é, na prática, uma organização interna à empresa, orientada predominantemente a projetos de desenvolvimento de veículos, mas que também eventualmente realiza os demais processos funcionais internos da organização maior, necessários para atender seus objetivos estratégicos. Já as demais áreas de uma montadora podem ser consideradas como 
organizações internas que executam predominantemente processos e atividades de rotina, apesar de participarem ativamente do processo de gerenciamento de novos produtos.

Com base no exposto, ainda é oportuno destacar-se as principais conceituações teóricas sobre o que são (i) processos e (ii) projetos.

\subsubsection{Definição de Processo}

Entre as principais definições de processos, destacam-se a da European Foundation for Quality Management (EFQM) e a do Project Management Institute (PMI) que formatam os seguintes conceitos:

Segundo a EFQM, "um processo é uma sequência de atividades, que agrega valor através da produção de resultados desejado a partir de uma variedade de entradas. Portanto, todas as organizações utilizam processos, comprando materiais, produzindo produtos, vendendo serviços..." I (EFQM, 2015-b).

Segundo o PMBOK ${ }^{\circledR}$ do PMI, "Um processo é um conjunto de ações e atividades interrelacionadas que são executadas para criar um produto, serviço ou resultado pré-especificado. Cada processo é caracterizado por suas entradas, ferramentas e técnicas que podem ser aplicadas, e as saídas resultantes.” (PMI, 2014b, p. 47).

\subsubsection{Excelência de Gestão de Processos}

Como forma de se avaliar a excelência da qualidade na gestão dos processos em geral de uma organização, existe atualmente a possibilidade de se seguir as recomendações e se submeter a auditorias prescritas por grandes instituições internacionais, sendo que, entre as principais, destacam-se:

\footnotetext{
1 "A process is a sequence of activities which adds value by producing required outputs from a variety of inputs. So, all organizations (sic) use processes ordering material, making products, selling services [...]".
} 
i. EFQM Model, da European Foundation for Quality Management (EFQM, 2015-a);

ii. Baldrige Performance Excellence Program, do norte-americano National Institute of Standards and Technology (NIST, 2014);

iii. Deming Prize, da Japanese Union of Scientists and Engineers (JUSE, 2015) ;

iv. Modelo de Excelência de Gestão (MEG), da brasileira Fundação Nacional da Qualidade (FNQ, 2014).

\subsubsection{Definição de Projeto}

Dentre as diversas definições de projeto e gerenciamento de projetos, elaboradas por diferentes autores, apresentam-se aqui algumas das principais definições clássicas que dão uma visão geral do que venham a ser estes conceitos.

James P. Lewis (1995, p. 14-15) define projeto como "um atividade única que tem começo e fim definidos, um claro objetivo definido, ou escopo de trabalho a ser executado, um orçamento pré-definido, e usualmente uma organização temporária que é desfeita, uma vez que o projeto está completo" 2 .

Para Kerzner (2006, p. 15), projeto é "[...] um empreendimento com objetivo bem definido, que consome recursos e opera sobre pressões de prazos, custo e qualidade".

Shenhar e Dvir (2010, p. 16-17) consideram que projeto é “[...] uma organização temporária e processo estabelecido para alcançar uma meta específica sob as restrições de tempo, orçamento e outros recursos".

O Guia PMBOK® (PMI, 2014b, p. 3) registra que "Projeto é um esforço temporário empreendido para criar um produto, serviço ou resultado único.” Em sua edição de 2004 (p. 7), este guia registrava que "Os projetos são um meio de organizar atividades que não podem ser abordadas dentro dos limites operacionais normais da organização. Os projetos são,

\footnotetext{
${ }^{2}$ A project is a one-time job that has defined starting and ending dates, a clearly specified objective, or scope of work to be performed, a pre-defined budget, and usually a temporary organization that is dismantled once the project is complete.
} 
portanto, frequentemente utilizados como um meio de atingir o plano estratégico de uma organização".

O guia ICB4 (IPMA, 2015a, p. 27) registra que "Um projeto é um esforço único, temporário, multidisciplinar e organizado para realizar entregas acordadas dentro de requerimentos e restrições predefinidos" 3 .

O guia PRINCE2 ${ }^{\circledR}($ OGC, 2011, p. 3) define projeto como “[...] uma organização temporária criada com o propósito de entregar um ou mais produtos de negócio, de acordo com um Business Case pré-acordado".

Segundo Maximiano (2014) a palavra projeto é usualmente utilizada em diferentes sentidos como de intenção, ideal, esboço, desenho, concepção física de um objeto e mesmo existencial.

No presente trabalho, “[...] a palavra projeto será usada no sentindo de empreendimento intencionalmente orientado para um objetivo." com características como resultados singulares no caso produtos, recursos organizados singularmente e restrições de prazo, custo e capacidade de mão de obra. (MAXIMIANO, 2014, p. 4).

“A forma de se conduzir um projeto, normalmente está relacionada ao seu objetivo ou tipo de produto que irá gerar [...]" (YUGUE, 2011, p. 20). Prado (2004, p. 46-48, apud ibid.) e Archibald (2003, p. 35) relacionam dez (10) principais categorias de projeto, dentre as quais se encontra a de Projetos de Desenvolvimento de Novos Produtos ou Serviços, objeto de estudo desta pesquisa.

\footnotetext{
${ }^{3}$ A Project is a unique, temporary, multidisciplinary and organized endeavor to realise agreed deliverables
} within predefined requirements and constrains. 


\subsubsection{Gerenciamento de Projetos}

Lewis (1995, p. 15) considera que o gerenciamento de projetos pode ser definido como "[...] o planejamento, programação e controle das atividades do projeto para atingir seus objetivos" 4 . Kerzner (2011, p. 15) acrescenta que os objetivos devem ser atingidos "[...] com êxito, para benefício dos participantes".

Para Shenhar e Devir (2010, p. 17), “[...] a gestão de projetos pode ser definida como o planejamento, a programação e o controle de uma série de tarefas integradas de forma a atingir seus objetivos".

Maximiano (2014, p. 26) define a administração de um projeto como "[...] o processo de tomar decisões para realizar atividades temporárias, com o objetivo de fornecer um resultado".

Segundo o Guia PMBOK ® (PMI, 2014b, p. 417), “Gerenciamento de projetos é a aplicação de conhecimento, habilidades, ferramentas e técnicas às atividades do projeto a fim de atender aos seus requisitos".

Segundo o ICB4 (IPMA, 2015a, p. 36), o gerenciamento de projetos é a "[...] aplicação de métodos, ferramentas, técnicas e competências para um projeto alcançar as metas".

Segundo o PRINCE2® da OGC (2011, p. 3) o "Gerenciamento de projeto é o planejamento, delegação, monitoramento e controle de todos os aspectos do projeto conforme a motivação dos envolvidos para atingir os objetivos do projeto [...]".

\subsubsection{Excelência na Gestão de Projetos}

O processo de gerenciamento de projetos é, em última análise, um macro processo funcional, composto por vários processos e sub-processos funcionais das organizações.

\footnotetext{
${ }^{4}$ Project Management is the planning, scheduling and controlling of Project activities to achieve project objectives.
} 
Desta forma, vários organismos internacionais e mesmo grandes empresas multinacionais procuram metodizar o processo de gerenciamento de projetos.

Os principais guias internacionais de competências na gestão de projetos são os:

i. PMBOK ${ }^{\circledR}$, "Project Management Body of Knowledge" (PMI, 2014b), atualmente em sua $5^{a}$ edição, elaborado pelo Project Management Institute (PMI, 2014a)“ mais focado nos principais processos da gestão de projetos;

ii. ICB4, "Individual Competence Baseline" (IPMA, 2015b), atualmente em sua versão 4.0, elaborado pela International Project Management Association (IPMA, 2015b) mais focado nas competências para uma boa gestão de projetos.

iii. PRINCE2® - “Managing Successful Projects with Prince2®” - PRojects In Controlled Environments - (OGC, 2011) mantido desde 2000 pelo Departamento de Comercio Inglês (OGC) e a partir de 2010 pelo Gabinete do Governo Inglês (UK.GOV, 2016), focado nos processos de gestão de projetos.

Neste trabalho, o Guia PMBOK® (PMI, 2014b) é o adotado como principal referência dos conhecimentos de processos em gerenciamento de projetos.

O Guia PMBOK® (PMI, 2014b) esclarece que os processos de projetos podem ser classificados em duas principais categorias: (i) Processos de gerenciamento de projeto (objeto do PMBOK ${ }^{\circledR}$ ); (ii) Processos orientados a produtos, considerados como processos funcionais da organização (comentados anteriormente) e fora do escopo do guia;

O Guia relaciona quarenta e sete (47) principais processos de gerenciamento de projetos e os agrupa logicamente em cinco grupos de processos, a saber:

i. Processos de Iniciação: definição de um novo projeto ou uma nova fase;

ii. Processos de Planejamento: definição do escopo e refinamento dos objetivos e linhas de ação do projeto;

iii. Processos de Execução: execução das atividades para satisfazer as especificações do projeto;

iv. Processos de Monitoramento e Controle: acompanhamento, análise e controle do progresso e do desempenho do projeto e, 
v. Processos de Encerramento: finalização de todas as atividades para o encerramento de uma fase ou do projeto.

Estes grandes grupos são executados interativamente durante uma ou várias Fases do Ciclo de Vida do Projeto e não devem ser confundidos com as fases do ciclo de vida do projeto si.

Os mesmos quarenta e sete (47) processos são também agrupados em dez (10) áreas do conhecimento distintas, que são discutidas nos seus capítulos de 4 a 13, e denominadas da seguinte forma:

4. Gerenciamento da Integração do Projeto;

5. Gerenciamento do Escopo do Projeto;

6. Gerenciamento do Tempo do Projeto;

7. Gerenciamento dos Custos do Projeto;

8. Gerenciamento da Qualidade do Projeto;

9. Gerenciamento dos Recursos Humanos do Projeto;

10. Gerenciamento das Comunicações do Projeto;

11. Gerenciamentos dos Riscos do Projeto;

12. Gerenciamento das Aquisições do Projeto e,

13. Gerenciamento das Partes Interessadas do Projeto.

\subsubsection{Caracterização de Projetos}

Dentre as diversas formas de caracterização de projeto elaboradas por diferentes autores, apresentam-se aqui algumas das principais conceituações clássicas, com foco na categoria de Projeto de Desenvolvimento de Novos Produtos e Serviços.

Maximiano (2015, p. 9) conceitua que "Todos os projetos são singulares e se diferenciam uns dos outros em função do contexto e do grau de dificuldade que oferecem para seus administradores". Como grau de dificuldade de um projeto, o autor identifica a complexidade técnica e relacional, a incerteza com o produto e com os métodos e a maturidade ou familiaridade (vide Figura 2). 


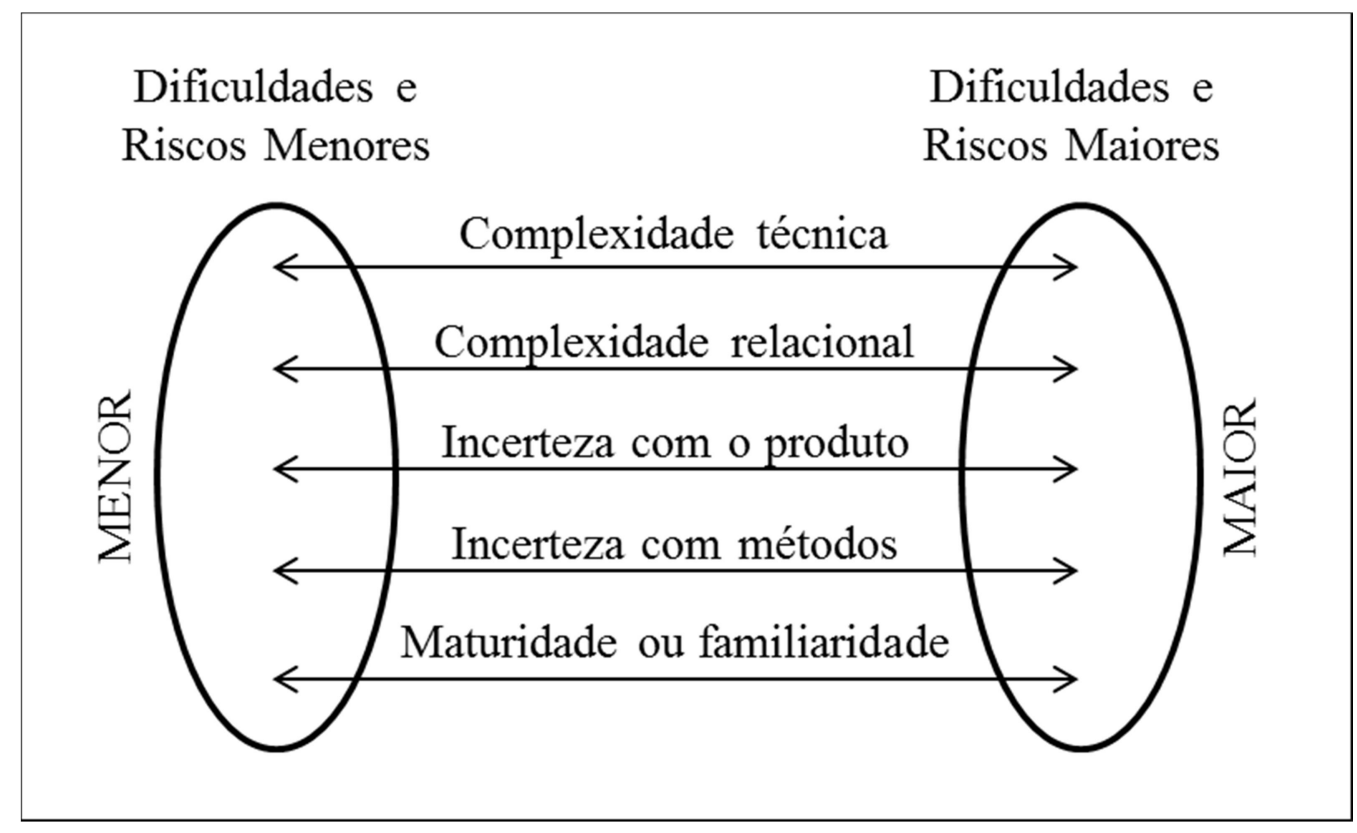

Figura 2 - Características que definem o grau de dificuldade e o risco do projeto segundo Maximiano

Fonte: Maximiano (2014)

Maximiano explicita que a "complexidade relacional" é função do comportamento e da quantidade de stakeholders (participantes / partes interessadas) do projeto e a "complexidade técnica" é função do grau de dificuldade de se construir o produto. Maximiano comenta ainda que "[...] segundo Galbraith (1977) a incerteza é a diferença entre a quantidade de informações necessária para realizar a tarefa e a quantidade de informações da qual não se dispõe (página 36)”. Explica por fim que outro fator que define o grau de dificuldade e risco do projeto "[...] é o grau de familiaridade com os projetos na organização." (idem, p.10 e 11).

Outros autores discorreram sobre os principais fatores de dificuldade e risco de projetos e utilizam-se comumente da expressão complexidade para descrever as complexidades, propriamente ditas, mas também as incertezas e maturidade comentadas por Maximiano.

Baccarini (1996) destaca como complexidade relacional a participação de diferentes organizações na execução de um projeto e/ou uma organização com muitas áreas internas. Já a complexidade técnica está frequentemente associada à dificuldade de se exercer as tarefas, visto entre outras o número de especialidades envolvidas em um projeto. 
Tatikonda e Rosenthal (2000), definem a complexidade de um projeto como a natureza, a quantidade e a magnitude das tarefas organizacionais e suas interações requeridas. Eles relacionaram como fatores de complexidade de um projeto: (i) o ineditismo da tecnologia de produto, (ii) o ineditismo da tecnologia do processo (de produção), (iii) a interdependência tecnológica (do produto e/ou produção), (iv) o ineditismo dos objetivos do projeto (custo, tempo e desempenho) e (v) a dificuldade do projeto (custo, tempo, desempenho e o projeto em si como um todo).

Geraldi e Adlbrecht (2007) classificam as complexidades de projeto como: (i) "de Fé" (as pessoas têm de confiar em fatores intangíveis e subjetivos, daí a denominação), (ii) "de Fato" (muita quantidade de informação interdependente) e "de Interação" (nas interfaces entre sistemas, empresas, times de projeto, outros).

Remington, Zolin e Rodney (2009) definem um projeto complexo como aquele que apresenta certo número de características de grau, ou nível de severidade, que faz com que seja extremamente difícil gerenciá-lo, controlá-lo e prever seus resultados. Como características de complexidade citam elevada interconectividade, não linearidade, adaptação e emergência. Em seus estudos, diferenciam "complexidade" de "severidade", explicando que o primeiro termo significa as dimensões que caracterizam a natureza da dificuldade enquanto o segundo, os fatores que tendem a agravar a complexidade.

Carvalho e Rabechini, (2011, p. 33) elaboraram o Modelo ${ }^{4}$, com quatro eixos orientadores: (i) integração ("entre áreas da organização, equipes multidisciplinares, elementos de diversas naturezas"); (ii) impacto ("efeitos que projetam no meio ambiente, nos interessados, no comportamento humano e na ética dos envolvidos"); (iii) inovação ("inexatidões de tecnológicas, de mercado e de informações, ausência de convicções, dificuldades tecnológicas e instabilidade); (iv) imediato (" restrições / limitações do projeto [...] que envolve atenção às metas de prazos, custos e qualidade"). De acordo com as intensidades destes eixos, os projetos são classificados em Modelo $I^{4}$ Pró-Valor ${ }^{\circledR}$ / único, / duplo, / triplo e / intenso. "A partir desses quatro clusters, os projetos são classificados de acordo com a intensidade desses I's se manifestam no projeto" (2011, p. 34). Vide exemplo na Figura 3. 


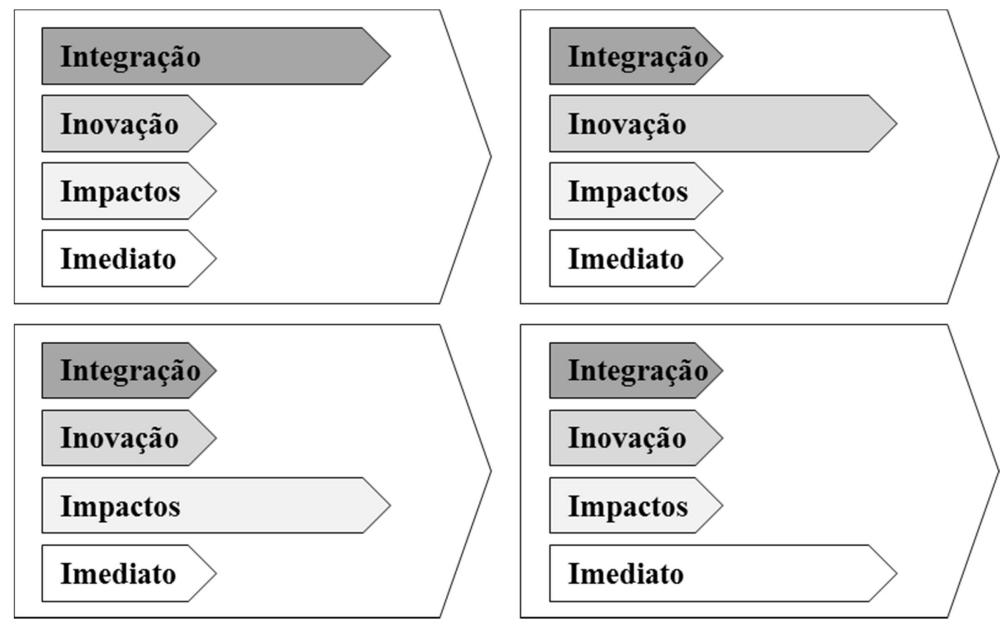

Figura 3 - Exemplo de Modelos I4 Pró-Valor ${ }^{\circledR} /$ Único

Fonte: Carvalho e Rabechini (2011)

Shenhar e Dvir (2010) propõem um modelo de gerenciamento de projetos denominado “Abordagem Diamante". Neste modelo, os projetos são caracterizados em função da: (i) Novidade (N - incerteza do projeto, do mercado ou de ambos); (ii) Tecnologia (T- incerteza tecnológica do projeto); (iii) Complexidade (C - do produto, tarefa e organização do projeto); (iv) Ritmo (R - urgência do projeto), conforme exemplo da Figura 4.

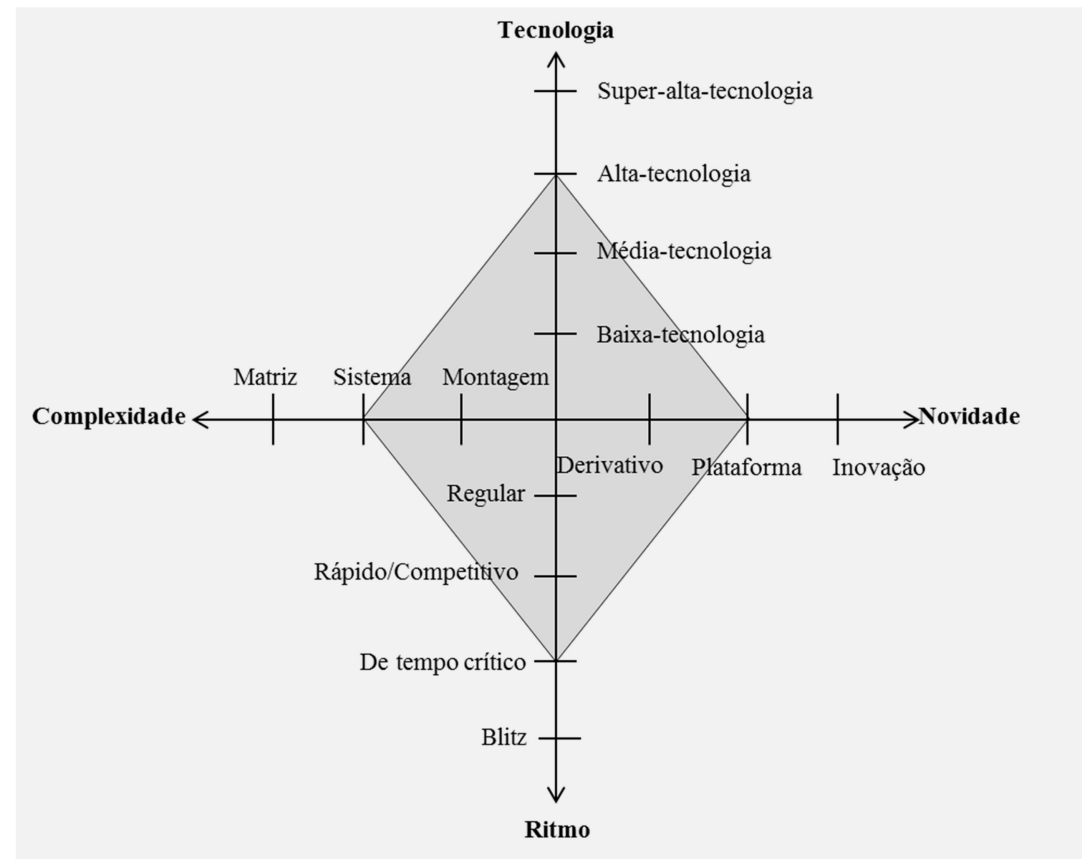

Figura 4 - O Modelo Diamante

Fonte: Shenhar e Dvir (2010) 
As dimensões de classificação são ainda subdivididas em diferentes categorias:

i. Novidade: (1) produtos derivativos - "extensões e melhorias de produtos existentes"; (2) produtos de plataforma - "novas gerações de linhas de produtos anteriores"; (3) produtos de inovação - "novos para o mundo";

ii. Tecnologia: (1) projetos de baixa-tecnologia - com "tecnologias existentes e bem estabelecidas"; (2) projetos de média-tecnologia - usam "tecnologias existentes [...], porém incorporam uma nova tecnologia ou característica nova que não existia nos produtos anteriores"; (3) projetos de alta-tecnologia - "maior parte das tecnologias empregadas é nova para a empresa, mas já existem e são disponíveis no começo do projeto"; (4) projetos de super-alta-tecnologia - utilizam "tecnologias que não existem no início do projeto";

iii. Complexidade: (1) projetos de montagem - "criação de uma coleção de elementos, componentes e módulos combinados [...] que desempenha uma função simples; (2) projetos de sistemas - "coleção complexa de elementos interativos e subsistemas que juntos desempenham várias funções para atender uma necessidade operacional específica"; (3) projetos de matriz - coleção grande [...] que funcionam em conjunto para alcançar um propósito comum";

iv. Ritmo: (1) projetos regulares - onde o "tempo não é crítico para o sucesso organizacional imediato"; (2) projetos rápido/competitivos - "mais comumente realizados por organizações industriais e voltados para o lucro"; (3) projetos de tempo crítico - "devem ser completados dentro de uma data específica"; (4) projetos blitz - são os mais urgentes, com tempos mais críticos (SHENHAR; DVIR, 2010, p. 58-61).

Tendo em vista a característica do processo de gerenciamento de desenvolvimento de produtos praticado pela indústria automobilística, esta categorização é a base escolhida para o estudo de caso desta dissertação.

“O PMBOK ® do PMI não faz a distinção entre tipos de projeto" (SHENHAR; DVIR, 2010, p. 228). 


\subsection{Parâmetros de Sucesso em Gerenciamento de Projetos}

A palavra sucesso está intimamente conectada a expectativa do resultado esperado por uma pessoa ou organização a respeito de um processo. Assim é que sua definição normalmente é complexa, longe de unanimidade ou consenso e objeto de diversos estudos.

De modo a buscar responder à principal questão de pesquisa, ("Quais são os Fatores Críticos de Sucesso (FCS) mais importantes para a execução do processo de desenvolvimento de veículos comerciais brasileiros?”) como também a uma das perguntas secundárias (“Quais são os critérios de avaliação do resultado mais importantes de um projeto bem sucedido de veículos comerciais brasileiros?"), é necessário diferenciar o que são os Fatores Críticos de Sucesso para o Gerenciamento de Projetos do que são os Critérios de Avaliação de Sucesso do Resultado do Projeto.

Esta distinção é de fundamental importância quando do estudo de parâmetros de sucesso de projetos, pois um projeto conduzido com sucesso não necessariamente leva a resultados considerados de sucesso (DE WITT, 1988). Paradoxalmente, embora mais dificilmente, um projeto pode ser bem sucedido, apesar de o gerenciamento de projeto ter eventualmente apresentado algumas deficiências.

Desta forma, serão analisadas inicialmente as referências teóricas sobre (i) os critérios de avaliação de sucesso do resultado do projeto e em seguida as referências teóricas sobre (ii) os fatores críticos de sucesso (FCS) na execução do gerenciamento de projetos.

\subsubsection{Critérios de Avaliação de Sucesso do Resultado do Projeto}

Segundo Shenhar e Dvir (2010, p. 21-22) “Os gerentes de projeto acreditam que conseguiram ter sucesso quando conseguem completar um projeto no tempo programado, dentro do orçamento e dentro das metas de desempenho (ou requisitos). Isto é comumente conhecido como restrição tripla (ou "triangulo de ferro" - vide Figura 5) do gerenciamento de projetos". 


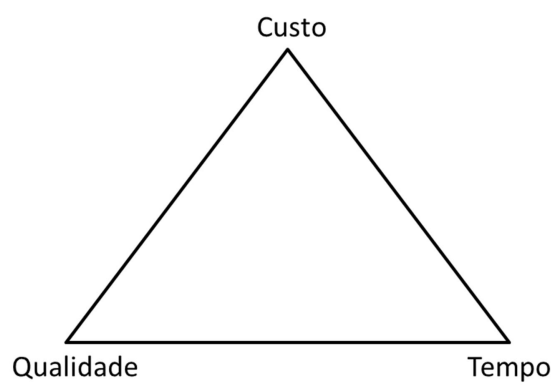

Figura 5 - O Triângulo de Ferro

Fonte: Atkinson (1999)

Para Baccarini (1999), há dois componentes distintos para se identificar o sucesso de um projeto: O sucesso do gerenciamento do projeto, que se refere à forma como o projeto é conduzido, e o sucesso do produto ou serviço resultado do projeto.

Para Kerzner (2006), a melhor explicação de sucesso pode ser definida em termos de (i) critérios primários, prazo, custo e qualidade, ligados a indicadores internos de um projeto e (ii) critérios secundários, principalmente a aceitação pelo cliente, que levam a indicadores externos ao gerenciamento do projeto.

Pinto e Slevin (1988b) propõem um modelo onde o sucesso e composto de critérios internos (projeto) e externos (clientes). Os critérios de projeto seriam tempo, custo e desempenho e os critérios de clientes seriam uso, satisfação e eficácia (vide Figura 6).

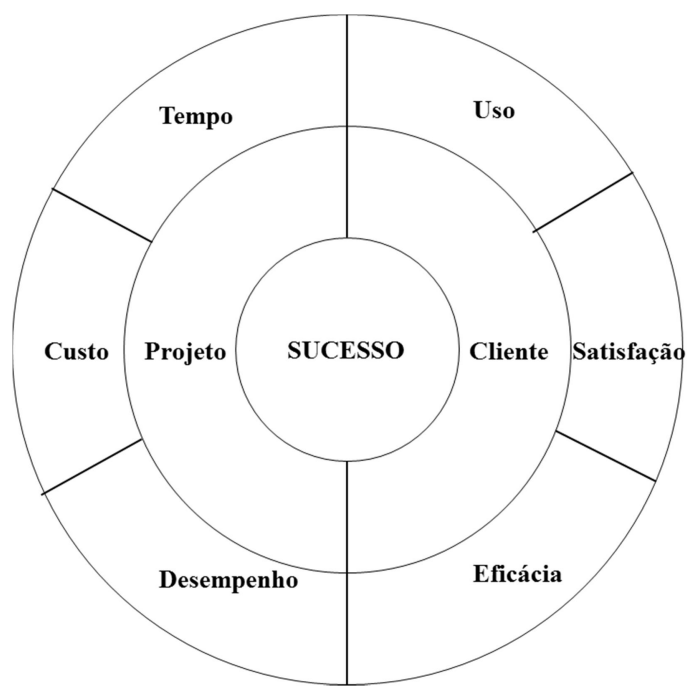

Figura 6 - Modelo de Sucesso de Projetos

Fonte: Pinto e Slevin (1988b) 
Em substituição ao Triângulo de Ferro, Atkinson (1999) propõe um modelo square route (rota quadrada) para critérios de sucesso (vide Figura 7), onde um dos cantos é (i) o próprio triângulo e os demais são (ii) o sistema de informação, (iii) os benefícios para a organização e (iv) os benefícios para as partes interessadas.

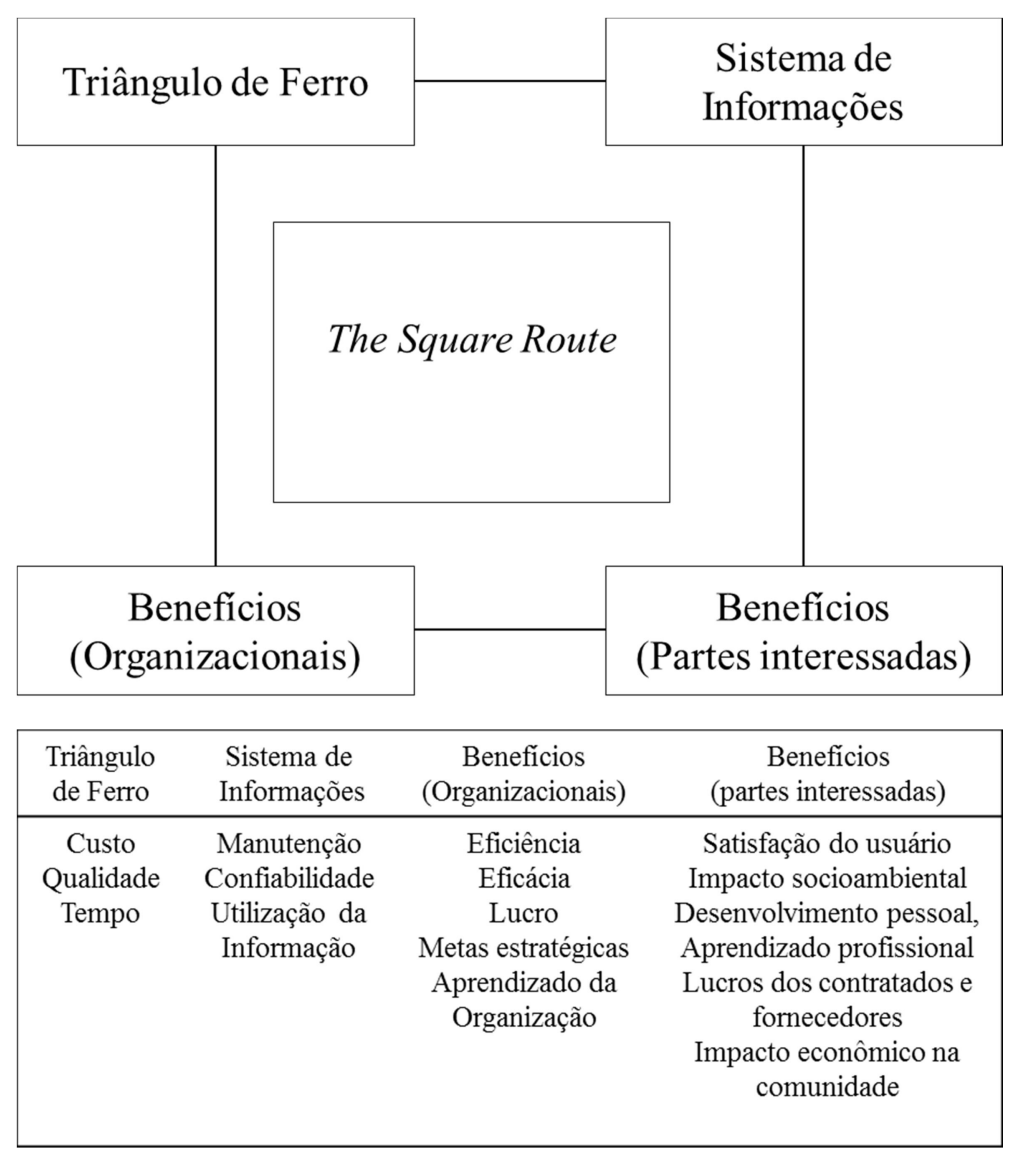

Figura 7 - The Square Route e seus Critérios de Sucesso

Fonte: Adaptado de Atkinson (1999)

Westerveld (2003) relacionou o Modelo de Excelência de Projetos ${ }^{\circledR}$ do EFQM com os resultados sobre critérios de sucesso de quatro publicações entre 1992 e 1999 (Kernzer-1992; Turner-1997; Wateridge-1998; Lim e Mohammed-1999) e estabeleceu seis áreas de resultados deste modelo relacionadas a critérios de avaliação de sucesso explicados conforme a Tabela 4. 
Tabela 4 - Áreas de Resultados relacionadas a Critérios de Avaliação de Sucesso

\begin{tabular}{|c|c|c|}
\hline Nr. & Resultados & Explicação \\
\hline 1 & $\begin{array}{l}\text { Resultado dos projetos } \\
\text {-Orçamento (Custo) } \\
\text {-Cronograma (Tempo) } \\
\text {-Qualidade }\end{array}$ & $\begin{array}{l}\text { O Triangulo de Ferro tradicional das metas de projeto. } \\
\text { Quase todos os projetos terão orçamento, cronograma e qualidade específicos. }\end{array}$ \\
\hline 2 & Apreciação do Cliente & $\begin{array}{l}\text { O cliente deseja o resultado do projeto para atender uma necessidade específica. } \\
\text { Que aspectos e critérios o cliente valoriza no julgamento do sucesso do projeto? }\end{array}$ \\
\hline 3 & $\begin{array}{l}\text { Apreciação do time de } \\
\text { projeto }\end{array}$ & $\begin{array}{l}\text { Os participantes do projeto preocupam-se em alcançar seus objetivos pessoais, } \\
\text { bem como um bom ambiente de trabalho }\end{array}$ \\
\hline 4 & Apreciação pelos usuários & $\begin{array}{l}\text { Os usuários estão preocupados com sua influência geral no projeto e a } \\
\text { funcionalidade do produto final }\end{array}$ \\
\hline 5 & $\begin{array}{l}\text { Apreciação pelos parceiros } \\
\text { contratados }\end{array}$ & $\begin{array}{l}\text { Parceiros contratados querem fazer lucro com o projeto e estão preocupados } \\
\text { com a obtenção de novas encomendas e possibilidades de aprendizado. }\end{array}$ \\
\hline 6 & $\begin{array}{l}\text { Apreciação pelas partes } \\
\text { interessadas }\end{array}$ & $\begin{array}{l}\text { As partes que não estão diretamente envolvidas no projeto, mas que tem uma } \\
\text { grande influência. Por exemplo: grupos ambientalistas, cidadãos e agências } \\
\text { governamentais. Estas partes gerenciam seus interesses específicos. }\end{array}$ \\
\hline
\end{tabular}

Fonte: Adaptado de Westerveld (2003)

Bannerman (2008) propõe um modelo de cinco níveis para a definição de sucesso de projetos considerando marcos principais, em diferentes períodos após o encerramento do projeto e sob diferentes perspectivas das partes interessadas: (i) o sucesso do processo, relacionado principalmente a disciplina na sua condução; (ii) o sucesso do gerenciamento do projeto, relativo aos tradicionais critérios de qualidade custos e prazos; (iii) o sucesso do produto, relacionado ao sucesso do resultado do projeto, em relação às suas especificações e a aceitação pelo cliente; (iv) o sucesso do negócio, relativo aos benefícios do projeto para a organização que o desenvolveu; (v) o sucesso estratégico, relativo à expansão do negócio ou outra vantagem competitiva originada pela execução do projeto (vide Figura 8). 


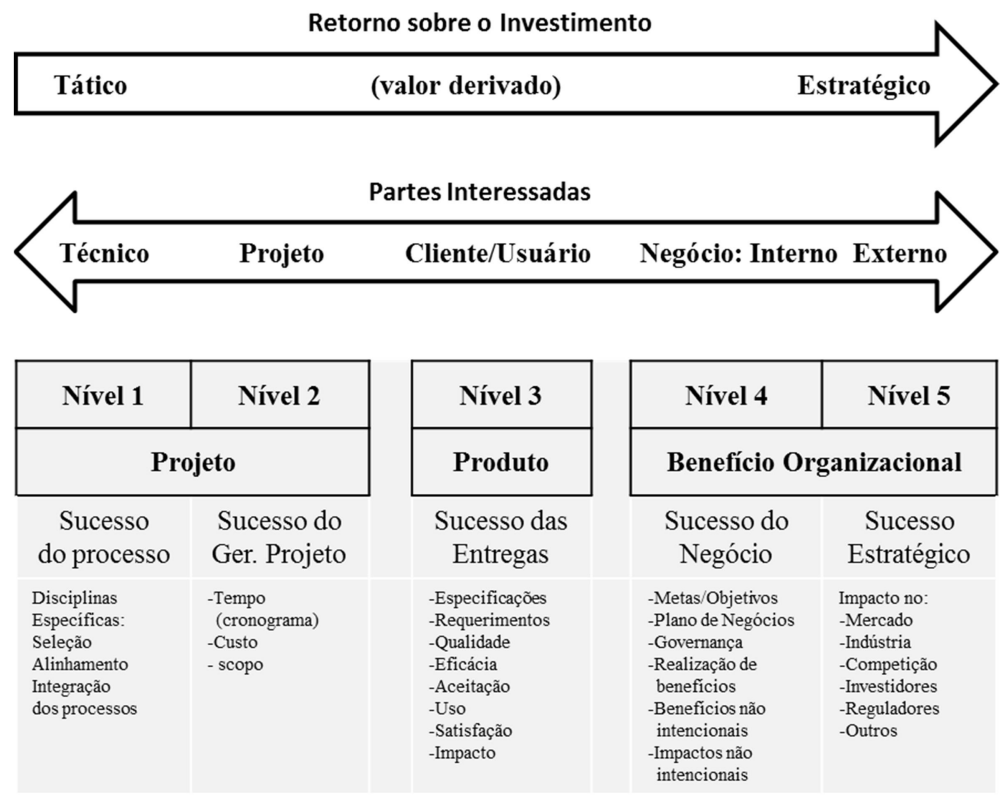

Figura 8 - Cinco níveis de sucesso do projeto segundo Bannerman Fonte: Adaptado de Bannerman (2008)

Barclay e Osei-Bryson (2010, p. 273) configuram uma hierarquia de constituintes para o desempenho de uma organização, observando que “[...] o desempenho de um projeto é visto como um resultado do sucesso do gerenciamento de projeto (GP), sucesso do projeto e sucesso do produto e está alinhado com os critérios de desempenho individuais das partes interessadas (Barclay, 2008; Collins and Baccarini, 2004)" 5 , conforme Figura 9.

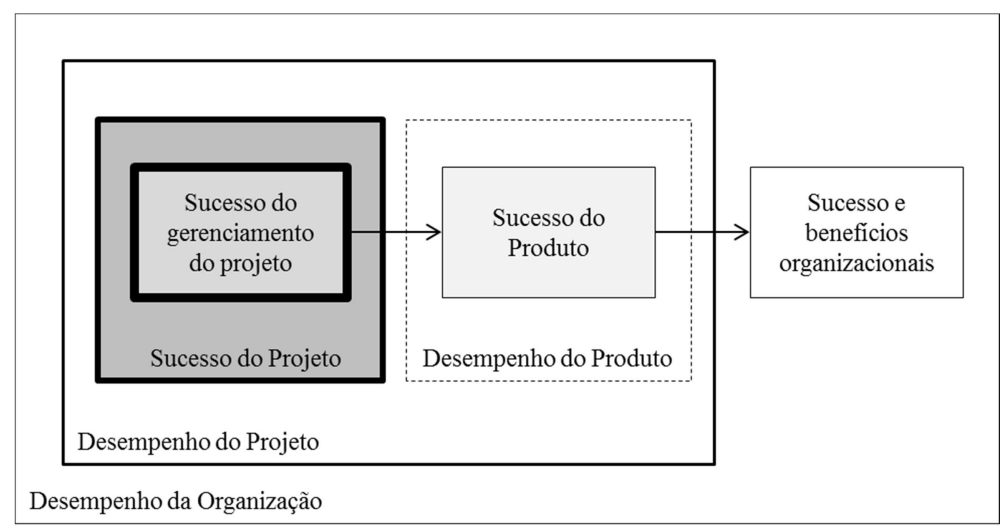

Figura 9 - Constituintes do desempenho da organização

Fonte: Adaptado de Barclay e Osei-Bryson (2010)

5 "Project performance is seen as an achievement of project management (PM) success, project success and product success and are aligned to the performance criteria of the individual stakeholders (Barclay, 2008; Collins and Baccarini 2004)”. 
O Guia PMBOK $®(P M I, 2014 b$, p. 35) afirma que o sucesso do projeto “[...] deve ser medido em termos da sua conclusão dentro das restrições de escopo, tempo, custo, qualidade, recursos e risco $[\ldots] "$ ".

Shenhar e Dvir (2010, p. 35-47), em sua abordagem Diamante, acreditam “[...] que o sucesso do projeto e do produto não devem ser separados". Eles sugerem que "uma avaliação abrangente do sucesso [...]" pode ser definida por cinco grupos de medidas (2010, p. 38): (i) Eficiência do Projeto - cumprimento das metas planejadas; (ii) Impacto no cliente representando as principais partes interessadas; (iii) Impacto na Equipe - como o projeto afeta a equipe e seus membros; (iv) Sucesso comercial e direto - impacto na organização; (v) Preparação para o futuro - benefícios de longo prazo. "Cada dimensão inclui várias submedidas possíveis, como listado na [...]" Figura 10.

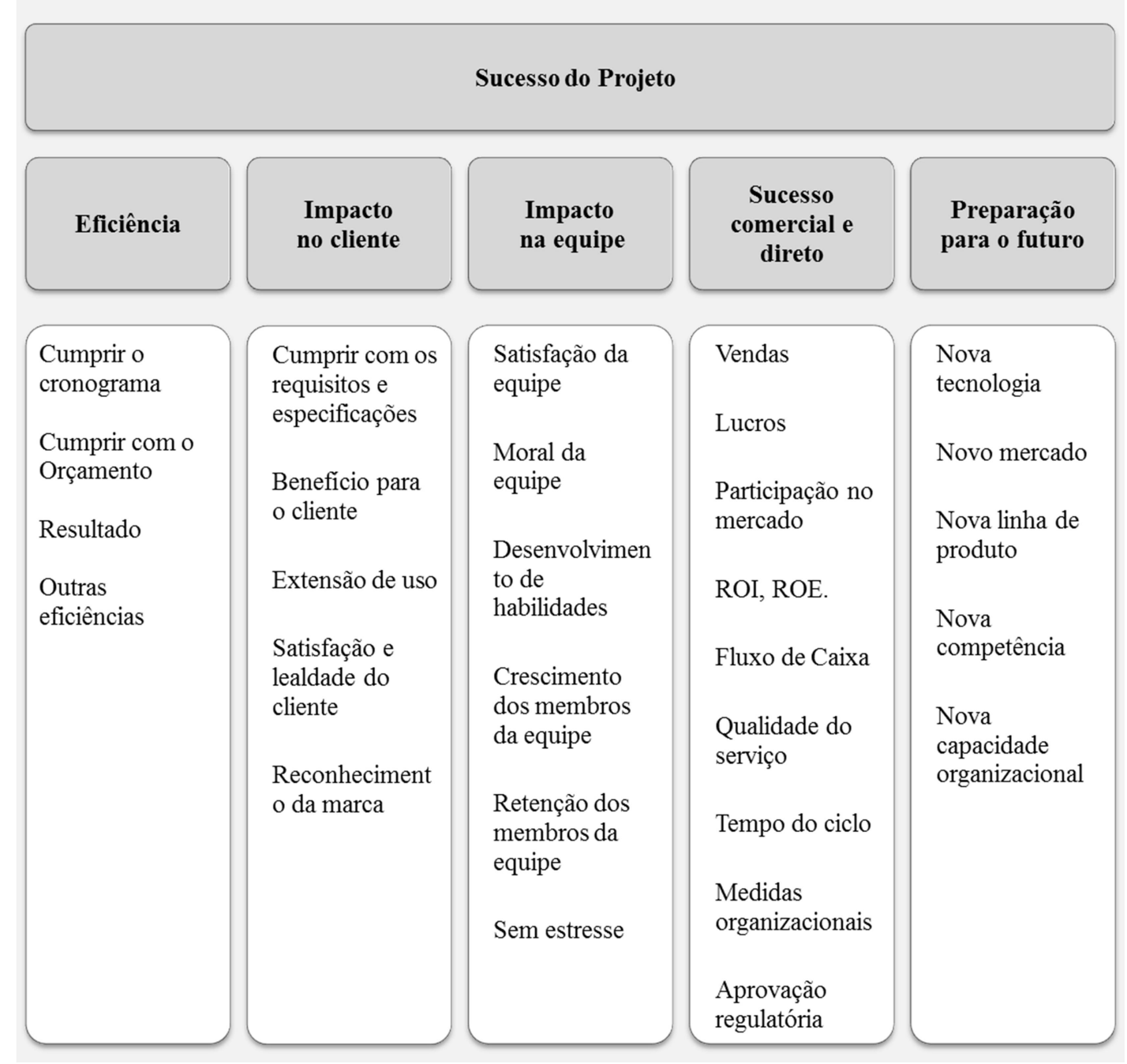

Figura 10 - Medidas específicas de sucesso

Fonte: Adaptado de Shenhar e Dvir (2010) 
Estas dimensões dão um caráter dinâmico ao conceito de sucesso, conforme esquematizado no Gráfico 2.

Gráfico 2 - Períodos de tempo das dimensões de sucesso

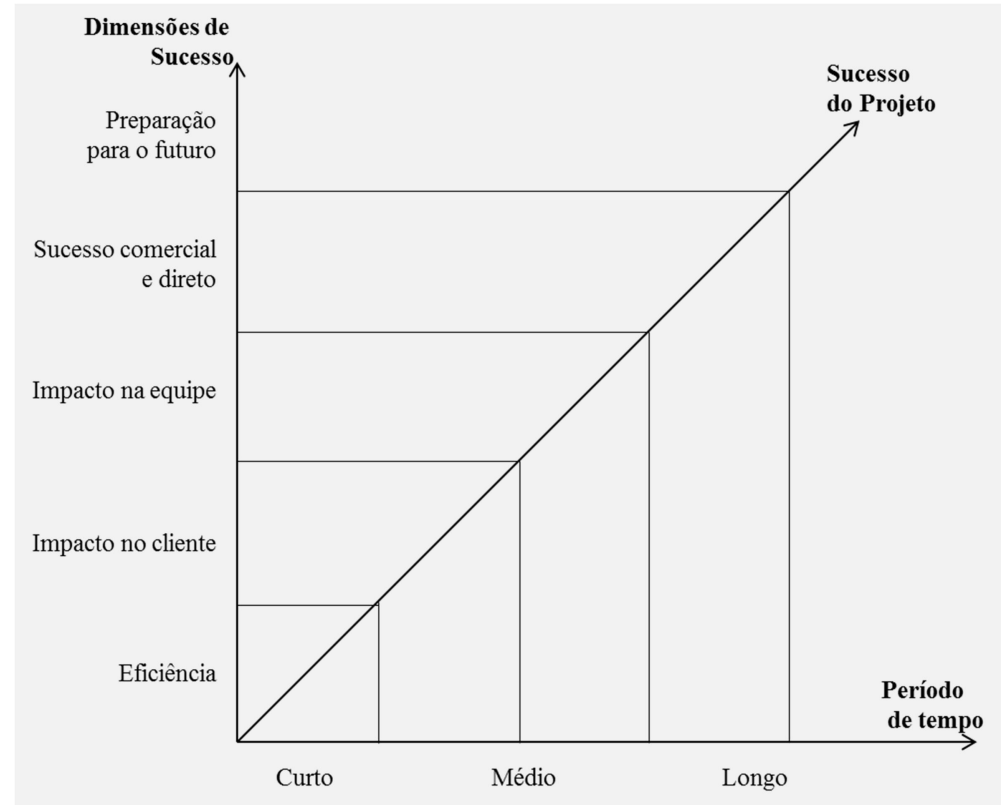

Fonte: Shenhar e Dvir (2010)

A importância relativa das cinco dimensões, com uma função de tempo, é demonstrada na Figura 11. "Como sugere a natureza das dimensões, sua importância relativa também muda, dependendo de quando elas são examinadas” (SHENHAR; DVIR, 2010, p. 42).

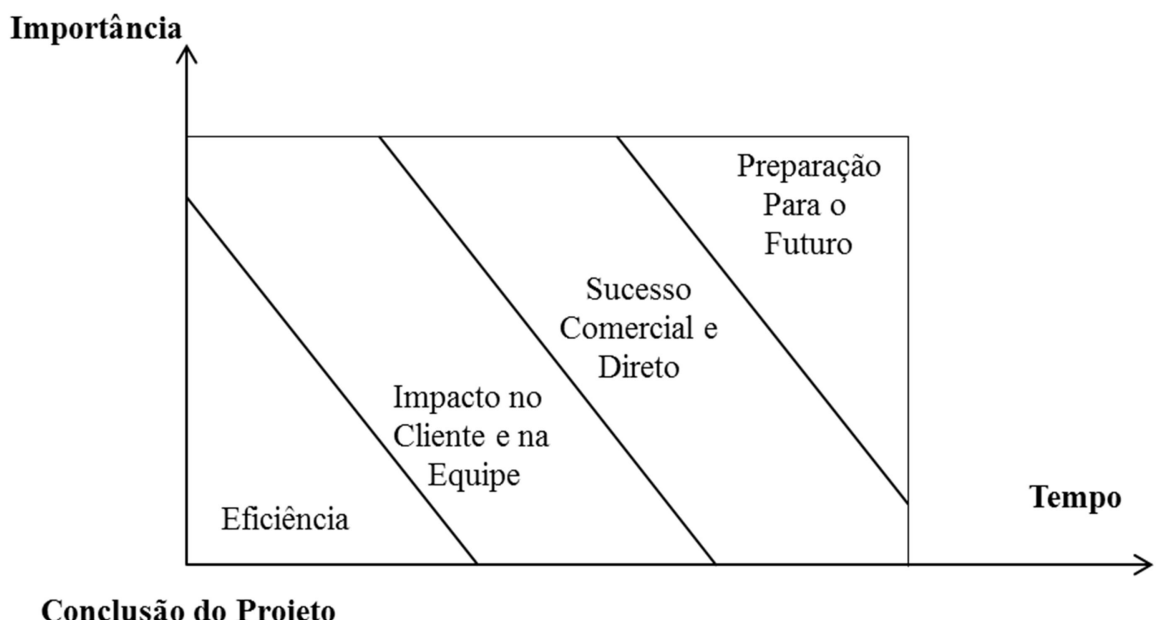

Figura 11 - Importância relativa das dimensões de sucesso: Uma questão de tempo Fonte: Shenhar e Dvir (2010) 
Shenhar e Dvir avaliam ainda que a "[...] importância relativa das dimensões de sucesso depende do projeto". Para eles, "Está claro que a satisfação do cliente e da equipe e o sucesso comercial e direto são importantes para todos os tipos de projetos. Assim sendo, a importância relativa do sucesso do projeto mede as mudanças com níveis de riscos e incertezas" (2010, p. 44), conforme a Figura 12.

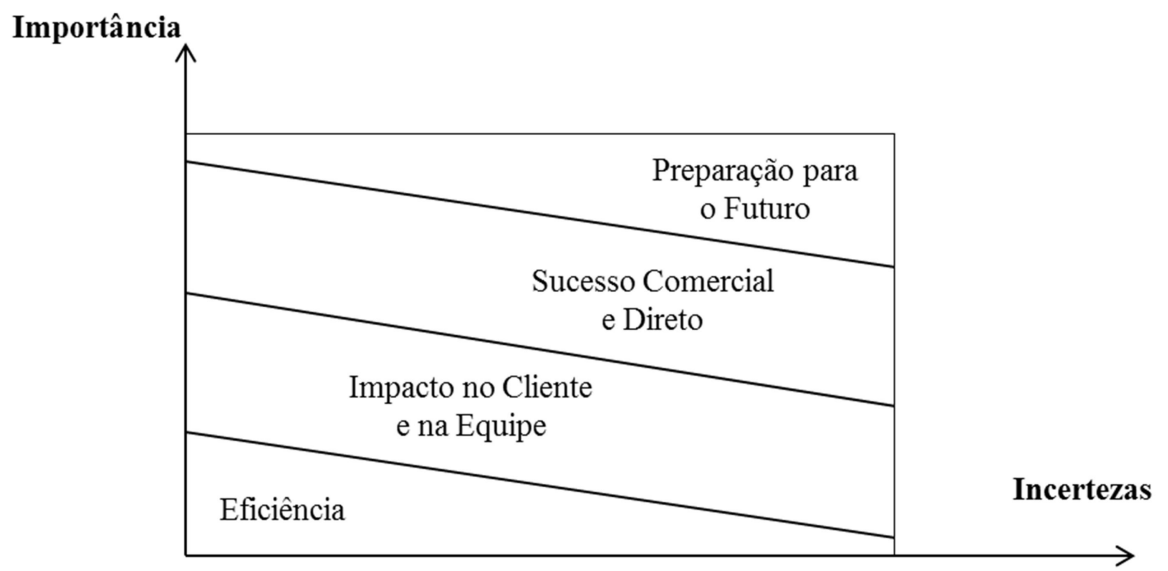

Figura 12 - Importância relativa das dimensões de sucesso depende do projeto Fonte: Shenhar e Dvir (2010)

Nesta dissertação, o modelo Diamante será utilizado como base da fundamentação teórica para os critérios de avaliação de sucesso do resultado de um projeto.

\subsubsection{Fatores Críticos de Sucesso na Execução do Gerenciamento de Projetos}

Um dos primeiros autores a comentar sobre o conceito de "fatores de sucesso" em gerenciamento de informações de empresas foi D. R. Daniel (1961), que considerava que o sistema de informações das empresas deveria ser seletivo e focar nos fatores de sucesso e que a maioria das indústrias apresentava usualmente entre três e seis fatores que determinam seu sucesso.

Em 1979 John F. Rockart comentava sobre uma "nova" abordagem de gerenciamento de informações chamada de "Método dos fatores críticos de sucesso" e desenvolvida pela Sloan School of Management do Massachusetts Institute of Technology (MIT), que apoiava as organizações a atingirem seus objetivos. Neste artigo, o autor define fatores críticos de sucesso como “[...] o número limitado de áreas em que os resultados, se satisfatórios, 
assegurarão um desempenho competitivo de sucesso para a organização" e consequentemente [...] "são áreas de atividade que deveriam receber contante e cuidadosa atenção do gerenciamento." 6 (ROCKART, 1979, p. 85).

Entre os autores que mais pesquisaram a análise dos fatores críticos de sucesso (FCS) destacase Jeffrey K. Pinto. Desde sua tese de doutorado, "Project Implementation. A Determination of Its Critical Success Factors, Moderators, and Their Relative Importance Across Stages in the Project Life Cycle" (Pittsburgh, PA: University of Pittsburgh, 1986) Pinto escreveu diversos artigos em parcerias com outros grandes autores como Slevin (PINTO; SLEVIN, 1987, 1988a, 1988b, 1989; SLEVIN; PINTO, 1986, 1987), Schultz (SCHULTZ; SLEVIN; PINTO, 1987), Prescot (PINTO; PRESCOTT, 1988, 1990), Mantel (PINTO; MANTEL JR., 1990), Kharbanda (PINTO; KHARBANDA, 1995, 1996) e livros / capítulos sobre sucesso na implantação de projetos como Successful Project Managers: Leading Your Team to Success (PINTO; KHARBANDA, 1995), Critical Success Factor in Success Information System Projects (PINTO; MILLET, 1999) e Project Critical Success Factors: The project Implementation Profile (PINTO; SLEVIN, 2006).

Nestes trabalhos, a proposição versa sobre um modelo denominado Processo de Implantação de Projetos (Project Implementation Profile - PIP) - vide Figura 13 - que relaciona como principais fatores críticos na execução de um projeto de sucesso, ao longo de seu ciclo de vida, os seguintes dez (10) principais itens:

i. Missão do Projeto - Referente aos objetivos da realização do projeto. As metas devem estar claras e terem sido compreendidas por todos da organização, inclusive os não diretamente envolvidos com o time de projeto;

ii. Apoio da Alta Direção - Este fator pode diferenciar o sucesso do fracasso do projeto. Para Beck (apud PINTO; SLEVIN,1987), “[...] o gerenciamento do projeto não só é

6 " [...] the limited number of areas in which results, if they are satisfactory, will ensure successful competitive performance for the organization. [...] are areas of activity that should receive constant and careful attention from management. 
dependente da alta direção quanto à autoridade, direção e apoio, como também é um instrumento seu para a implantação de planos ou metas para a organização" 7 ;

iii. Planejamento e Cronograma do Projeto - Referente à importância do desenvolvimento de um plano detalhado das etapas requeridas para execução do projeto. Nutt (apud, idem 1987) “[...] enfatiza a importância do processo inicial de planejamento, composto de definição do escopo, desdobramento do trabalho e atribuições de recursos e atividades" ${ }^{\text {; }}$

iv. Consulta ao Cliente - Onde o "cliente" aqui é qualquer pessoa que irá de alguma forma fazer uso do projeto, seja o cliente fora da empresa ou um departamento dentro da organização. Manley (apud, idem 1987) “[...] encontrou que o apoio do cliente ao projeto apresenta enorme variação, conforme o grau de seu envolvimento pessoal durante a execução deste projeto" ${ }^{9}$;

v. Pessoal - Referente à natureza do pessoal envolvido no projeto, incluindo seu recrutamento, sua seleção e treinamento. Hammond (apud, idem 1987) “[...] desenvolveu um modelo de plano de contingência que inclui as "pessoas" como uma variável situacional cujos conhecimentos, habilidades, metas e personalidades devem ser consideradas na avaliação do ambiente de desenvolvimento do projeto" ${ }^{10}$;

vi. Atividades Técnicas - Referente à importância da implantatação dever ser conduzida por pessoas devidamente qualificadas e estarem disponíveis os recursos tecnológicos adequados à execução do projeto;

\footnotetext{
${ }^{7}[$ [...] not only dependent upon top management for authority, direction, and support, but as ultimately the conduit for implementing top magagement's plans, or goals, for the organization."

${ }^{8}$ [...] emphasizes the importance of process planning, breaking down planning into four stages: formulation, conceptualization, detailing, and evaluation.

${ }^{9}$ [...] found that the degree to which clients are personally involved in the implementation process will cause great variation in their support for that project.

${ }^{10}$ [...] has developed a contingency model of the implementation process which includes "people" as a situational variable whose knowledge, skills, goals, and personalities must be considered in assessing the environment of the organization.
} 
vii. Aceitação do Cliente - Em adição à consulta do cliente em fases anteriores, a aceitação do projetos por estes clientes permanece como de fundamental importância para seu sucesso. Este fator refere-se aos estágios finais do projeto, quando à eficácia do projeto deve ser determinada. Muito frequentemente, acredita-se que apenas a consulta ao cliente seria o suficiente e não se valida sua aceitação. Pinto e Slevin (1987) colocam que vários autores, entre eles Bean e Radnor, consideram que a verificação da aceitação pelo cliente deve ser uma fase do projeto como qualquer outra;

viii. Monitoração e Feedback - Referente ao processo de controle de projeto onde, a cada etapa de execução, o pesssoal chave deve receber o feedback sobre como o projeto está em relação à previsão planejada. Neste modelo, este fator refere-se não só ao controle das despesas (budget) e cronograma, como também ao desempenho dos membros do time de gerenciamento;

ix. Comunicação - A necessidade de canais de comunicação adequados é extremamente importante na criação de uma atmosfera para o sucesso da realização do projeto. A comunicação é importante não só internamente ao time de gerenciamento como também com todos os integrantes da organização e mesmo com os clientes;

x. Solução de Problemas - Problemas sempre existirão. O importante é que o gerenciamento de projetos tenha planejado cuidadosamente atividades que previamente auxiliem a resolvê-los.

Estes fatores compõem o modelo de dez (10) fatores críticos de processo de implantação de projetos $^{11}$ (PIP), que mostra fluxo e sequência no tempo destes fatores, sendo que os autores observam que este modelo não prioriza os FCS entre si (SLEVIN; PINTO, 1986).

\footnotetext{
${ }^{11}$ Ten Key Factors of the Project Implementation Profile
} 


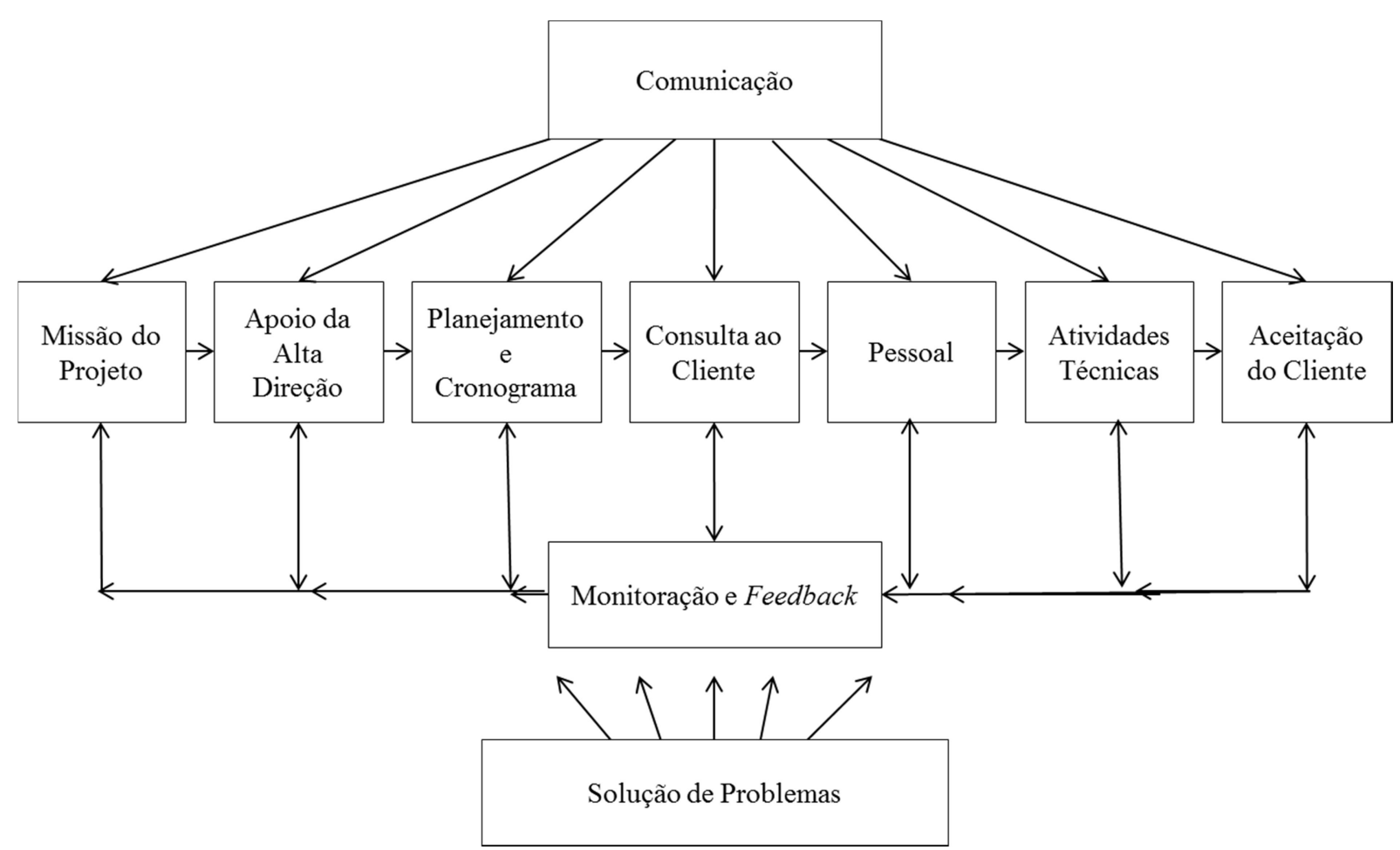

Figura 13 - Modelo de Dez Fatores Críticos do Processo de Implantação de Projeto Copyright@1984 Randall L. Schultz and Dennis P. Slevin. Used with Permission

Fonte: Adaptado de Slevin e Pinto (1986)

Neste modelo, conforme Figura 13, além de 7 fatores sequenciados (no tempo) segundo um caminho crítico, são relacionados outros 3 fatores que hipoteticamente ocorrem necessária e simultaneamente em harmonia com fluxo.

Bellassi e Tukel (1996), a partir da análise de sete listas de fatores críticos de sucesso, elaboradas entre 1971 e 1989 (cinco anteriormente relacionadas por Pinto e Slevin em 1987: Chandler-1971; Martin-1976; Leland e King-1983; Locke-1984; Sales e Baker Murphy e Fisher-1983; acrescidas de Morris e Hough-1987 e Pinto e Slevin-1989), propuseram um modelo de determinação de fatores críticos, onde estes fatores são agrupados em quatro principais áreas relacionadas: (i) ao projeto; (ii) ao gerente e membros do time de projeto; (iii) à organização e (iv) ao ambiente externo (vide Figura 14). 


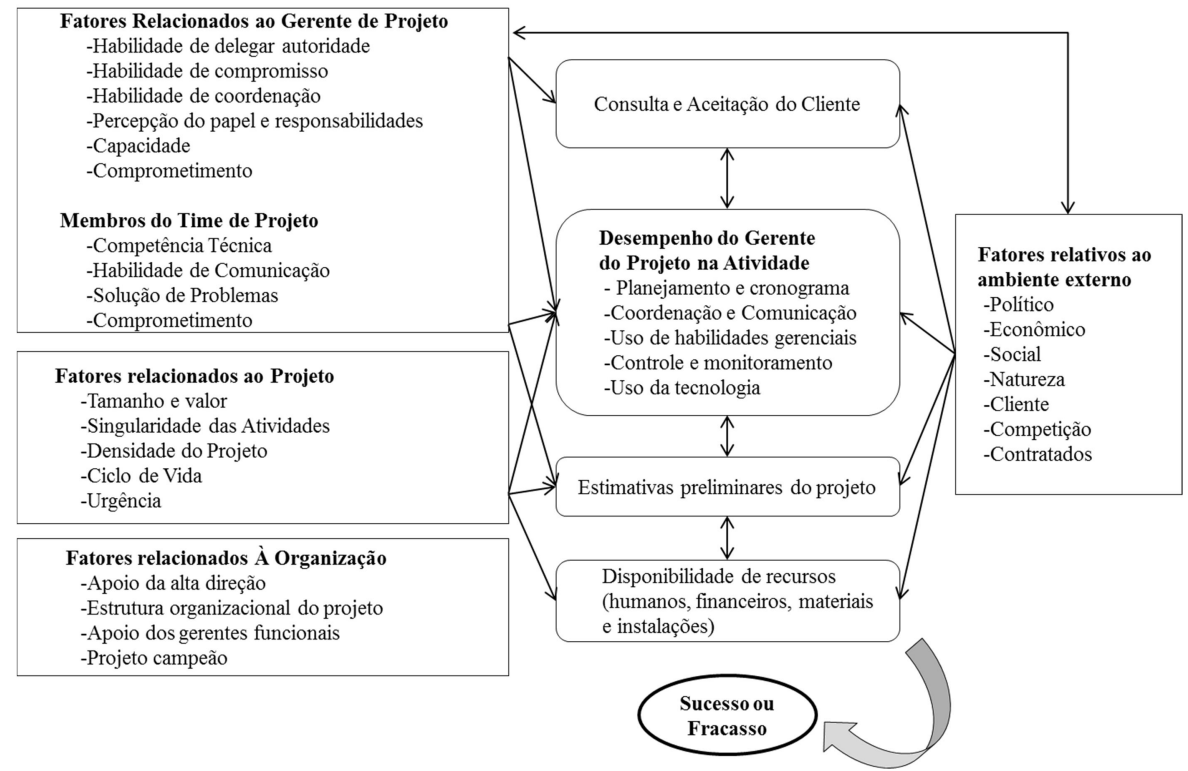

Figura 14 - Fatores Críticos de Sucesso / Fracasso segundo Bellassi e Tukel Fonte: Adaptado de Bellassi e Tukel (1996)

Westerveld (2003) relacionou o Modelo de Excelência de Projetos ${ }^{\circledR}$ do EFQM com os resultados sobre fatores críticos de sucesso de quatro publicações entre 1987 e 1996 (Morris e Hough-1987; Pinto e Slevin-1988; Munns e Bjeirmi-1996; Belassi e Tukel-1996) e estabeleceu 6 áreas de resultados deste modelo relacionadas a fatores críticos de sucesso conforme a Tabela 5.

Tabela 5 - Áreas de Resultados relacionadas a Fatores Críticos de Sucesso

\begin{tabular}{|l|l|l|}
\hline Nr. & Área de Resultados & Explicação \\
\hline 1 & Liderança e time & $\begin{array}{l}\text { Representa a forma como o gerente de projeto executa o projeto e como as tarefas e } \\
\text { responsabilidades estão divididas. Estilo de liderança e cooperação no time de } \\
\text { projeto influenciam muito os hábitos de trabalho dentro da organização do projeto. }\end{array}$ \\
\hline 2 & Política e estratégia & $\begin{array}{l}\text { Quais são os objetivos do projeto e como eles são realizados? } \\
\text { Combinação de interesses das partes interessadas de forma a ter um produto final. }\end{array}$ \\
\hline 3 & $\begin{array}{l}\text { Gerenciamento das } \\
\text { partes interessadas }\end{array}$ & $\begin{array}{l}\text { Como o projeto interagir com as várias partes interessadas? } \\
\text { A cooperação da organização do projeto com partes externas determinará o } \\
\text { posicionamento do projeto em seu ambiente. }\end{array}$ \\
\hline 4 & Recursos & $\begin{array}{l}\text { Os recursos devem ser utilizados de forma eficaz e eficiente a fim de alcançar o } \\
\text { máximo beneficio para as partes envolvidas. }\end{array}$ \\
\hline 5 & $\begin{array}{l}\text { Contratados } \\
\text { Cada organização de projeto estabelece relações contratuais. } \\
\text { As escolhas de contratos e parceiros gira em torno das tarefas na mão de partes } \\
\text { contratantes competentes. }\end{array}$ \\
\hline 6 & $\begin{array}{l}\text { Gerenciamento do } \\
\text { Projeto } \\
\text {-Cronograma } \\
\text {-Orçamento } \\
\text {-Organização } \\
\text {-Qualidade } \\
\text {-Informação } \\
\text {-Riscos }\end{array}$ & $\begin{array}{l}\text { Como o controle operacional do projeto tomar posições? } \\
\text { Os aspectos de agendamento tradicionais de controle de projeto desempenham um } \\
\text { papel fundamental neste processo. }\end{array}$ \\
\hline
\end{tabular}

Fonte: Adaptado de Westerveld (2003) 
Fortune e White (2006) fazem uma revisão de 63 publicações e mapeiam 23 dos 27 fatores críticos de sucesso encontrados numa revisão de 63 publicações conforme Modelo Formal de Sistemas (vide Figura 15). Estes 23 fatores críticos de sucesso são classificados por eles em nove (09) diferentes clusters: (i) Metas e objetivos; (ii) Monitoramento de desempenho; (iii) Decisores; (iv) Transformações; (v) Comunicação; (vi) Ambiente; (vii) Limites; (viii) Recursos; (ix) Continuidade.

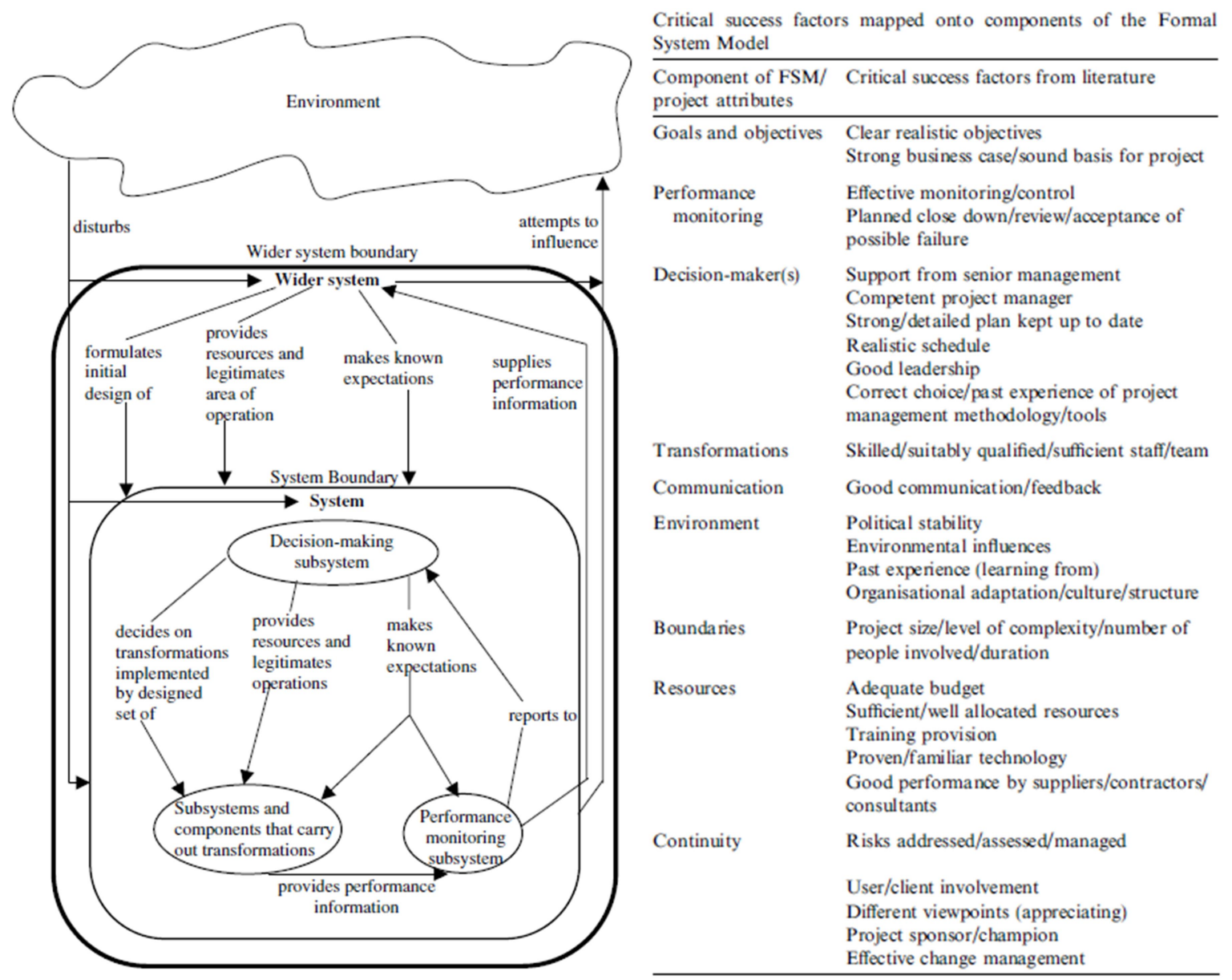

Figura 15 - Fatores Críticos de Sucesso mapeados conforme Modelo Formal de Sistemas Fonte: Fortune e White (2006)

Carvalho e Rabechini (2011, p. 51-53) chamam os fatores críticos de sucesso de "[...] variáveis gerenciais distintas a serem controladas" em função de cada tipo de projeto. Desta forma apresentam um relacionamento entre as áreas de gerenciamento (escopo, recursos humanos, prazos, custos, aquisições, riscos, comunicação, qualidade, jurídica, ética, marketing, responsabilidade social, meio ambiente, saúde, segurança, criatividade, 
conectividade e redes, gestão do conhecimento) e os clusters do Modelo $I^{4}$ (Inovação, Integração, Imediatas Entregas e Impactos).

Tendo em vista a representatividade da relação de fatores críticos de sucesso, elaborada por Jeffrey K. Pinto et al e descrita neste item, bem como sua aplicabilidade para projetos de desenvolvimento de veículos comerciais, esta foi a relação adotada para a condução do estudo de caso desta dissertação. 


\section{METODOLOGIA}

A presente dissertação foi desenvolvida como um projeto de pesquisa acadêmica de mestrado profissional e escrita com base no manual para formatação e edição de dissertações e teses da Comissão de Pós-Graduação da Faculdade de Economia, Administração e Contabilidade da Universidade de São Paulo (CPG-FEA-USP, 2008), seguindo as diretrizes ABNT para confecção de teses e dissertações (SIBI/USP, 2009).

Conforme proposta do Mestrado Profissional em Empreendedorismo (MPE), da FEA-USP coordenado pelo Prof. Dr. Martinho Isnard Ribeiro de Almeida, a definição do tema da pesquisa nasceu a partir da experiência profissional do autor, em gerenciamento de projetos de desenvolvimento de veículos comerciais (caminhões e ônibus), utilizando-se do rigor da pesquisa acadêmica já consolidada (veja vídeos conforme referências EMPRAD USP, 2014a e 2014b).

Desta forma, buscou-se investigar academica/cientificamente um acontecimento prático e contemporâneo da indústria automobilistica brasileira, que se caracteriza por empresas multinacionais que desenvolvem veículos comerciais através de times brasileiros de gerenciamento de projetos.

O esquema de atividades para a realização da dissertação encontra-se mostrado na Figura 16 e foi elaborado conforme precrito por Marconi e Lakatos (2010).

Tendo em vista o autor desta dissertação ter tido experiência profissional de mais de 30 anos com Desenvolvimento de Veículos Comerciais, definiu-se como objetivos principais pesquisar a importância dos Fatores Críticos de Sucesso (FCS) para a execução do Processo de Gerenciamento do Desenvolvimento de Produtos e a importância dos Critérios de Avaliação de Sucesso dos Resultados de Projetos em uma empresa tradicional da indústria automobilística brasileira de veículos comerciais.

Para embasamento do referencial teórico (capítulo 2) foi feita uma pesquisa bibliográfica, ou de fontes secundárias, conforme preconizada por Marconi e Lakatos (2010), que procurou relacionar os principais autores clássicos assim como teses, dissertações, monografias, artigos acadêmicos e outras publicações sobre as teorias estudadas. 


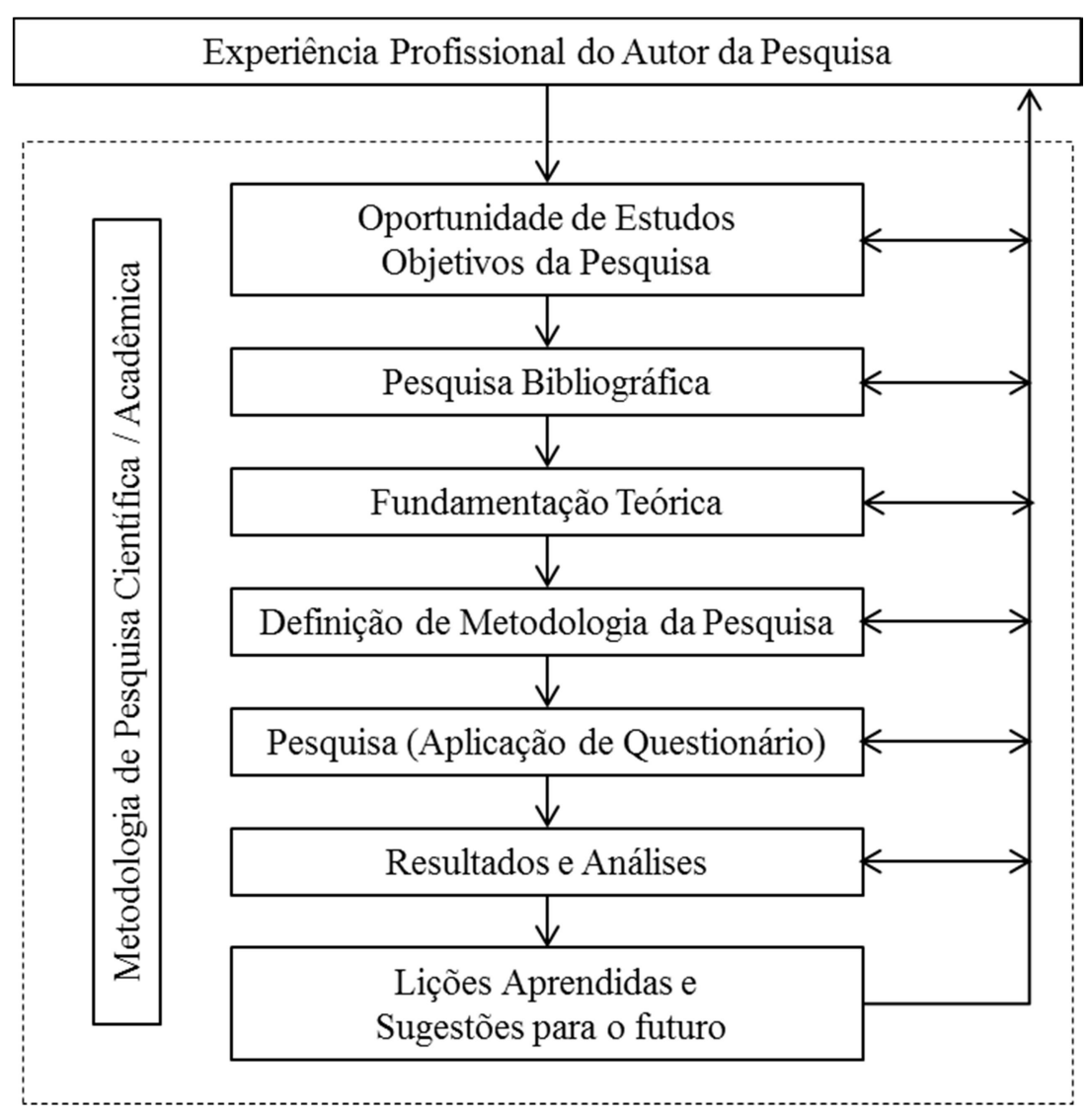

Figura 16 - Fluxo de atividades / Metodologia de pesquisa

As principais bases de dados de pesquisa utilizadas entre 2014 e 2016 foram acessadas por meio dos seguintes sítios eletrônicos (portais de internet):

i. Sistema Integrado de Bibliotecas da Universidade de São Paulo (SIBI USP, 2014) com suas conexões aos subsistemas Dedalus, Portal de Busca Integrada, Portal de Revistas USP, Produção Intelectual, Repositório Cruesp, Teses e Dissertações e Vocabulário Controlado;

ii. Portal de Periódicos da Coordenação de Aperfeiçoamento de Pessoal de Nível Superior, fundação do Ministério da Educação (CAPES/MEC, 2014);

iii. Web of Science (THOMSON REUTERS, 2014); ScienceDirect (ELSEVIER, 2014);

iv. Research Gate (RESEARCH GATE, 2014);

v. Sistema de Bibliotecas da Universidade Estadual de Campinas (UNICAMP, 2014);

vi. Google Acadêmico (GOOGLE, 2014);

vii. ProQuest Dissertations and Theses (PROQUEST, 2015); 
O processo de pesquisa bibliográfica foi efetuado nos idiomas Português e Inglês e relacionado aos temas: (i) gerenciamento de projetos; (ii) sucesso; (iii) indicadores de sucesso; (iv) fatores críticos de sucesso e; (v) indústria automobilistica, pesquisados individualmente ou associados. A partir destas investigações, foram selecionados livros, teses, dissertações, manuais de gerenciamento de projeto, artigos e documentos de sítios eletrônicos mais representativos em função de citações e da semelhança dos objetos de estudo.

Em relação à metodologia de pesquisa de campo, optou-se pela execução de uma pesquisa qualitativa, tendo em vista que, "o fenômeno a ser estudado só pode ser captado através da observação e/ou interação" (MARTINS; THEÓPHILO, 2009, p. 142). Assim é que, definiuse pela formatação de um estudo de caso, em profundidade, em uma empresa "tradicional", sendo que as técnicas utilizadas foram as de entrevista e observação.

Outra justificativa para esta escolha do método de estudo de caso é que, segundo Yin (2010, p. 39) “O estudo de caso é uma investigação empírica que investiga um fenômeno contemporâneo em profundidade e em seu contexto de vida real, especialmente quando os limites entre o fenômeno e o contexto não são claramente evidentes".

Definido o método, como forma de estruturar a investigação do estudo de caso (capítulo 4), foi elaborado um questionário base para a pesquisa qualitativa, focalizado em conceitos de Shenhar e Dvir sobre classificação de projetos e critérios de sucesso do projeto e Jeffrey K. Pinto et al (descritos no capítulo 2) sobre fatores críticos de sucesso para a execução do projeto.

Este questionário de pesquisa foi inicialmente elaborado em texto impresso e testado preliminarmente com alguns especialistas, potenciais entrevistados, conforme prescrito por Martins e Theóphillo (2009).

Otimizado, o questionário foi adaptado para a ferramenta de pesquisa eletrônica Google Forms para envio por correio eletrônico (e-mail) e preenchimento online na internet. A ferramenta Google Forms foi adotada por sua popularidade, pensando que o entrevistado ficaria mais tranquilo em responder nesta plataforma, do que em outras plataformas não tão populares mas igualmente disponíveis gratuitamente como SurveyMonkey e Type Form. Este tipo de ferramenta eletrônica tem a vantagem de facilitar o entrevistado no ato de responder a 
pesquisa, porém tem suas limitações de formatação, ficando ligeiramente diferente em relação à forma do questionário original em papel, apesar de manter o mesmo conteúdo.

O questionário de pesquisa foi composto basicamente de cinco (5) tópicos (vide Apêndice 1), a saber:

i. Dados profissionais dos entrevistados: gênero; ocupação / função hierárquica; atividade funcional na organização; tempo de experiência profissional; tipo de participação no gerenciamento de projeto;

ii. Nome do veículo desenvolvido (resposta opcional);

iii. Caracterização do projeto com critérios adaptados da abordagem diamante de Shenhar e Dvir (2010): novidade do veículo em relação ao mercado; tecnologia do veículo ou de seus principais sistemas importantes; complexidade de fornecimento de sistemas importantes; tempo disponível para realização do projeto;

iv. Classificação (priorização) dos critérios de sucesso que contribuem para o resultado do projeto, adaptados dos cinco critérios de Shenhar e Dvir (2010): eficiência; clientes; equipe; viabilidade; sustentabilidade. Estes critérios deveriam ser classificados segundo a opinião do respondente e também segundo o entendimento do respondente sobre o grau de importância dado por sua empresa;

v. Classificação / priorização dos fatores críticos de sucesso para a execução do execução do projeto, adaptados dos dez critérios de Jeffrey K. Pinto et al: missão; apoio da alta direção; planejamento e cronograma; consulta a clientes; pessoal; atividades técnicas; aceitação do cliente; acompanhamento e feedback; comunicação; solução de problemas.

A pesquisa foi direcionada a profissionais envolvidos com gerenciamento de projetos da montadora selecionada, tendo sido solicitado que houvesse representantes de diversas áreas e não só da Engenharia de Produtos.

A partir dos questionários respondidos (vide Apêndice 2), elaborou-se uma análise e interpretação dos resultados, conforme apresentados no capítulo 4 desta dissertação. 
Inicialmente verificaram-se os perfis dos entrevistados e as principais características dos projetos da montadora nos quais os entrevistados participaram. A seguir, com foco nas perguntas relativas ao critérios de sucesso de projeto e de fatores críticos de sucesso para execução do projeto, as respostas foram analisadas quanto ao grupo em geral e também em subgrupos em função dos perfis dos entrevistados e das características dos projetos.

Os resultados foram compilados em diagramas de barras a título de exemplos e principalmente em tabelas comparativas coloridas, como forma de representá-los graficamente, já que isto se mostrou a melhor forma de exposição entre diversas disposições gráficas analisadas (gráficos lineares, de colunas, de barras, superfície, radar, etc.). Nestas tabelas coloridas, cada cor representa um único critério de sucesso para avaliação do resultado do projeto ou um único fator crítico de sucesso para sua execução.

Estes resultados foram sintetizados no capitulo 5, onde foram formuladas as conclusões e também analisadas as principais lições aprendidas, as principais limitações desta dissertação e sugeridos alguns potenciais estudos futuros.

Interessante observar que este fluxo demonstrado na Figura 16 é interativo, havendo constante revisões e loopings entre suas fases (exceto a fase de pesquisa final de campo, evidentemente). Cada fase elaborada, influencia todas as demais e o processo de estudo se repete e se complementa por diversas vezes. 


\section{ESTUDO DE CASO / ANÁLISE DE RESULTADOS}

Foram enviados 84 questionários por meio de mensagens eletrônicas (e-mails) a profissionais participantes de gerenciamento de projetos de veículos comerciais da montadora em estudo.

Foram recebidas 62 respostas, o que perfaz um índice de respostas de $74 \%$ considerado adequado e satisfatório, visto as limitações do método, como incompreensões por parte dos entrevistados e mesmo a sua disposição em dar informações (MARCONI; LAKATOS, 2010).

Estas 62 respostas recebidas encontram-se tabeladas no Apêndice 2 desta dissertação e formam um conjunto de resultados conforme apresentados na sequência deste capítulo.

Um dos questionários respondidos teve de ser invalidado totalmente, devido a problemas de preenchimento incorreto das opões de respostas. Um segundo entrevistado teve suas respostas para o último tópico também invalidadas pelo mesmo motivo. Como a identificação pessoal dos entrevistados era opcional, não houve possibilidade de contatar especificamente estas duas pessoas de modo a revalidar suas respostas.

Como produto final, foram recebidas 61 respostas válidas para as perguntas dos tópicos de $1 \mathrm{a}$ 4 e 60 respostas válidas para as perguntas do tópico 5 do questionário.

Observa-se que o tópico 2 do questionário, que solicitava informação opcional sobre o nome do veículo derivado do projeto de desenvolvimento de produto, não foi compilado para efeito de análises.

\subsection{Perfil dos Entrevistados}

O tópico 1 do questionário solicitou os principais dados profissionais dos entrevistados e possibilitou o seguinte levantamento sobre o universo pesquisado: 


\subsubsection{Gênero}

Responderam as questões da pesquisa 58 homens (95\%) e 03 mulheres (05\%).

Gráfico 3 - Gênero dos entrevistados

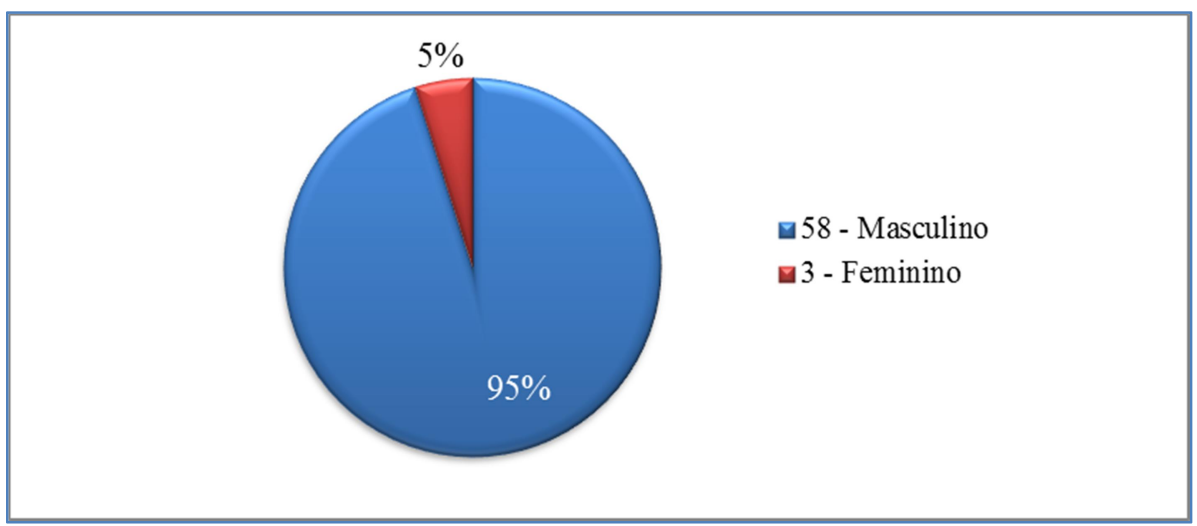

\subsubsection{Ocupação / Função Hierárquica}

Os respondentes são em sua maioria executivos (98\%) e se identificaram como

i. Presidente / Vice-Presidente / Diretor Pleno (07 pessoas - 11\%);

ii. Diretor Adjunto / Gerente Sênior (19 pessoas - 31\%);

iii. Gerente / Supervisor (34 pessoas - 56\%);

iv. Mestre / Especialista (01 pessoa - 02\%).

Para efeitos de análise de outros resultados adiante da pesquisa, os dois últimos grupos serão considerados como um único.

\section{Gráfico 4 - Ocupação / Função Hierárquica}

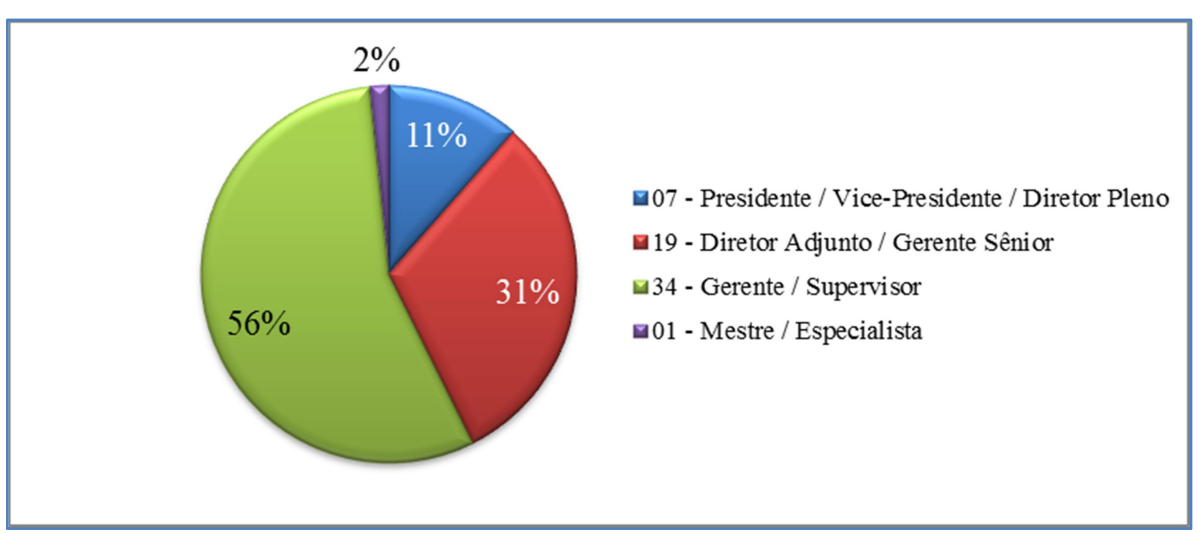




\subsubsection{Atividade Funcional na Organização}

Percebe-se que os respondentes atuam principalmente na área de (i) Desenvolvimento de Produtos (41pessoas - 67\%), seguida da área de (ii) Industrialização (12 pessoas - 20\%), Vendas (04 pessoas - 6,5\%) e (iii) "Processos de Suporte" - RH / Compras / Finanças / Controladoria (04 pessoas $-6,5 \%)$.

Gráfico 5 - Atividade por Área Funcional

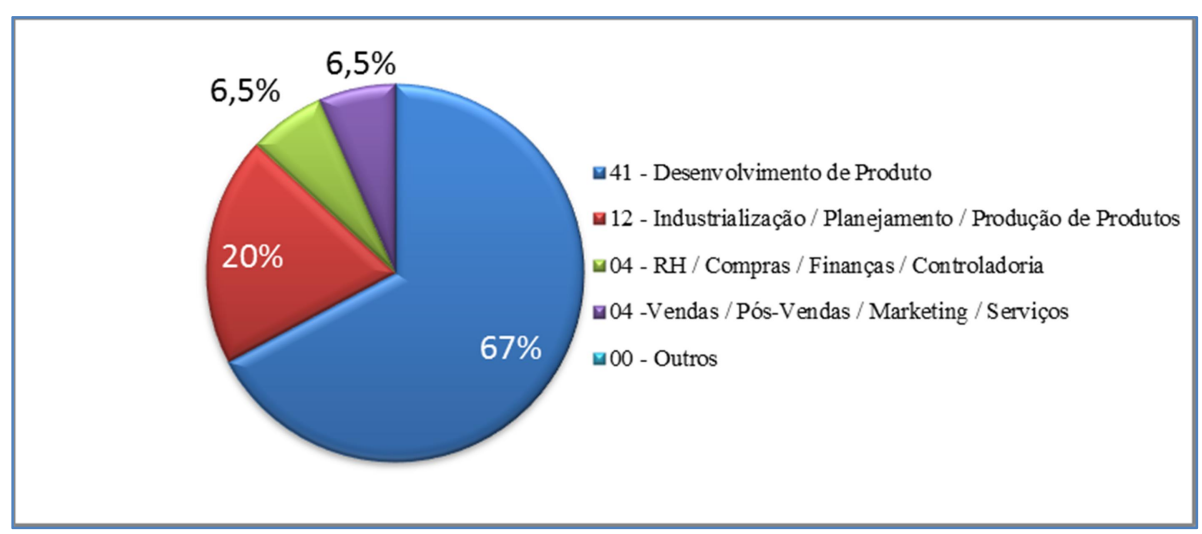

\subsubsection{Tempo de Experiência Profissional}

O perfil dos entrevistados é predominantemente de profissionais com muita experiência, havendo 25 pessoas (41\%) com mais de 20 anos de atividades, 29 pessoas (48\%) entre 11 e 20 anos e 07 pessoas (11\%) com menos de 10 anos de experiência.

Gráfico 6 - Tempo de Experiência Profissional

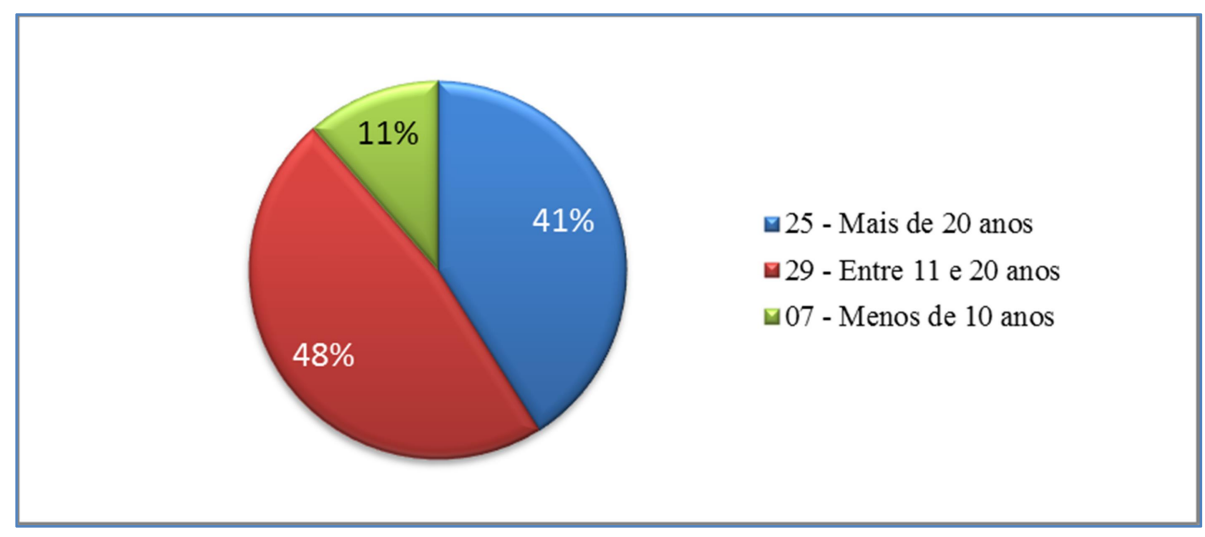




\subsubsection{Participação no Gerenciamento do Projeto}

Perguntadas sobre sua participação no projeto sobre o qual refletiam, verifica-se que a maioria dos entrevistados (43 pessoas - 71\%) exerceu a função de (i) Gerente / Líder de Projeto. Exerceram funções em (ii) Comitê de Direção / Decisão de Projeto 11 pessoas (18\%) e outras 07 pessoas (11\%) foram (iii) participantes dos grupos de gerenciamento.

Gráfico 7 - Participação no Gerenciamento de Projeto

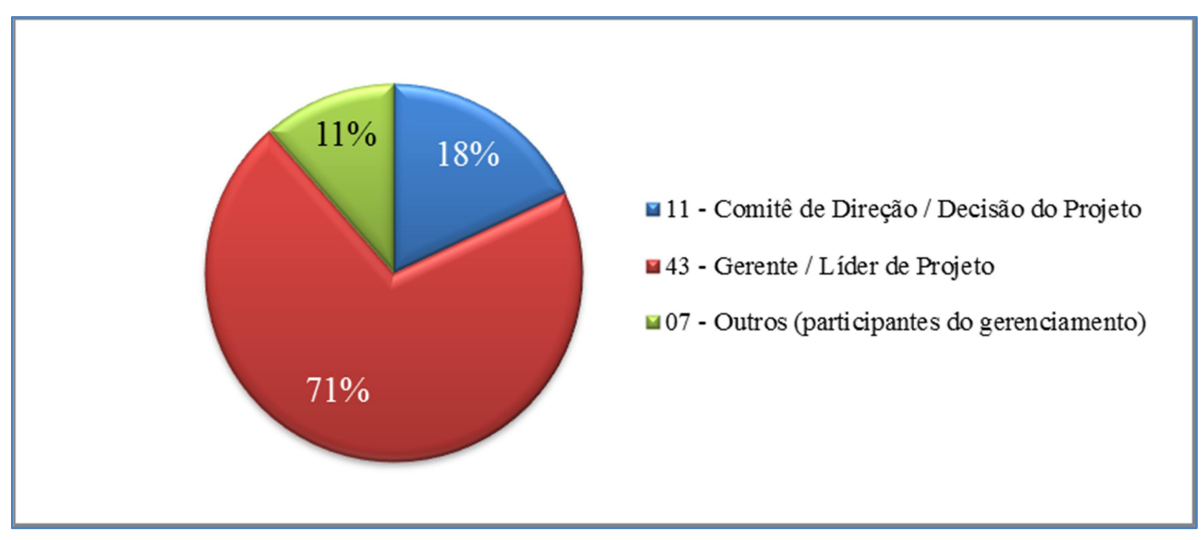

\subsection{Caracterização dos Projetos Referenciados pelos Entrevistados}

O tópico 3 do questionário, solicitou aos entrevistados que classificassem os projetos de referência em que participaram, baseando-se nas seguintes características, adaptadas das definições de Shenhar e Dvir (2010), relacionadas entre parenteses:

i. Novidade do produto em relação ao mercado:

- Facelift (Derivativo): extensões e melhorias de produtos existentes;

- Sucessor (Plataforma): novas gerações de linhas de produtos existentes;

- Inédito (Inovador): novos conceiros de veículos ou de sistemas veiculares importantes (cabine / quadro / motor / transmissão / eixos / direção / suspensão/ freios);

ii. Tecnologia do veículo ou de sistema veicular importante do veículo:

- Baixa (Baixa): veículo não apresenta novas tecnologias (por ex.: nacionalizações);

- Média (Média e Alta): veículo apresenta novas tecnologias recém existentes;

- Alta (Super-Alta-Tecnologia): veículo apresenta tecnologias desenvolvidas durante o projeto; 
iii. Complexidade referente aos tipos de fornecimento dos sistemas veiculares importantes:

- Baixa (Montagem): sistemas fornecidos por sua própria empresa;

- Média (Sistema): sistemas fornecidos por empresas pertencentes à mesma holding proprietária da empresa:

- Alta (Matriz): sistemas fornecidos por empresas sem qualquer vínculo com a empresa;

iv. Tempo (Ritmo) disponível para desenvolvimento do veículo (execução do projetos):

- Normal (Regular e Rápido / Competitivo): determinado normalmente pela empresa;

- Crítico (Crítico): determinado por uma legislação específica conhecida;

- Urgente (Blitz): determinado por uma janela de oportunidade (ex.: nova licitação).

\subsubsection{Novidade dos Veículos em Relação ao Mercado}

Das respostas recebidas, pode-se perceber que a empresa trabalha primordialmente com novos produtos, em sua maioria (87\%) inéditos ou sucessores de uma linha atual, e em menor atividade (13\%) com melhorias de produtos existentes (facelift).

Gráfico 8 - Novidade dos produtos em relação ao mercado

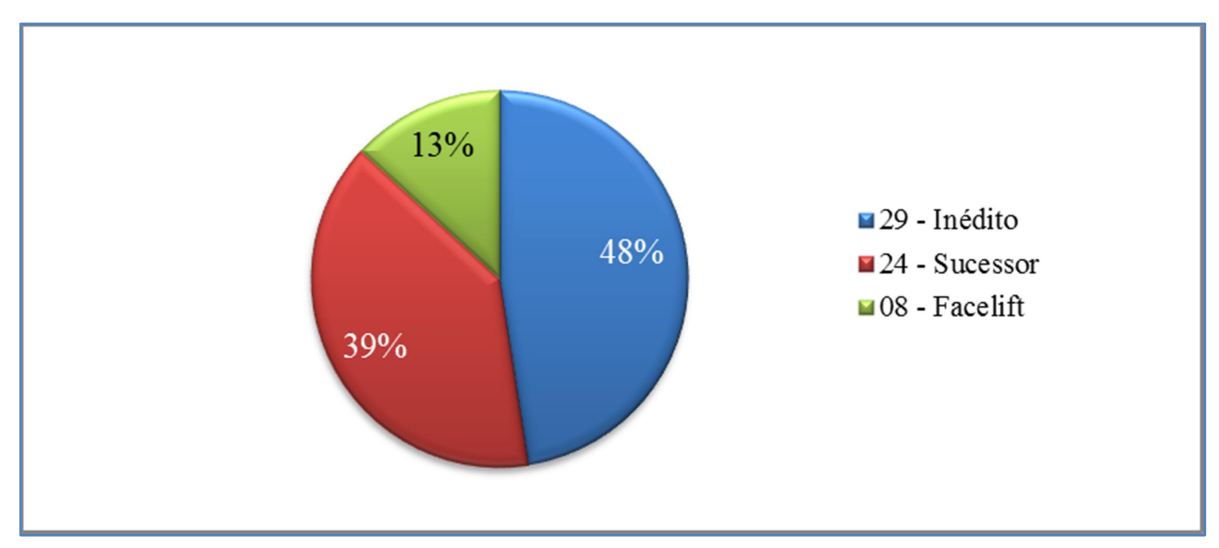




\subsubsection{Tecnologia dos Veículos ou de seus Principais Sistemas Importantes}

Os veículos desenvolvidos, em sua maioria (88\%), apresentam grau elevado de novas tecnologias desenvolvidas durante o projeto ou que foram recém-desenvolvidas na época do seu desenvolvimento (alta e média tecnologia). Poucos projetos (12\%) representaram veículos sem novas tecnologias de produto (baixa tecnologia).

Gráfico 9 - Tecnologia dos veículos ou de seus sistemas importantes

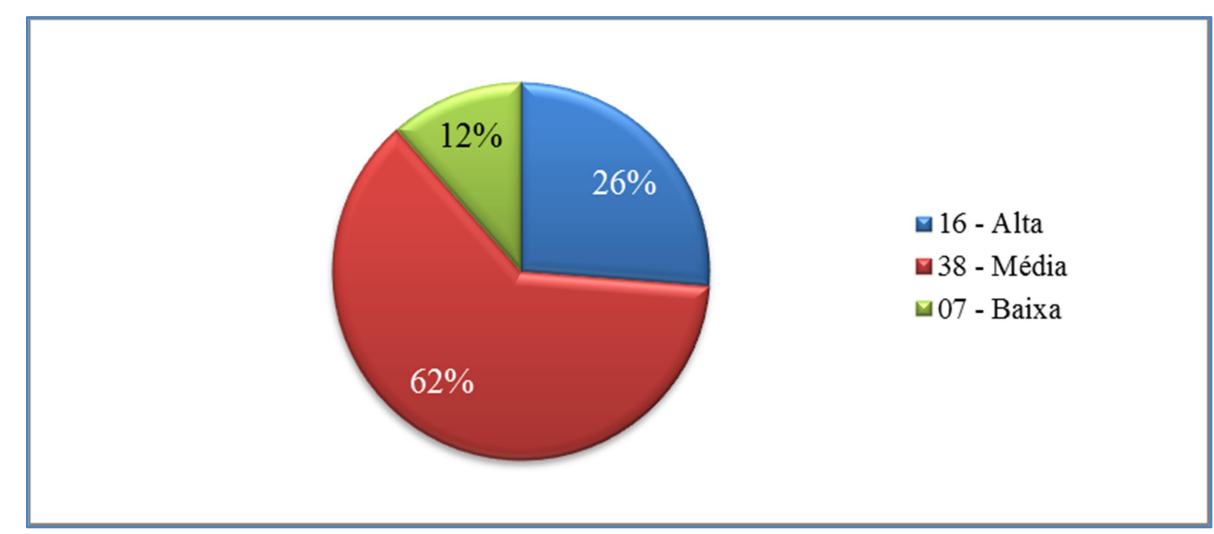

\subsubsection{Complexidade de Fornecimento de Sistemas Importantes}

Os sistemas importantes dos veículos relacionados foram, em sua maioria (89\%), fornecidos por outras empresas (complexidade alta e média) e poucos (11\%) apresentaram componentes fornecidos pela própria empresa (complexidade baixa).

Gráfico 10 - Complexidade do fornecimento de sistemas importantes

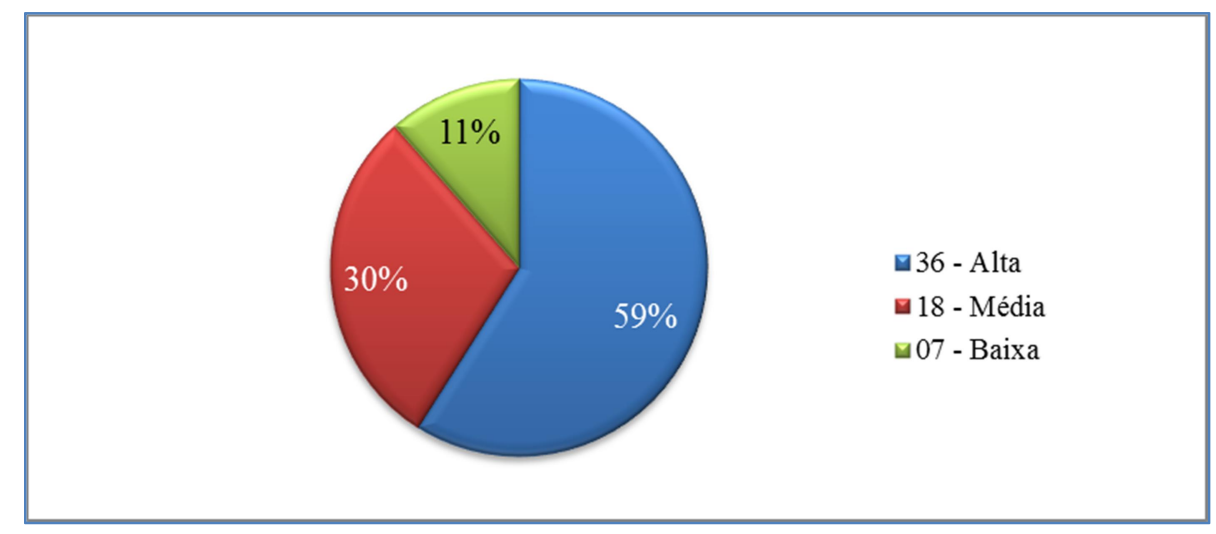




\subsubsection{Tempo Disponível para Desenvolvimento do Projeto}

Os tempos para os desenvolvimentos dos projetos da empresa caracterizam-se em sua maioria (77\%) pela urgência de novas janelas de oportunidade ou criticidade de novas legislações, sendo poucos $(23 \%)$ os projetos considerados com tempos de desenvolvimento normais, definidos conforme necessidade da empresa.

Gráfico 11 - Tempo disponível para desenvolvimento do projeto

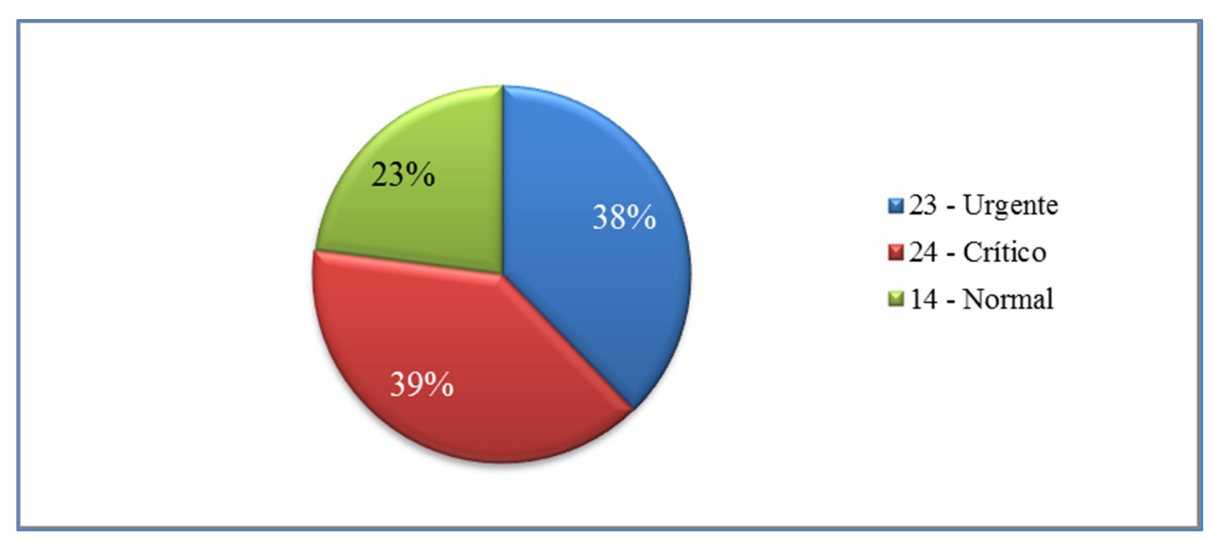

\subsection{Classificação dos Critérios de Sucesso do Resultado do Projeto}

O tópico 4 do questionário buscou identificar a priorização de cinco (5) critérios de sucesso pré-determinados para um bom resultado de projeto, segundo a própria opinião do entrevistado e segundo o seu entendimento sobre o grau de importância adotado por sua empresa.

Os cinco (5) critérios de sucesso pré-determinados que deveriam ser priorizados foram adaptados da classificação conforme modelo de Shenhar e Dvir (2010), relacionados entre parênteses, e são:

i. Eficiência (Eficiência): cronograma e orçamento do projeto conforme planejado inicialmente;

ii. Clientes (Impacto no Cliente): satisfação dos clientes e usuários com o escopo do produto; 
iii. Equipe (Impacto na Equipe): satisfação e desenvolvimento pessoal dos participantes do projeto;

iv. Viabilidade (Sucesso Comercial e Direto): resultados financeiros e mercadológicos da empresa com o projeto;

v. Sustentabilidade (Preparação para o Futuro): como o projeto contribui para o desenvolvimento de novas competências que preparam adequadamente a empresa para oportunidades futuras.

Cada critério deveria ser avaliado com notas entre 5 (mais importante) e 1 (menos importante), não devendo haver notas iguais para critérios diferentes.

O resultado de priorização foi obtido por meio da somatória dos resultados das multiplicações do número de vezes que um critério recebeu determinada nota pelo valor da própria nota.

Exemplo: se o critério Clientes recebeu:

+36 vezes a nota $5=>36 * 5=180$

+10 vezes a nota $4=>10 * 4=40$

+09 vezes a nota $3=>09 * 3=27$

+05 vezes a nota $2=>05 * 2=10$

+01 vez a nota $1=>01 * 1=01$

$=$ este critério totalizou um valor de $\mathrm{n}=258$ pontos $(180+40+27+10+01=258)$.

\subsubsection{Priorização segundo a opinião dos entrevistados}

A título de exemplo, os gráficos 12 a 16 a seguir mostram a distribuição de notas que cada critério de sucesso de resultado do projeto teve, entre 5 (mais importante) e 1 (menos importante), segundo a opinião pessoal de todos os entrevistados. 
Gráfico 12 - Distribuição de notas de CLIENTES

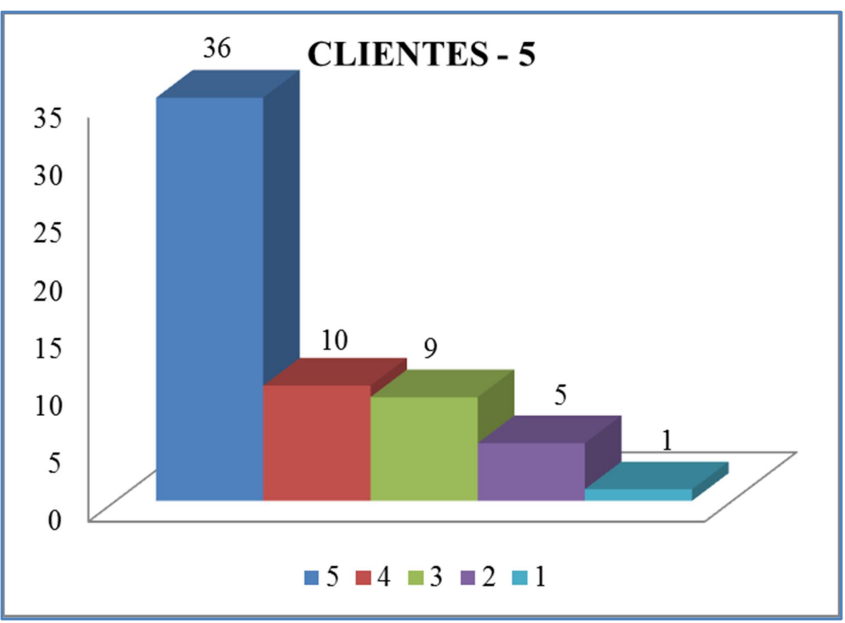

Gráfico 13 - Distribuição de notas de VIABILIDADE

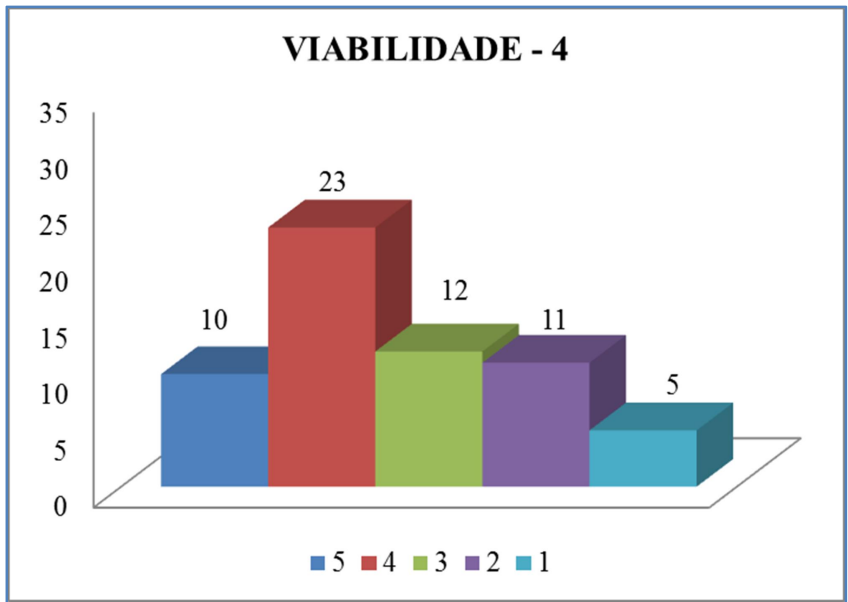

Gráfico 14 - Distribuição de notas de EFICIÊNCIA

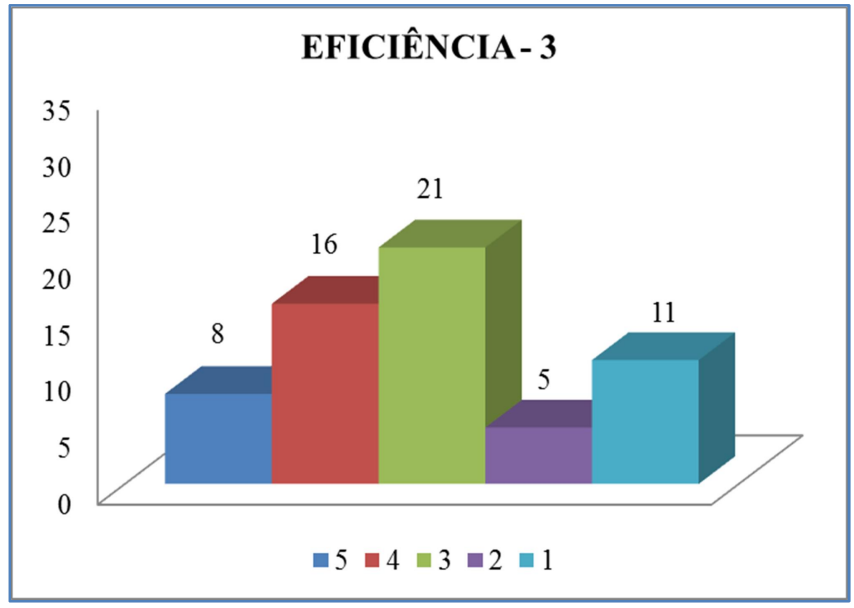


Gráfico 15 - Distribuição de notas de EQUIPE

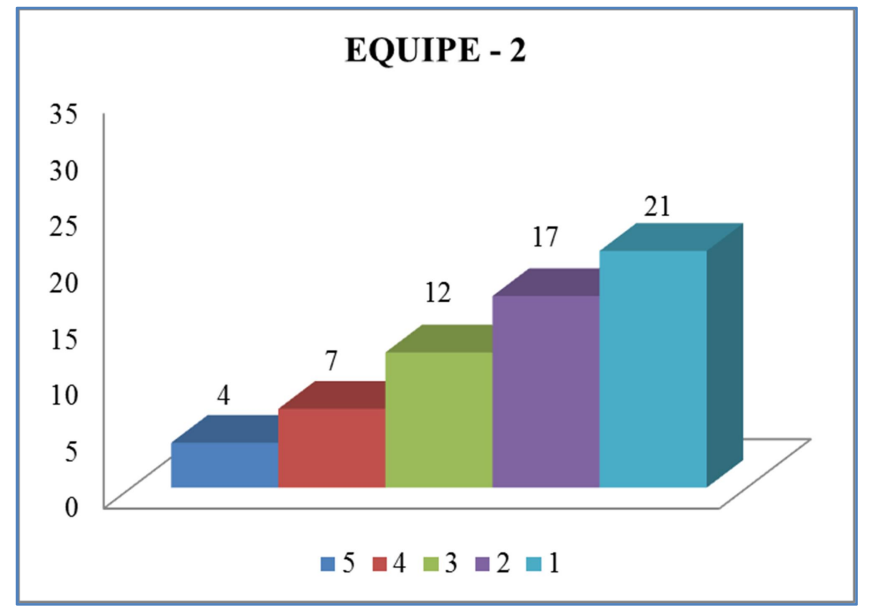

Gráfico 16 - Distribuição de notas de SUSTENTABILIDADE

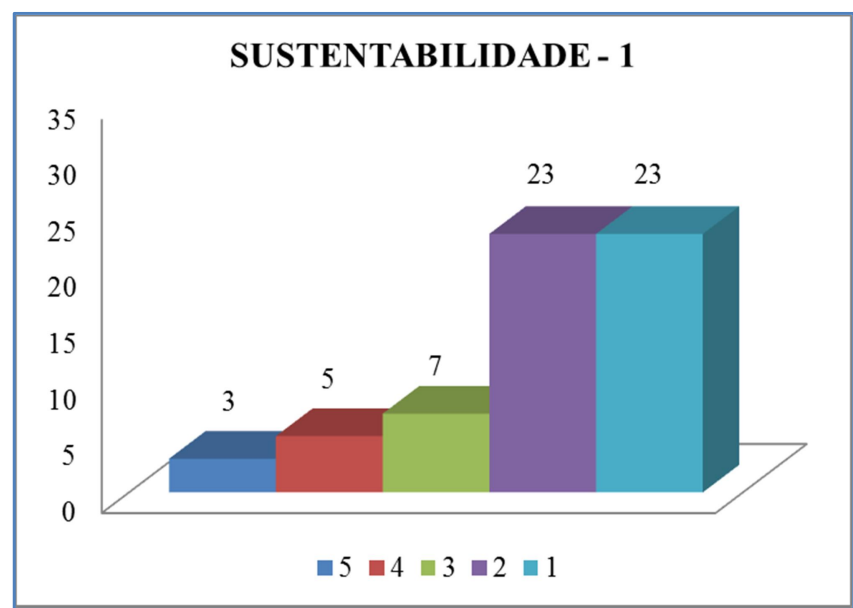

Os resultados da priorização geral dos critérios pré-determinados mostraram a seguinte classificação (vide Tabela 6):
i. Clientes
com 258 pontos;
ii. Viabilidade
com 205 pontos;
iii. Eficiência
com 188 pontos;
iv. Equipe
com 139 pontos;
v. Sustentabilidade com 125 pontos. 
Tabela 6 - Priorização Pessoal dos Critérios

\begin{tabular}{|c|c|}
\hline \multirow{2}{*}{ NOTAS } & $\begin{array}{c}\text { PRIORIZAÇÃO } \\
\text { PESSOAL }\end{array}$ \\
\cline { 2 - 2 } & Critério (n ${ }^{\text {o }}$ de pontos) \\
\hline \multirow{2}{*}{5} & $\begin{array}{c}\text { CLIENTES } \\
258\end{array}$ \\
\hline \multirow{2}{*}{4} & VIABILIDADE \\
& 205 \\
\hline 3 & EFICIÊNCIA \\
& 188 \\
\hline 2 & $\begin{array}{c}\text { EQUIPE } \\
139\end{array}$ \\
\hline 1 & SUSTENTABILIDADE \\
\end{tabular}

Do cruzamento destes resultados de priorização pessoal com o referencial teórico no qual esta dissertação se baseia, observa-se que o critério de Viabilidade (médio para longo prazo segundo Shenhar e Dvir) é mais valorizado que os critérios de Eficiência e Equipe (considerados de curto e médio prazo para Shenhar e Dvir).

Isto provavelmente se justifica em função dos entrevistados terem se baseado em projetos recentemente realizados, porém já terminados e, portanto, há certa confirmação da teoria de Shenhar e Dvir que afirma que a importância destes critérios tem um caráter dinâmico e varia ao longo do tempo no qual o projeto é avaliado.

De forma a se analisar se as prioridades aqui encontradas tem influência do perfil do entrevistado ou mesmo da característica do projeto executado, foram feitas as seguintes estratificações:

- Priorização Pessoal em função do perfil do entrevistado: (i) Nível Hierárquico; (ii) Área Funcional; (iii) Tempo de Experiência Profissional; (iv) Participação no Projeto;

- Priorização Pessoal em função das características dos projetos: (i) Novidade; (ii) Tecnologia; (iii) Complexidade; (iv) Tempo.

A seguir encontram-se todas as estratificações com seus respectivos resultados. 


\subsubsection{Priorização Pessoal em Função do Perfil do Entrevistado}

Buscando-se verificar a estratificação de priorização pessoal em função do nível hierárquico dos entrevistados, forma-se a seguinte Tabela 7 , onde cada cor representa um critério de sucesso:

Tabela 7 - Priorização Pessoal em função do Nível Hierárquico

\begin{tabular}{|c|c|c|c|c|}
\hline \multirow[t]{2}{*}{ NOTAS } & $\begin{array}{l}\text { PRIOR. PESSOAL } \\
(\text { Entrevistados }=61)\end{array}$ & $\begin{array}{l}\text { G-I } \\
(7)\end{array}$ & $\begin{array}{l}\text { G-II } \\
(19)\end{array}$ & $\begin{array}{l}\text { G-III } \\
(35)\end{array}$ \\
\hline & Critério ( $\mathrm{n}^{\mathrm{o}}$ de pontos) & \multicolumn{3}{|c|}{$\mathrm{n}^{\circ}$ de pontos } \\
\hline 5 & $\begin{array}{c}\text { CLIENTES } \\
258\end{array}$ & 29 & 90 & 139 \\
\hline 4 & $\begin{array}{c}\text { VIABILIDADE } \\
205 \\
\end{array}$ & 26 & 69 & 115 \\
\hline 3 & $\begin{array}{c}\text { EFICIÊNCIA } \\
188 \\
\end{array}$ & 23 & 50 & 110 \\
\hline 2 & $\begin{array}{c}\text { EQUIPE } \\
139\end{array}$ & 16 & 41 & 88 \\
\hline 1 & $\begin{array}{c}\text { SUSTENTABILIDADE } \\
125 \\
\end{array}$ & 11 & 35 & 73 \\
\hline \multicolumn{5}{|c|}{ G-I = Presidente / Vice-Presidente / Diretor Pleno } \\
\hline & \multicolumn{4}{|c|}{ G-II = Diretor Adjunto / Gerente Sênior } \\
\hline & \multicolumn{4}{|c|}{ G-III = Gerente / Supervisor / Mestre / Especialista } \\
\hline
\end{tabular}

Desta Tabela 7 observa-se que, em relação ao resultado geral (todos os 61 entrevistados), o GIII, mais operacional, percebe o critério Eficiência como segunda prioridade, em vez da Viabilidade. Enquanto isto, o G-II percebe o critério Sustentabilidade como mais importante que o Equipe. O G-I alinha suas prioridades com a opinião geral, com Clientes e Viabilidade como mais destacados.

Há que se considerar nestas comparações as diferentes quantidades de participantes de cada grupo. No entanto, esta proporção é próxima da proporção comumente encontrada em hieraquias de organizações.

Estratificando-se a priorização pessoal, agora em função das áreas funcionais dos entrevistados, tem-se a seguinte Tabela 8: 
Tabela 8 - Priorização Pessoal em função da Área Funcional

\begin{tabular}{|c|c|c|c|c|c|}
\hline \multirow[t]{2}{*}{ NOTAS } & $\begin{array}{l}\text { PRIOR. PESSOAL } \\
(\text { Entrevistados }=61)\end{array}$ & $\begin{array}{c}\mathrm{D} \\
(41) \\
\end{array}$ & $\begin{array}{c}\mathrm{I} \\
(12) \\
\end{array}$ & $\begin{array}{l}V \\
(4) \\
\end{array}$ & $\begin{array}{l}\mathrm{T} \\
(4) \\
\end{array}$ \\
\hline & Critério ( $\mathrm{n}^{\mathrm{o}}$ de pontos) & \multicolumn{4}{|c|}{$\mathrm{n}^{\mathrm{o}}$ de pontos } \\
\hline 5 & $\begin{array}{c}\text { CLIENTES } \\
258 \\
\end{array}$ & 170 & 51 & 17 & 20 \\
\hline 4 & $\begin{array}{l}\text { VIABILIDADE } \\
205 \\
\end{array}$ & 144 & 35 & 14 & 12 \\
\hline 3 & $\begin{array}{c}\text { EFICIÊNCIA } \\
188 \\
\end{array}$ & 126 & 39 & 13 & 10 \\
\hline 2 & $\begin{array}{l}\text { EQUIPE } \\
139 \\
\end{array}$ & 98 & 30 & 8 & 10 \\
\hline 1 & $\begin{array}{c}\text { SUSTENTABILIDADE } \\
125\end{array}$ & 77 & 25 & 8 & 8 \\
\hline & $\begin{array}{l}\mathrm{D}=\text { Desenvolvimento de } \mathrm{P} \\
\mathrm{I}=\text { Industrialização } / \text { Plan } \\
\mathrm{V}=\text { Vendas } / \text { Pós-Vendas } \\
\mathrm{T}=\mathrm{RH} / \text { Compras } / \text { Finan }\end{array}$ & $\begin{array}{l}\text { lutos } \\
\text { mento } \\
\text { Aarket } \\
\text { / Con }\end{array}$ & $\begin{array}{l}\text { dução } \\
\text { Serviç } \\
\text { doria }\end{array}$ & rodu & \\
\hline
\end{tabular}

Desta Tabela 8 nota-se que a classificação geral do critério Equipe é mais importante que o critério de Sustentabilidade, devido à forte influência das opiniões dos que trabalham na área de Desenvolvimento de Produtos. Apesar das opinões das demais áreas serem diferentes, observa-se que as pontuações são muito próximas (empate na área de Vendas em relação aos dois critérios), o que limita uma análise mais aprofundada.

Buscando-se a estratificação da priorização pessoal em função do tempo de experiência profissional dos entrevistados, forma-se a seguinte Tabela 9:

Tabela 9 - Priorização Pessoal em função do Tempo de Experiência Profissional

\begin{tabular}{|c|c|c|c|c|}
\hline \multirow{3}{*}{ NOTAS } & \multirow{2}{*}{$\begin{array}{l}\text { PRIOR. PESSOAL } \\
(\text { Entrevistados }=61)\end{array}$} & $>20$ & 10 e 20 & $<10$ \\
\hline & & $(25)$ & (29) & $(7)$ \\
\hline & Critério ( $\mathrm{n}^{\mathrm{o}}$ de pontos) & \multicolumn{3}{|c|}{$\mathrm{n}^{\mathrm{o}}$ de pontos } \\
\hline 5 & $\begin{array}{l}\text { CLIENTES } \\
258\end{array}$ & 103 & 129 & 26 \\
\hline 4 & $\begin{array}{l}\text { VIABILIDADE } \\
205\end{array}$ & 90 & 93 & 22 \\
\hline 3 & $\begin{array}{c}\text { EFICIÊNCIA } \\
188\end{array}$ & 71 & 91 & 26 \\
\hline 2 & $\begin{array}{c}\text { EQUIPE } \\
139\end{array}$ & 60 & 72 & 16 \\
\hline 1 & $\begin{array}{c}\text { SUSTENTABILIDADE } \\
125\end{array}$ & 51 & 50 & 15 \\
\hline & $>20=$ Experiência Profiss & acim & 20 anos & \\
\hline & 10 e $20=$ Experiência Profis & en & 20 anos & \\
\hline & $<10=$ Experiência Profis & abai & 10 anos & \\
\hline
\end{tabular}


Observa-se que, nesta Tabela 9, os agrupamentos mostram um maior alinhamento sendo que a única inversão de priorização é no grupo de mais de 20 anos de experiência que enxerga o critério Sustentabilidade mais importante que o critério Equipe.

Estratificando-se a priorização pessoal, agora em função da particpação dos entrevistados no gerenciamento do projeto, tem-se a seguinte Tabela 10:

Tabela 10 - Priorização Pessoal em função da Participação no Projeto

\begin{tabular}{|c|c|c|c|c|}
\hline \multirow{3}{*}{ NOTAS } & \multirow{2}{*}{$\begin{array}{l}\text { PRIOR. PESSOAL } \\
(\text { Entrevistados }=61)\end{array}$} & COMITE & GERENTE & PARTIC. \\
\hline & & 11 & 43 & 7 \\
\hline & Critério ( $\mathrm{n}^{\mathrm{o}}$ de pontos) & \multicolumn{3}{|c|}{$\mathrm{n}^{\mathrm{o}}$ de pontos } \\
\hline 5 & $\begin{array}{l}\text { CLIENTES } \\
258\end{array}$ & 47 & 181 & 30 \\
\hline 4 & $\begin{array}{c}\text { VIABILIDADE } \\
205 \\
\end{array}$ & 40 & 139 & 21 \\
\hline 3 & $\begin{array}{c}\text { EFICIÊNCIA } \\
188 \\
\end{array}$ & 33 & 134 & 16 \\
\hline 2 & $\begin{array}{c}\text { EQUIPE } \\
139 \\
\end{array}$ & 24 & 101 & 14 \\
\hline 1 & $\begin{array}{l}\text { SUSTENTABILIDADE } \\
125\end{array}$ & 21 & 90 & 14 \\
\hline & Comite $=$ Comite de Dirçã & ecisão & rojeto & \\
\hline & Gerente = Gerente / Líder & jeto & & \\
\hline
\end{tabular}

Nesta Tabela 10 nota-se também uma alinhamento, sendo a única inversão de priorização no grupo de Participantes, mais operacional, que considera a Eficiência mais importante que a Viabilidade, de forma semelhante ao observado na estratificação por hierarquia. 


\subsubsection{Priorização Pessoal em Função das Características dos Projetos}

Buscando-se verificar a estratificação da priorização pessoal em função da novidade do veículo em relação ao mercado, forma-se a seguinte Tabela 11:

Tabela 11 - Priorização Pessoal em função da Novidade

\begin{tabular}{|c|c|c|c|c|}
\hline \multirow{2}{*}{ NOTAS } & $\begin{array}{c}\text { PRIOR. PESSOAL } \\
(\text { Entrevistados }=61)\end{array}$ & $\begin{array}{c}\mathrm{I} \\
27\end{array}$ & $\begin{array}{c}\mathrm{S} \\
25\end{array}$ & $\begin{array}{c}\mathrm{F} \\
8\end{array}$ \\
\cline { 2 - 5 } & Critério (n ${ }^{\text {o de pontos) }}$ & \multicolumn{3}{|c|}{$\mathrm{n}^{\text {o }}$ de pontos } \\
\hline 5 & $\begin{array}{c}\text { CLIENTES } \\
258\end{array}$ & 116 & 110 & 32 \\
\hline 4 & $\begin{array}{c}\text { VIABILIDADE } \\
205\end{array}$ & 96 & 78 & 31 \\
\hline 3 & $\begin{array}{c}\text { EFICIENCIA } \\
188\end{array}$ & 91 & 71 & 26 \\
\hline 2 & $\begin{array}{c}\text { EQUIPE } \\
139\end{array}$ & 68 & 54 & 17 \\
\hline 1 & $\begin{array}{l}\text { SUSTENTABILIDADE } \\
125\end{array}$ & 64 & 47 & 14 \\
\hline \multirow{2}{*}{$\begin{array}{l}\mathrm{I}=\text { Inédito } \\
\text { S }=\text { Sucessor } \\
\text { F= Facelift }\end{array}$} & & & \\
\hline
\end{tabular}

Observa-se desta Tabela 11 que, aparentemente, a priorização pessoal dos critérios de sucesso de projeto pelos entrevistados não varia em função da novidade do produto em relação ao mercado.

Estratificando-se a priorização pessoal, agora em função da tecnolologia dos veículos ou de seus principais sistemas importantes, tem-se a seguinte Tabela 12: 
Tabela 12 - Priorização Pessoal em função da Tecnologia

\begin{tabular}{|c|c|c|c|c|}
\hline \multirow[t]{2}{*}{ NOTAS } & $\begin{array}{l}\text { PRIOR. PESSOAL } \\
(\text { Entrevistados }=61)\end{array}$ & $\begin{array}{l}\mathrm{A} \\
16\end{array}$ & $\begin{array}{l}\mathrm{M} \\
38\end{array}$ & $\begin{array}{l}\mathrm{B} \\
7\end{array}$ \\
\hline & Critério (n $\mathrm{n}^{\mathrm{o}}$ de pontos) & \multicolumn{3}{|c|}{$\mathrm{n}^{\circ}$ de pontos } \\
\hline 5 & $\begin{array}{l}\text { CLIENTES } \\
258\end{array}$ & 70 & 158 & 30 \\
\hline 4 & $\begin{array}{l}\text { VIABILIDADE } \\
205 \\
\end{array}$ & 55 & 129 & 27 \\
\hline 3 & $\begin{array}{c}\text { EFICIÊNCIA } \\
188 \\
\end{array}$ & 46 & 115 & 21 \\
\hline 2 & $\begin{array}{c}\text { EQUIPE } \\
139 \\
\end{array}$ & 32 & 92 & 15 \\
\hline 1 & $\begin{array}{c}\text { SUSTENTABILIDADE } \\
125\end{array}$ & 37 & 76 & 12 \\
\hline
\end{tabular}

Nesta Tabela 12, nota-se que os entrevistados consideram que para produtos de baixa tecnologia, o critério Eficiência é mais importante que o Viabilidade.

Buscando-se a estratificação da priorização pessoal em função da complexidade do fornecimento dos principais sistemas importantes, forma-se a seguinte Tabela 13:

Tabela 13 - Priorização Pessoal em função da Complexidade

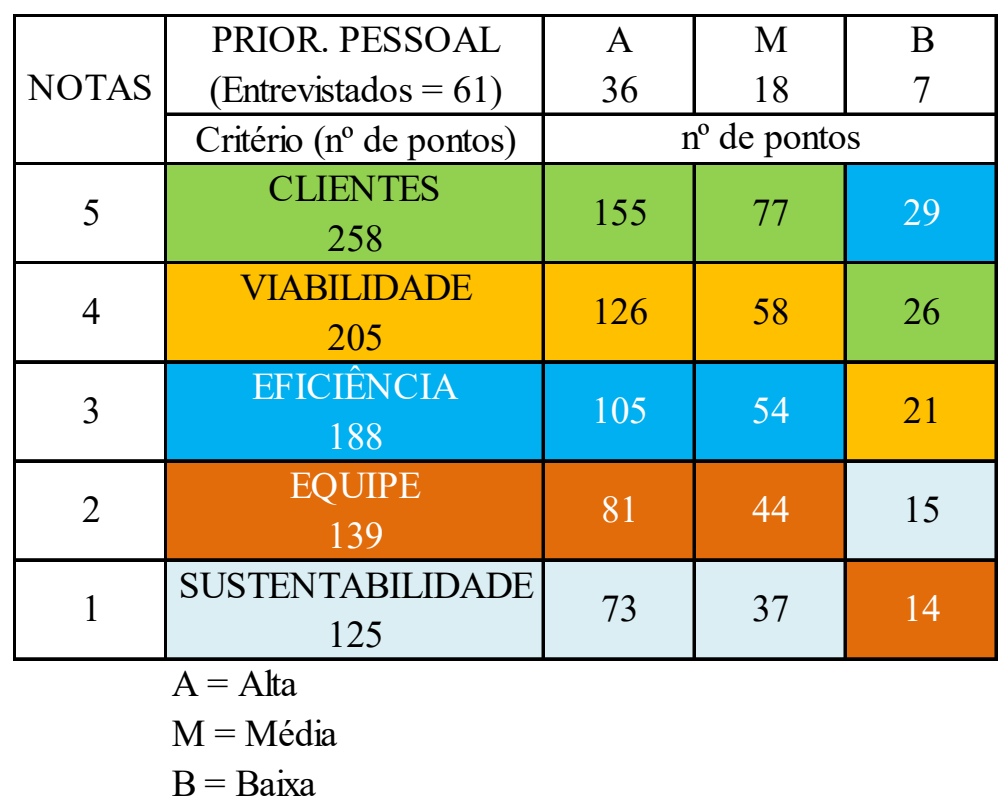


Desta Tabela 13, nota-se a mesma consideração da importância do critério Eficiência para produtos de baixa complexidade. Os critérios Equipe e Sustentabilidade, apesar de ordenados inversamente, tem praticamente o mesmo valor para este tipo de produto.

Das tabelas 12 e 13 observa-se uma confirmação do que Shenhar e Dvir acreditam, quando dizem que "para projetos de baixo risco, o cumprimento das restrições de recursos é mais crítico e relevante do que para projetos de risco mais alto" (2010, p. 43).

Estratificando-se a priorização pessoal, agora em função do tempo disponível para o desenvolvimento dos projetos, tem-se a seguinte Tabela 14:

Tabela 14 - Priorização Pessoal em função do Tempo

\begin{tabular}{|c|c|c|c|c|}
\hline \multirow{2}{*}{ NOTAS } & $\begin{array}{c}\text { PRIOR. PESSOAL } \\
(\text { Entrevistados }=61)\end{array}$ & $\begin{array}{c}\mathrm{U} \\
23\end{array}$ & $\begin{array}{c}\mathrm{C} \\
24\end{array}$ & $\begin{array}{c}\mathrm{N} \\
14\end{array}$ \\
\cline { 2 - 5 } & Critério (n de pontos) & \multicolumn{3}{|c|}{$\mathrm{n}^{\mathbf{0}}$ de pontos } \\
\hline 5 & $\begin{array}{c}\text { CLIENTES } \\
258\end{array}$ & 102 & 101 & 55 \\
\hline 4 & $\begin{array}{c}\text { VIABILIDADE } \\
205\end{array}$ & 78 & 85 & 43 \\
\hline 3 & $\begin{array}{c}\text { EFICIENCIA } \\
188\end{array}$ & 77 & 75 & 35 \\
\hline 2 & $\begin{array}{c}\text { EQUIPE } \\
139\end{array}$ & 59 & 53 & 34 \\
\hline 1 & $\begin{array}{l}\text { SUSTENTABILIDADE } \\
125\end{array}$ & 44 & 46 & 28 \\
\hline \multirow{2}{*}{$\begin{array}{l}\mathrm{U}=\text { Urgente } \\
\mathrm{C}=\text { Crítico } \\
\mathrm{N}=\text { Normal }\end{array}$} & & \\
\hline
\end{tabular}

Desta Tabela 14 percebe-se que os respondentes consideram que o critério Eficiência praticamente empata com o de Viabilidade em projetos Urgentes. O critério Sustentabilidade é considerado mais importante que o Equipe para projetos críticos, provavelmente pela alusão ao cumprimento de legislações contida na definição da característica. 


\subsubsection{Priorização adotada pela empresa, segundo os entrevistados}

O objetivo deste segundo questionamento foi o de conhecer o que o entrevistado entende ser a priorização de critérios de sucesso para o resultado do projeto adotada pela empresa e confrontar este entendimento com a sua opinião pessoal.

Da mesma forma que no item 4.3.1, a título de exemplo, os gráficos 17 a 21 a seguir mostram a distribuição de notas que cada critério teve entre 5 (mais importante) e 1 (menos importante) considerando-se agora o entendimento dos entrevistados sobre a valorização dos critérios de sucesso adotada pela empresa.

Gráfico 17 - Distribuição de notas de VIABILIDADE

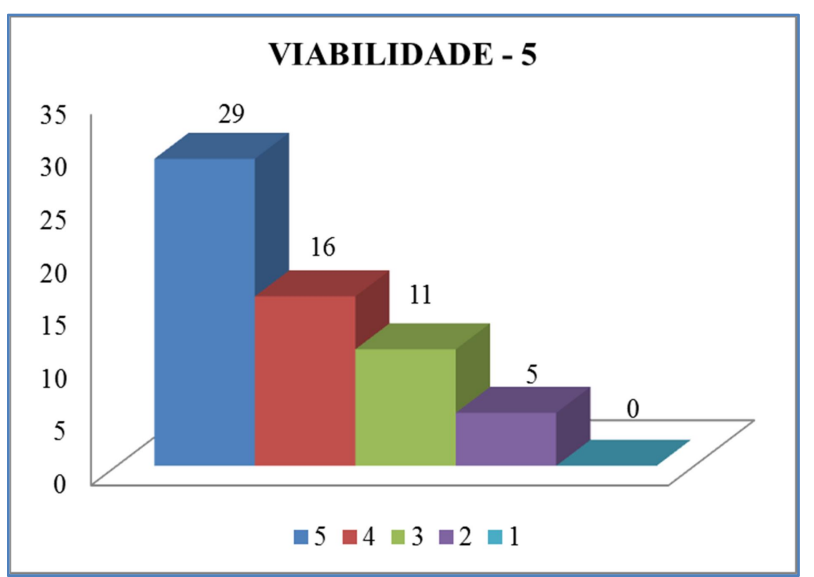

Gráfico 18 - Distribuição de notas de CLIENTES

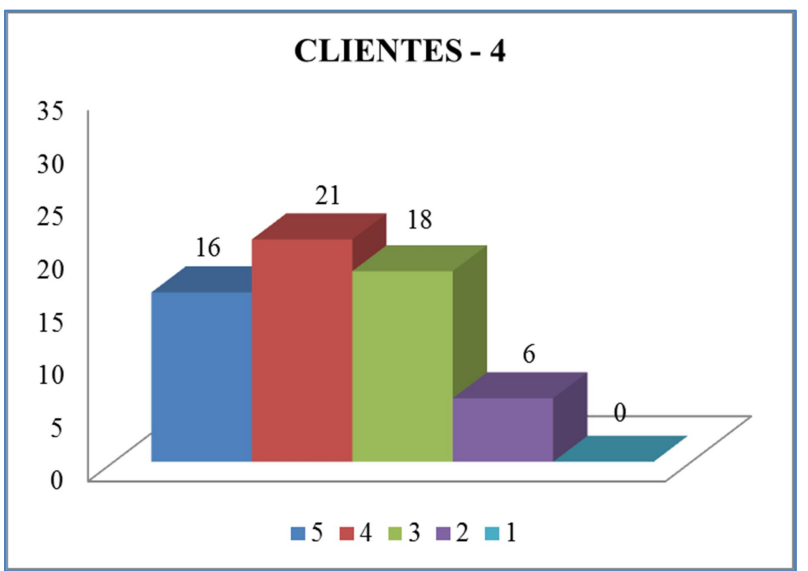


Gráfico 19 - Distribuição de notas de EFICIÊNCIA

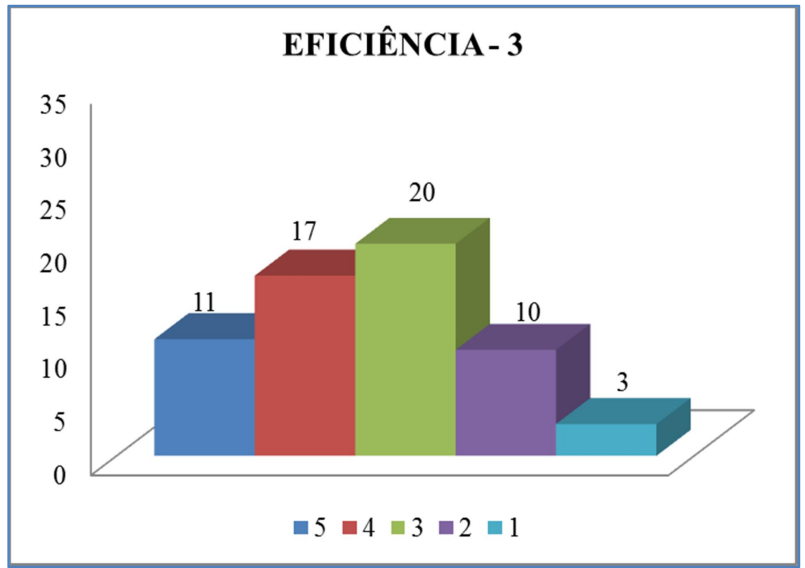

Gráfico 20 - Distribuição de notas de SUSTENTABILIDADE

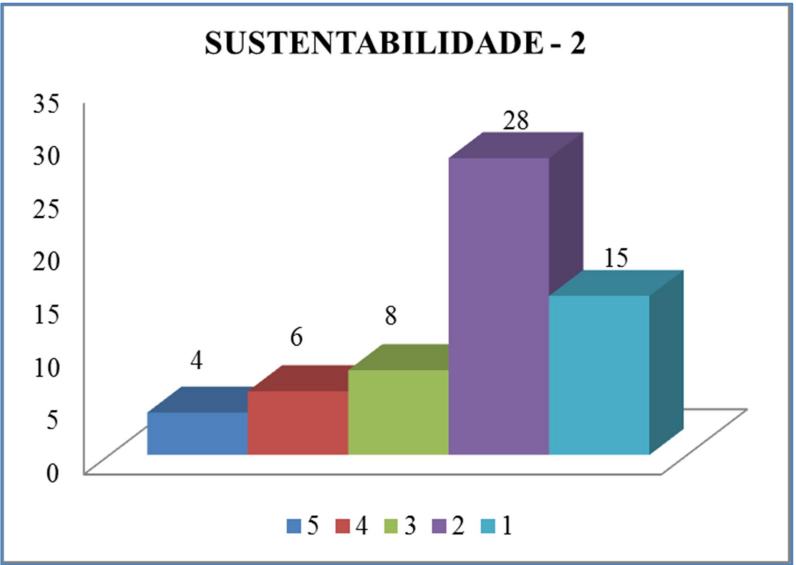

Gráfico 21 - Distribuição de notas de EQUIPE

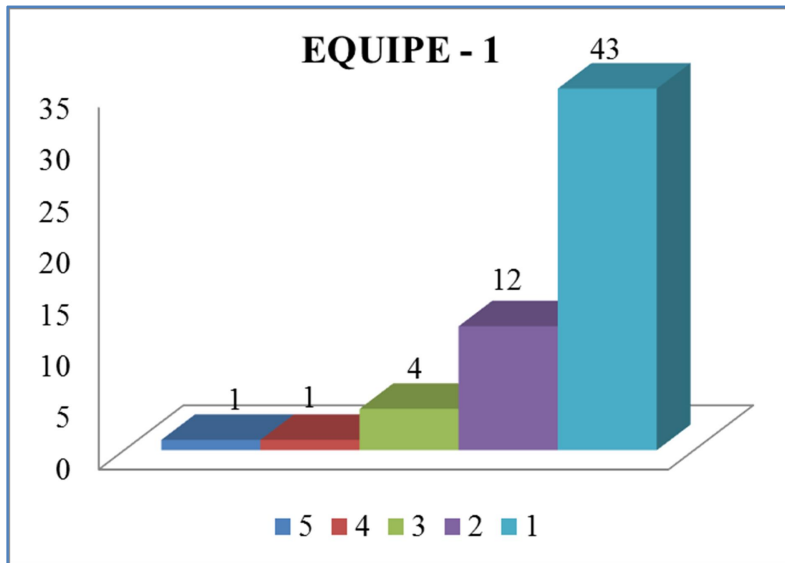


Os resultados da priorização geral dos critérios de sucesso mostraram a seguinte classificação: (i) Viabilidade com 252 pontos; (ii) Clientes com 230 pontos; (iii) Eficiência com 206 pontos; (iv) Sustentabilidade com 139 pontos e (v) Equipe com 88 pontos.

Interessante perceber de imediato destes resultados que, em geral, os entrevistados entendem que a empresa adota uma priorização diferente para os critérios de sucesso do resultado de um projeto bem sucedido.

De modo a melhor enxergar esta diferença geral de percepções entre a opinião pessoal e o que a empresa valoriza, forma-se a seguinte Tabela 15:

Tabela 15 - Comparação de Priorização de Critérios: Pessoal x Empresa

\begin{tabular}{|c|c|c|}
\hline \multirow{2}{*}{ NOTAS } & $\begin{array}{c}\text { PRIORIZAÇÃO } \\
\text { PESSOAL }\end{array}$ & $\begin{array}{c}\text { PRIORIZAÇÃO } \\
\text { EMPRESA }\end{array}$ \\
\cline { 2 - 3 } & \multicolumn{2}{|c|}{ Critério ( $\mathrm{n}^{\circ}$ de pontos) } \\
\hline \multirow{2}{*}{5} & CLIENTES & $\begin{array}{c}\text { VIABILIDADE } \\
252\end{array}$ \\
\hline \multirow{2}{*}{4} & VIABILIDADE & CLIENTES \\
& 205 & 230 \\
\hline \multirow{2}{*}{3} & EFICIÊNCIA & EIFICIÊNCIA \\
& 188 & 206 \\
\hline \multirow{2}{*}{2} & EQUIPE & 139 \\
\hline \multirow{2}{*}{1} & 139 & SUSTENTABILIDADE \\
& SUSTENTABILIDADE \\
\end{tabular}

Confirma-se desta Tabela 15 que as pessoas veem a priorização adotada pela empresa diferentemente da sua priorização individual. Os critérios Clientes e Viabilidade alternam-se entre os mais importantes e o Equipe e Sustentabilidade alternam-se entre os menos importante, ficando o critéro Eficiência no nível intermediário em ambas análises.

Nota-se que os entrevistados colocam que a empresa adota critérios que valorizam mais o longo prazo, segundo Shenhar e Dvir, valorizando relativamente critérios de Viabilidade e Sustentabilidade de forma mais importante do que suas opiniões pessoais. 
De modo a se analisar se as prioridades encontradas nestas avaliações pessoal $\mathrm{x}$ empresa tem influência do perfil do entrevistado ou mesmo da característica do projeto executado, foram feitas as seguintes comparações de estratificações:

- Comparação da Priorização Pessoal x Empresa em função do perfil do entrevistado: (i) Nível Hierárquico; (ii) Área Funcional; (iii) Tempo de Experiência Profissional; (iv) Participação no Projeto.

- Comparação da Priorização Pessoal x Empresa em função das características dos projetos: (i) Novidade; (ii) Tecnologia; (iii) Complexidade; (iv) Tempo.

A seguir encontram-se todas as comparações de estratificações e seus respectivos resultados.

\subsubsection{Priorização Pessoal x Empresa em Função do Perfil do Entrevistado}

Buscando-se verificar a comparação da estratificação de priorização pessoal x empresa em função do nível hierárquico dos entrevistados, tem-se a seguinte Tabela 16:

Tabela 16 - Comparação de Priorização Pessoal x Empresa, por Nível Hierárquico

\begin{tabular}{|c|c|c|c|c|c|c|c|c|}
\hline \multirow[t]{2}{*}{ NOTAS } & $\begin{array}{l}\text { PRIOR. PESSOAL } \\
(\text { Entrevistados }=61)\end{array}$ & $\begin{array}{l}\text { G-I } \\
(7)\end{array}$ & $\begin{array}{l}\text { G-II } \\
(19)\end{array}$ & $\begin{array}{c}\text { G-III } \\
(35)\end{array}$ & \multirow{2}{*}{$\begin{array}{l}\text { PRIOR. EMPRESA } \\
(\text { Entrevistados }=61) \\
\text { Critério }\left(\mathrm{n}^{\circ} \text { de pontos) }\right.\end{array}$} & $\begin{array}{l}\text { G-I } \\
(7)\end{array}$ & $\begin{array}{l}\text { G-II } \\
(19)\end{array}$ & $\begin{array}{l}\text { G-III } \\
(35)\end{array}$ \\
\hline & Critério ( $\mathrm{n}^{\circ}$ de pontos) & \multicolumn{3}{|c|}{$\mathrm{n}^{\mathrm{o}}$ de pontos } & & \multicolumn{3}{|c|}{$\mathrm{n}^{\mathrm{o}}$ de pontos } \\
\hline 5 & $\begin{array}{c}\text { CLIENTES } \\
258 \\
\end{array}$ & 29 & 90 & 139 & $\begin{array}{c}\text { VIABILIDADE } \\
252 \\
\end{array}$ & 29 & 79 & 144 \\
\hline 4 & $\begin{array}{l}\text { VIABILIDADE } \\
205\end{array}$ & 26 & 69 & 115 & $\begin{array}{c}\text { CLIENTES } \\
230\end{array}$ & 29 & 76 & 125 \\
\hline 3 & $\begin{array}{c}\text { EFICIÊNCIA } \\
188 \\
\end{array}$ & 23 & 50 & 110 & $\begin{array}{c}\text { EIFICIÊNCIA } \\
206 \\
\end{array}$ & 26 & 61 & 119 \\
\hline 2 & $\begin{array}{c}\text { EQUIPE } \\
139\end{array}$ & 16 & 41 & 88 & $\begin{array}{l}\text { SUSTENTABILIDADE } \\
139\end{array}$ & 13 & 45 & 81 \\
\hline 1 & $\begin{array}{c}\text { SUSTENTABILIDADE } \\
125\end{array}$ & 11 & 35 & 73 & $\begin{array}{c}\text { EQUIPE } \\
88\end{array}$ & 8 & 24 & 56 \\
\hline
\end{tabular}

Desta Tabela 16, observa-se que enquanto na avaliação pessoal há diferenças de priorização entre os diferentes níveis hierárquicos, quando se avalia a priorização que os entrevistados consideram que a empresa adota, o resultado é homogêneo. 
O grupo G-III afirma prioridades totalmente diferentes entre a opinião pessoal e o entendimento sobre o que a empresa adota como importante.

O grupo G-II tem uma visão diferente apenas nos dois principais critérios sendo igual nos demais.

O interessante a notar é que mesmo o grupo G-I que, em última análise, é formado pelos mais altos representantes da empresa, a saber Presidente / Vice-presidente / Diretor Pleno, tem visões "pessoal" versus "empresa" diferentes, tanto nos critérios mais importantes quanto nos menos importantes (apesar de na análise "empresa", haver um empate entre o primeiro e segundo critério). De uma análise mais detalhada dos dados, percebe-se que 4 dos 7 respondentes afirmam prioridades diferentes entre suas opiniões e o que pensam a empresa prioriza. Aqui percebe-se a necessidade de se aprofundar a pesquisa, de modo a se ter um melhor entendimento do porquê desta diferença.

Em relação à comparação da estratificação priorização pessoal x empresa em função das áreas funcionais dos entrevistados, forma-se a seguinte Tabela 17 comparativa:

Tabela 17 - Comparação de Priorização Pessoal x Empresa, por Área Funcional

\begin{tabular}{|c|c|c|c|c|c|c|c|c|c|c|}
\hline \multirow[t]{2}{*}{ NOTAS } & $\begin{array}{l}\text { PRIOR. PESSOAL } \\
\text { (Entrevistados }=61 \text { ) }\end{array}$ & $\begin{array}{c}D \\
(41)\end{array}$ & $\begin{array}{c}\mathrm{I} \\
(12)\end{array}$ & $\begin{array}{l}\mathrm{V} \\
(4)\end{array}$ & $\begin{array}{c}\mathrm{T} \\
(4)\end{array}$ & \multirow{2}{*}{$\begin{array}{c}\text { PRIOR. EMPRESA } \\
\text { (Entrevistados }=61) \\
\text { Critério }\left(n^{\circ} \text { de pontos) }\right.\end{array}$} & $\begin{array}{c}\mathrm{D} \\
(41)\end{array}$ & $\begin{array}{c}\mathrm{I} \\
(12)\end{array}$ & $\begin{array}{l}\mathrm{V} \\
(4)\end{array}$ & $\begin{array}{c}\mathrm{T} \\
(4)\end{array}$ \\
\hline & Critério ( $\mathrm{n}^{\mathrm{o}}$ de pontos) & \multicolumn{4}{|c|}{$\mathrm{n}^{\circ}$ de pontos } & & \multicolumn{4}{|c|}{$\mathrm{n}^{\circ}$ de pontos } \\
\hline 5 & $\begin{array}{l}\text { CLIENTES } \\
258\end{array}$ & 170 & 51 & 17 & 20 & $\begin{array}{c}\text { VIABILIDADE } \\
252\end{array}$ & 178 & 50 & 16 & 18 \\
\hline 4 & $\begin{array}{l}\text { VIABILIDADE } \\
205\end{array}$ & 144 & 35 & 14 & 12 & $\begin{array}{c}\text { CLIENTES } \\
230\end{array}$ & 151 & 44 & 14 & 15 \\
\hline 3 & $\begin{array}{c}\text { EFICIÊNCIA } \\
188 \\
\end{array}$ & 126 & 39 & 13 & 10 & $\begin{array}{l}\text { EIFICIÊNCIA } \\
206 \\
\end{array}$ & 137 & 40 & 11 & 14 \\
\hline 2 & $\begin{array}{c}\text { EQUIPE } \\
139 \\
\end{array}$ & 98 & 30 & 8 & 10 & $\begin{array}{c}\text { SUSTENTABILIDADE } \\
139 \\
\end{array}$ & 92 & 30 & 10 & 7 \\
\hline 1 & $\begin{array}{c}\text { SUSTENTABILIDADE } \\
125 \\
\end{array}$ & 77 & 25 & 8 & 8 & $\begin{array}{c}\text { EQUIPE } \\
88 \\
\end{array}$ & 57 & 16 & 9 & 6 \\
\hline
\end{tabular}

Desta Tabela 17 observa-se que o Grupo D (mais numeroso) considera que a empresa tem priorização diferente em relação à Viabilidade e Clientes nos critérios mais importantes e entre Equipe e Sustentabilidade nos menos importantes, influenciando o resultado geral. 
O grupo I consideram que a empresa prioriza os critérios de sucesso da mesma forma que suas opiniões pessoais. Os do grupo $\mathrm{T}$ praticamente também, considerando-se a pequena diferença de pontuações.

Interessante notar que o grupo $\mathrm{V}$ considera que a empresa coloca o critério Clientes como a terceira prioridade, atrás de Viabilidade e Eficiência, de forma bem diferente de suas opiniões pessoais. Talvez isto represente uma "reclamação" inversa, sendo que os integrantes não enxergam por parte da empresa uma priorização a Clientes da mesma forma que eles individualmente veem e que consideram a empresa deveria adotar.

Comparando-se a a estratificação da priorização pessoal x empresa em função do tempo de experiência profissional dos entrevistados, tem-se a seguinte Tabela 18:

Tabela 18 - Comparação de Priorização Pessoal x Empresa, por Experiência Profissional

\begin{tabular}{|c|c|c|c|c|c|c|c|c|}
\hline \multirow{3}{*}{ NOTAS } & \multirow{2}{*}{$\begin{array}{l}\text { PRIOR. PESSOAL } \\
(\text { Entrevistados }=61 \text { ) }\end{array}$} & $>20$ & 10 e 20 & \multirow{2}{*}{$\begin{array}{l}<10 \\
(7) \\
\end{array}$} & \multirow{2}{*}{$\begin{array}{l}\text { PRIOR. EMPRESA } \\
(\text { Entrevistados }=61)\end{array}$} & \multirow{2}{*}{$\begin{array}{l}>20 \\
(25)\end{array}$} & \multirow{2}{*}{$\frac{10 \text { e } 20}{(29)}$} & \multirow{2}{*}{$\begin{array}{l}<10 \\
(7)\end{array}$} \\
\hline & & (25) & (29) & & & & & \\
\hline & Critério ( $\mathrm{n}^{\circ}$ de pontos) & \multicolumn{3}{|c|}{$\mathrm{n}^{\circ}$ de pontos } & Critério (n $\mathrm{n}^{\mathrm{o}}$ de pontos) & \multicolumn{3}{|c|}{$\mathrm{n}^{\circ}$ de pontos } \\
\hline 5 & $\begin{array}{c}\text { CLIENTES } \\
258\end{array}$ & 103 & 129 & 26 & $\begin{array}{l}\text { VIABILIDADE } \\
252\end{array}$ & 106 & 118 & 28 \\
\hline 4 & $\begin{array}{l}\text { VIABILIDADE } \\
205\end{array}$ & 90 & 93 & 22 & $\begin{array}{c}\text { CLIENTES } \\
230\end{array}$ & 93 & 110 & 27 \\
\hline 3 & $\begin{array}{c}\text { EFICIÊNCIA } \\
188\end{array}$ & 71 & 91 & 26 & $\begin{array}{c}\text { EIFICIÊNCIA } \\
206\end{array}$ & 79 & 103 & 24 \\
\hline 2 & $\begin{array}{c}\text { EQUIPE } \\
139\end{array}$ & 60 & 72 & 16 & $\begin{array}{c}\text { SUSTENTABILIDADE } \\
139\end{array}$ & 66 & 58 & 15 \\
\hline 1 & $\begin{array}{c}\text { SUSTENTABILIDADE } \\
125 \\
\end{array}$ & 51 & 50 & 15 & $\begin{array}{l}\text { EQUIPE } \\
\quad 88 \\
\end{array}$ & 31 & 46 & 11 \\
\hline & $\begin{array}{l}20=\text { Experiência Profiss } \\
10 \text { e } 20=\text { Experiência Profiss }\end{array}$ & $\mathrm{cim}$ & $\begin{array}{l}0 \text { anos } \\
20 \text { anos }\end{array}$ & & & & & \\
\hline
\end{tabular}

Conforme comentado no item 4.3.1 esta estratificação é a que mostra resultados mais alinhados com os resultados gerais. Enquanto nas opiniões pessoais, apenas o grupo acima de 20 anos de experiência profissional diverge nas 2 últimas prioridades em relação ao resultado geral, na opinião sobre o que a empresa adota há um total alinhamento entre os resultados parciais e o geral.

Por fim, comparando-se a estratificação da priorização pessoal x empresa em função da participação do entrevistado no projeto, forma-se a seguinte Tabela 19: 
Tabela 19 - Comparação de Priorização Pessoal x Empresa, por Participação no Projeto

\begin{tabular}{|c|c|c|c|c|c|c|c|c|}
\hline \multirow{3}{*}{ NOTAS } & \multirow{2}{*}{$\begin{array}{l}\text { PRIOR. PESSOAL } \\
(\text { Entrevistados = 61) } \\
\end{array}$} & COMITE & GERENTE & PARTIC. & \multirow{2}{*}{$\begin{array}{l}\text { PRIOR. EMPRESA } \\
(\text { Entrevistados }=61)\end{array}$} & COMITE & GERENTE & PARTIC. \\
\hline & & 11 & 43 & 7 & & 11 & 43 & 7 \\
\hline & Critério ( $\mathrm{n}^{\mathrm{o}}$ de pontos) & \multicolumn{3}{|c|}{$\mathrm{n}^{\mathrm{o}}$ de pontos } & Critério ( $\mathrm{n}^{\mathrm{o}}$ de pontos) & \multicolumn{3}{|c|}{$\mathrm{n}^{\circ}$ de pontos } \\
\hline 5 & $\begin{array}{c}\text { CLIENTES } \\
258\end{array}$ & 47 & 181 & 30 & $\begin{array}{l}\text { VIABILIDADE } \\
252\end{array}$ & 46 & 180 & 29 \\
\hline 4 & $\begin{array}{l}\text { VIABILIDADE } \\
205 \\
\end{array}$ & 40 & 139 & 21 & $\begin{array}{c}\text { CLIENTES } \\
230 \\
\end{array}$ & 42 & 165 & 26 \\
\hline 3 & $\begin{array}{c}\text { EFICIÊNCIA } \\
188\end{array}$ & 33 & 134 & 16 & $\begin{array}{c}\overline{\text { EIFICIÊNCIA }} \\
206\end{array}$ & 40 & 135 & 25 \\
\hline 2 & $\begin{array}{c}\text { EQUIPE } \\
139\end{array}$ & 24 & 101 & 14 & $\begin{array}{c}\text { SUSTENTABILIDADE } \\
139\end{array}$ & 23 & 101 & 16 \\
\hline 1 & $\begin{array}{c}\text { SUSTENTABILIDADE } \\
125\end{array}$ & 21 & 90 & 14 & $\begin{array}{l}\text { EQUIPE } \\
88\end{array}$ & 14 & 100 & 9 \\
\hline
\end{tabular}

Desta Tabela 19, observa-se que os valores gerais da priorização da empresa são relativamente uniformes (exceto no grupo Participantes) e influenciados pelas resposta do grupo Gerente, que apresenta resultados muito semelhantes ao geral (considerando-se os critérios Sustentabilidade e Equipe do grupo Gerente como empate) devido a quantidade de pessoas existentes neste estrato.

De forma análoga, o grupo Comite aproxima-se da resposta geral, se as priorizações de Clientes e Eficiência forem consideradas como empate.

O grupo Participantes, da mesma forma que na avaliação pessoal, enxerga que a empresa dá grande valor ao critério Eficiência. Talvez aqui, estes participantes acreditem na importância que a empresa dá à necessidade que estas pessoas tenham um bom desempenho durante a execução dos projetos. 


\subsubsection{Priorização Pessoal x Empresa em Função das Características dos Projetos}

Buscando-se verificar a comparação da estratificação de priorização pessoal x empresa em função da novidade dos veículos em relação ao mercado, tem-se a seguinte Tabela 20:

Tabela 20 - Comparação de Priorização Pessoal x Empresa, por Novidade

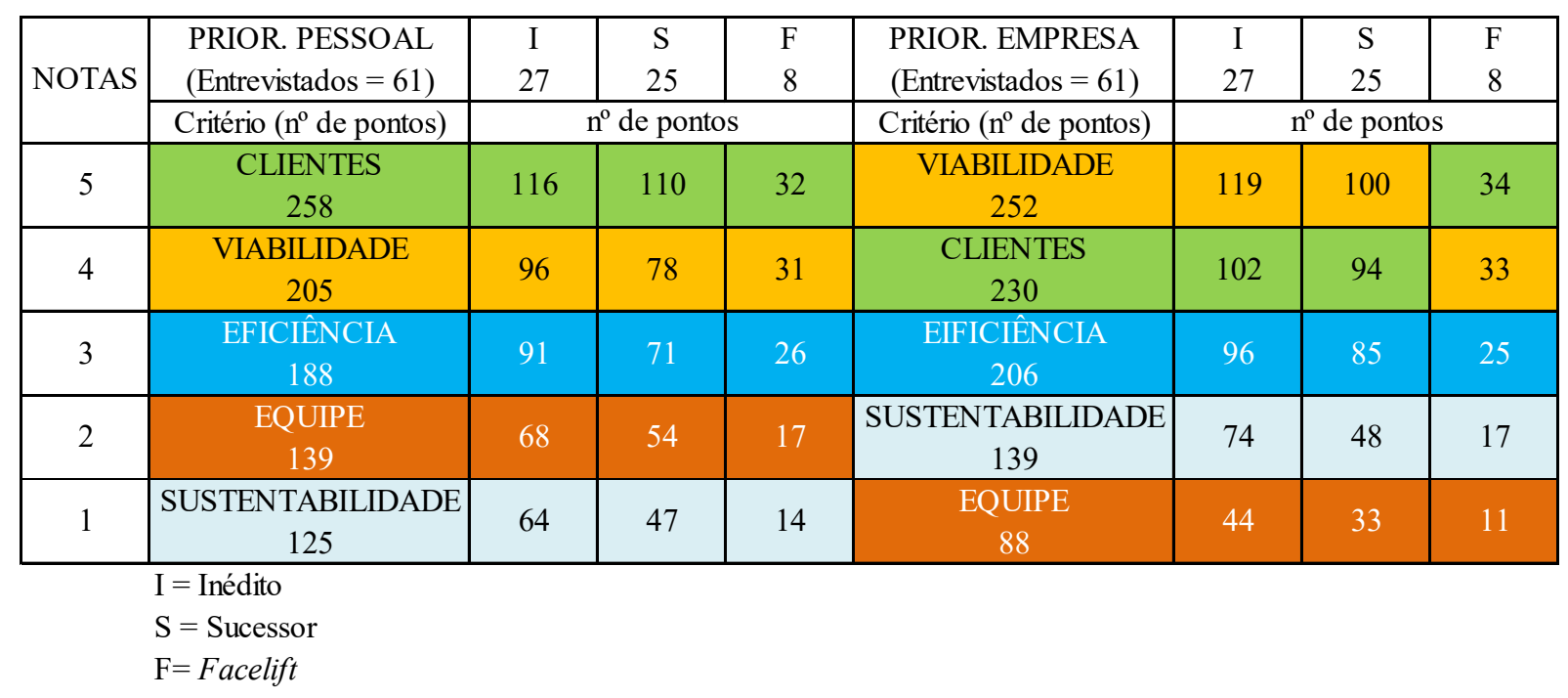

Desta Tabela 20, observa-se que, se os valores dos critérios Viabilidade e Clientes dos produtos facelift forem considerados como empate, a opinião dos entrevistados sobre priorização dada pela empresa também não é influenciada pela Novidade dos veículos em relação ao mercado (da mesma forma que não influencia a opinião pessoal).

Em relação à comparação da estratificação de priorização pessoal x empresa em função da tecnologia dos veículos ou dos seus principais sistemas importantes, forma-se a seguinte Tabela 21 comparativa: 
Tabela 21 - Comparação de Priorização Pessoal x Empresa, por Tecnologia

\begin{tabular}{|c|c|c|c|c|c|c|c|c|}
\hline \multirow[t]{2}{*}{ NOTAS } & $\begin{array}{l}\text { PRIOR. PESSOAL } \\
(\text { Entrevistados = 61) }\end{array}$ & $\begin{array}{l}\text { A } \\
16\end{array}$ & $\begin{array}{l}\mathrm{M} \\
38\end{array}$ & $\begin{array}{l}\text { B } \\
7\end{array}$ & \multirow{2}{*}{$\begin{array}{l}\text { PRIOR. EMPRESA } \\
(\text { Entrevistados }=61) \\
\text { Critério }\left(\mathrm{n}^{\circ} \text { de pontos) }\right.\end{array}$} & $\begin{array}{l}\text { A } \\
16\end{array}$ & $\begin{array}{l}M \\
38\end{array}$ & $\begin{array}{l}\text { B } \\
7\end{array}$ \\
\hline & Critério ( $\mathrm{n}^{\mathrm{o}}$ de pontos) & \multicolumn{3}{|c|}{$\mathrm{n}^{\mathrm{o}}$ de pontos } & & \multicolumn{3}{|c|}{$\mathrm{n}^{\mathrm{o}}$ de pontos } \\
\hline 5 & $\begin{array}{c}\text { CLIENTES } \\
258 \\
\end{array}$ & 70 & 158 & 30 & $\begin{array}{c}\text { VIABILIDADE } \\
252 \\
\end{array}$ & 65 & 159 & 31 \\
\hline 4 & $\begin{array}{c}\text { VIABILIDADE } \\
205 \\
\end{array}$ & 55 & 129 & 27 & $\begin{array}{c}\text { CLIENTES } \\
230 \\
\end{array}$ & 60 & 139 & 31 \\
\hline 3 & $\begin{array}{c}\text { EFICIÊNCIA } \\
188\end{array}$ & 46 & 115 & 21 & $\begin{array}{c}\text { EIFICIÊNCIA } \\
206\end{array}$ & 53 & 131 & 22 \\
\hline 2 & $\begin{array}{c}\text { EQUTPE } \\
139 \\
\end{array}$ & 32 & 92 & 15 & $\begin{array}{c}\text { SUSTENTABILIDADE } \\
139 \\
\end{array}$ & 46 & 81 & 12 \\
\hline 1 & \begin{tabular}{|c|} 
SUSTENTABILIDADE \\
125
\end{tabular} & 37 & 76 & 12 & $\begin{array}{l}\text { EQUIPE } \\
88 \\
\end{array}$ & 16 & 60 & 12 \\
\hline
\end{tabular}

Desta Tabela 21, observa-se que, diferentemente do observado na priorização pessoal, os entrevistados pensam que a priorização da empresa sobre os critérios de sucesso dos projetos não está vinculada à Tecnologia aplicada nos produtos da empresa. O critério Eficiência está claramente numa posição intermediária de prioridade.

Comparando-se a estratificação da priorização pessoal $\mathrm{x}$ empresa em função da complexidade de fornecimento de sistemas importantes, tem-se a seguinte Tabela 22:

Tabela 22 - Comparação de Priorização Pessoal x Empresa, por Complexidade

\begin{tabular}{|c|c|c|c|c|c|c|c|c|}
\hline NOTAS & $\begin{array}{l}\text { PRIOR. PESSOAL } \\
(\text { Entrevistados }=61)\end{array}$ & $\begin{array}{c}\mathrm{A} \\
36 \\
\end{array}$ & $\begin{array}{l}\mathrm{M} \\
18 \\
\end{array}$ & $\begin{array}{l}\mathrm{B} \\
7 \\
\end{array}$ & $\begin{array}{l}\text { PRIOR. EMPRESA } \\
(\text { Entrevistados }=61)\end{array}$ & $\begin{array}{l}A \\
36 \\
\end{array}$ & $\begin{array}{l}\mathrm{M} \\
18 \\
\end{array}$ & $\begin{array}{l}\mathrm{B} \\
7\end{array}$ \\
\hline & Critério ( ${ }^{\circ}$ de pontos) & \multicolumn{3}{|c|}{$\mathrm{n}^{\mathrm{o}}$ de pontos } & Critério ( $\mathrm{n}^{\mathrm{o}}$ de pontos) & \multicolumn{3}{|c|}{$\mathrm{n}^{\mathrm{o}}$ de pontos } \\
\hline 5 & $\begin{array}{c}\text { CLIENTES } \\
258\end{array}$ & 155 & 77 & 29 & $\begin{array}{l}\text { VIABILIDADE } \\
252\end{array}$ & 149 & 74 & 29 \\
\hline 4 & $\begin{array}{l}\text { VIABILIDADE } \\
205\end{array}$ & 126 & 58 & 26 & $\begin{array}{c}\text { CLIENTES } \\
230\end{array}$ & 133 & 70 & 27 \\
\hline 3 & $\begin{array}{c}\text { EFICIÊNCIA } \\
188\end{array}$ & 105 & 54 & 21 & $\begin{array}{l}\text { EIFICIÊNCIA } \\
206\end{array}$ & 126 & 58 & 22 \\
\hline 2 & $\begin{array}{l}\text { EQUIPE } \\
139\end{array}$ & 81 & 44 & 15 & $\begin{array}{c}\text { SUSTENTABILIDADE } \\
139\end{array}$ & 82 & 41 & 16 \\
\hline 1 & $\begin{array}{c}\text { SUSTENTABILIDADE } \\
125\end{array}$ & 73 & 37 & 14 & $\begin{array}{l}\text { EQUIPE } \\
88\end{array}$ & 50 & 27 & 11 \\
\hline
\end{tabular}


Desta Tabela 22, observa-se que os entrevistados também pensam que a priorização da empresa sobre os critérios de sucesso dos projetos não está vinculada à Complexidade de Fornecimento. Aqui também o critério Eficiência está numa posição intermediária de priorização.

Por fim, comparando-se a estratificação de priorização pessoal x empresa em função do tempo disponível para o desenvolvimento do projeto, forma-se a seguinte Tabela 23:

Tabela 23 - Comparação de Priorização Pessoal x Empresa, por Tempo

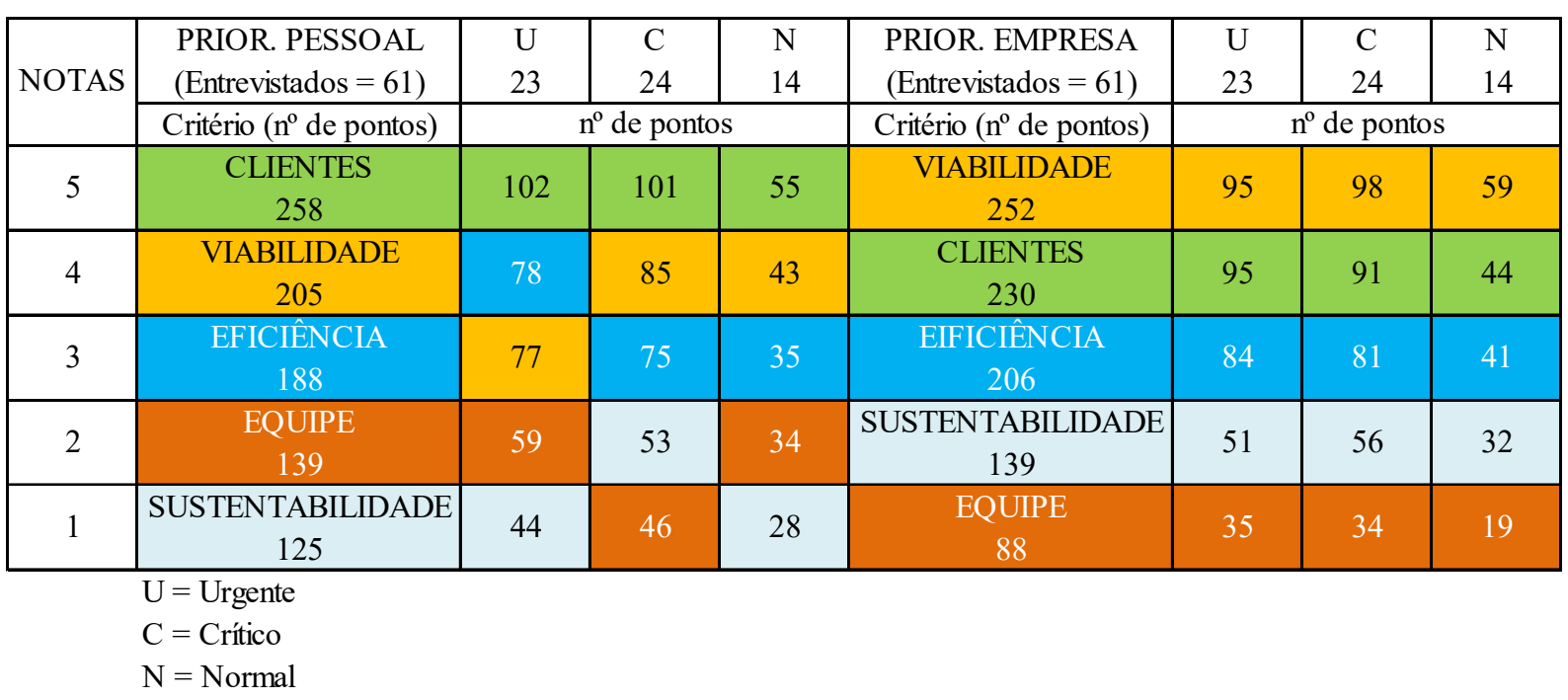

Desta Tabela 23, também não se observa variação de priorização da empresa em função do Tempo disponível para a execução do projeto.

De uma forma geral, das tabelas de 20 a 23, observa-se uma negação do que Shenhar e Dvir acreditam, quando dizem que "para projetos de baixo risco, o cumprimento das restrições de recursos é mais crítico e relevante do que para projetos de risco mais alto" (2010, p. 43), ao contrário do que os mesmos entrevistados indicam quando priorizam os critérios segundo as suas opiniões pessoais. 


\subsection{Classificação dos Fatores Críticos de Sucesso para a Execução do Projeto}

O tópico 5 da pesquisa buscou identificar a priorização de dez fatores críticos de sucesso prédeterminados para um bom resultado de projeto, segundo a própria opinião dos entrevistados.

Os dez (10) fatores críticos de sucesso pré-determinados, que deveriam ser priorizados, foram adaptados da classificação conforme modelo de Pinto e Slevin (1987) e são:

i. Missão - objetivos do projeto claramente definidos desde o inicio;

ii. Apoio da Alta Direção - suporte da alta direção em prover os recursos necessários, autoridade e poder para o sucesso da implantação;

iii. Planejamento e Cronograma - existência de plano detalhado, incluindo cronograma, milestones, necessidades de mão de obra, etc., para a execução integral do projeto;

iv. Consulta a Clientes - consulta a clientes no início do projeto e informação sobre o seu progresso, inclusive decisões sobre inclusão de suas sugestões;

v. Pessoal - qualificação e quantidade de pessoas adequadas à realização do projeto;

vi. Atividades Técnicas - recursos tecnológicos adequados à realização do projeto;

vii. Aceitação do Cliente - verificação da aceitação e disposição de utilização do produto em sua última versão pelos potenciais clientes e usuários;

viii. Acompanhamento e Feedback - monitoração de todos os aspectos importantes ao progresso do projeto por meio de revisões periódicas planejadas;

ix. Comunicação - disposição de informações por meio de canais e formatos adequados a todos os participantes do projeto;

x. Solução de Problemas - capacidade e agilidade de gerenciamento de crises e desvios de projeto, utilizando todos os recursos humanos e tecnológicos necessários. 
Cada critério deveria ser avaliado com notas entre 10 (mais importante) e 1 (menos importante), não devendo haver notas iguais para fatores diferentes. O resultado de priorização foi obtido por meio da somatória dos resultados das multiplicações do número de vezes que um critério recebeu determinada nota pelo valor da própria nota.

Exemplo: se o critério Missão recebeu:

+30 vezes a nota $10=>33 * 10=300$

+12 vezes a nota $9=>12 * 9=108$

+03 vezes a nota $8 \Rightarrow 03 * 8=24$

+02 vezes a nota $7 \Rightarrow 02 * 7=14$

+00 vez a nota $6 \Rightarrow 00 * 6=00$

+02 vezes a nota $5 \Rightarrow 02 * 5=10$

+00 vez a nota $4=>00 * 4=00$

+04 vezes a nota $3 \Rightarrow 04 * 3=12$

+03 vezes a nota $2 \Rightarrow 03 * 2=06$

+04 vezes a nota $1=>04 * 1=04$

$=$ este critério totalizou um valor de $\mathrm{N}=478$ pontos $(300+108+24+14+0+10+0+12+6+4=478)$.

Tendo em vista a complexidade e consequente dificuldade de priorização destes fatores críticos de sucesso, optou-se por questionar apenas a opinão pessoal dos entrevitados e não sobre seu seu entendimento sobre o que a empresa adota como prioritário.

A título de exemplo, os gráficos 22 a 31 a seguir mostram a distribuição de notas que cada fator crítico de sucesso teve entre 10 (mais importante) e 1 (menos importante) considerandose todos os entrevistados. 
Gráfico 22 - Distribuição de notas de MISSÃO

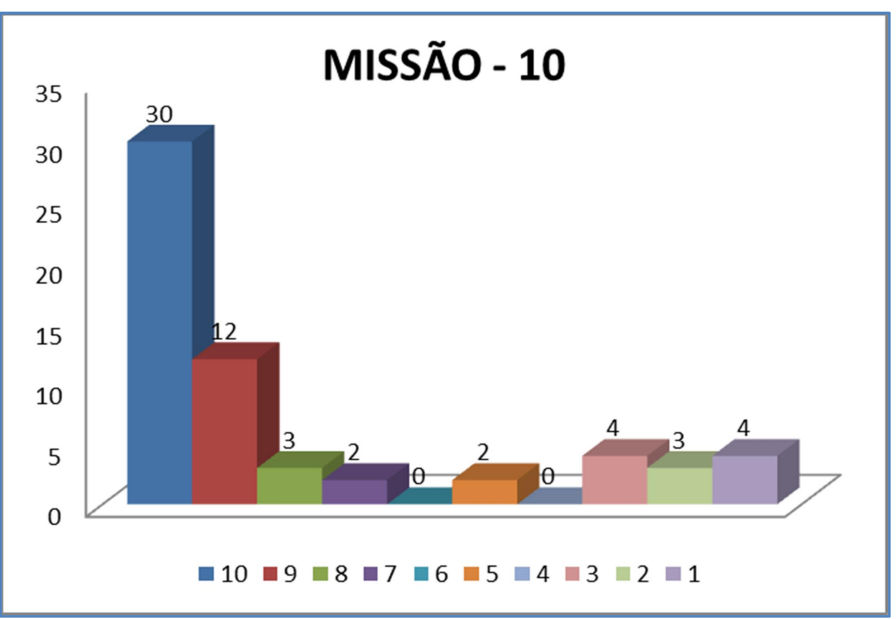

Gráfico 23 - Distribuição de notas de PLANEJAMENTO E CRONOGRAMA

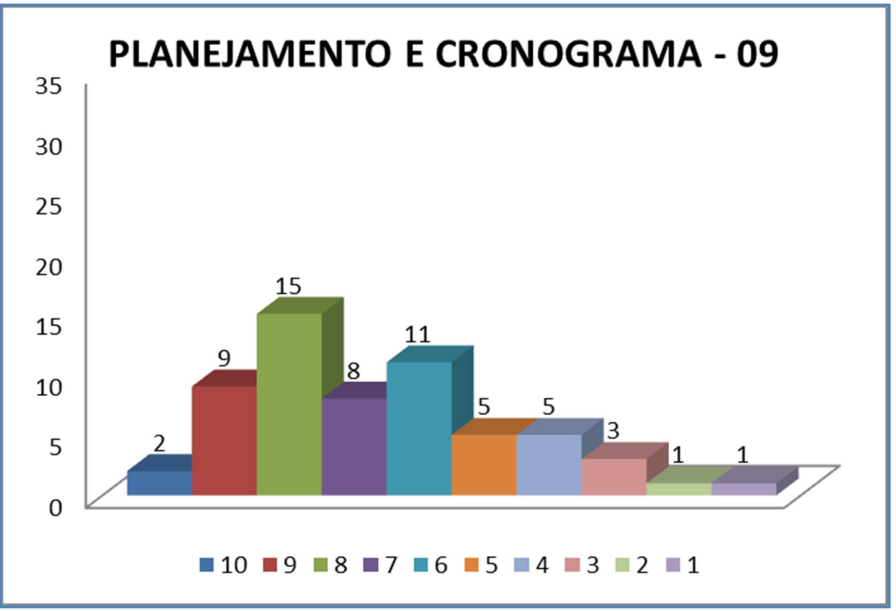

Gráfico 24 - Distribuição de notas de CONSULTA A CLIENTES

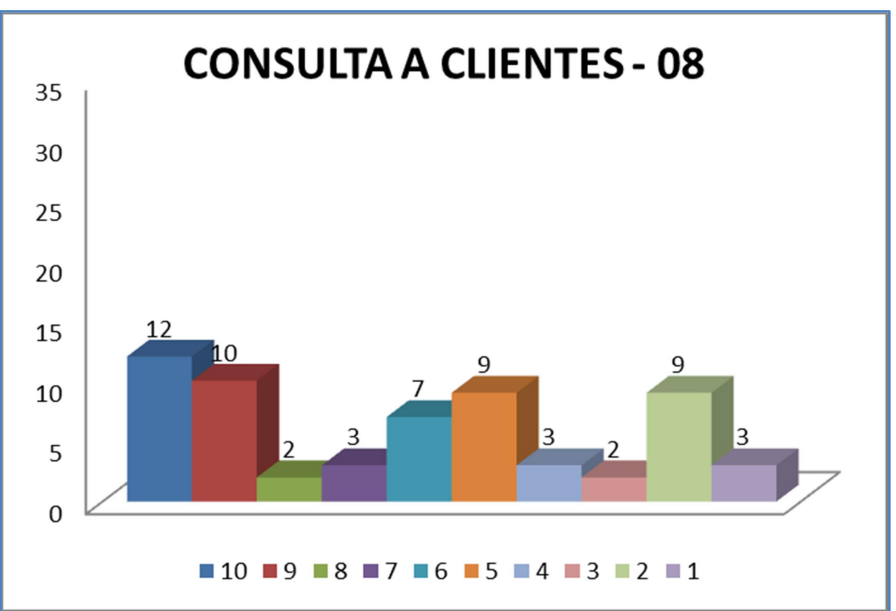


Gráfico 25 - Distribuição de notas de PESSOAL

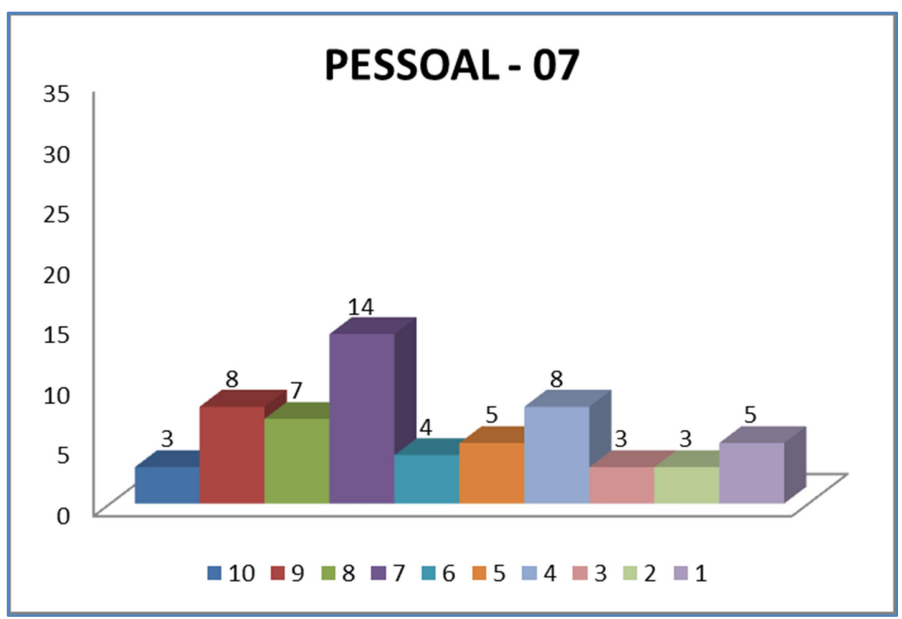

Gráfico 26 - Distribuição de notas de APOIO DA ALTA DIREÇÃO

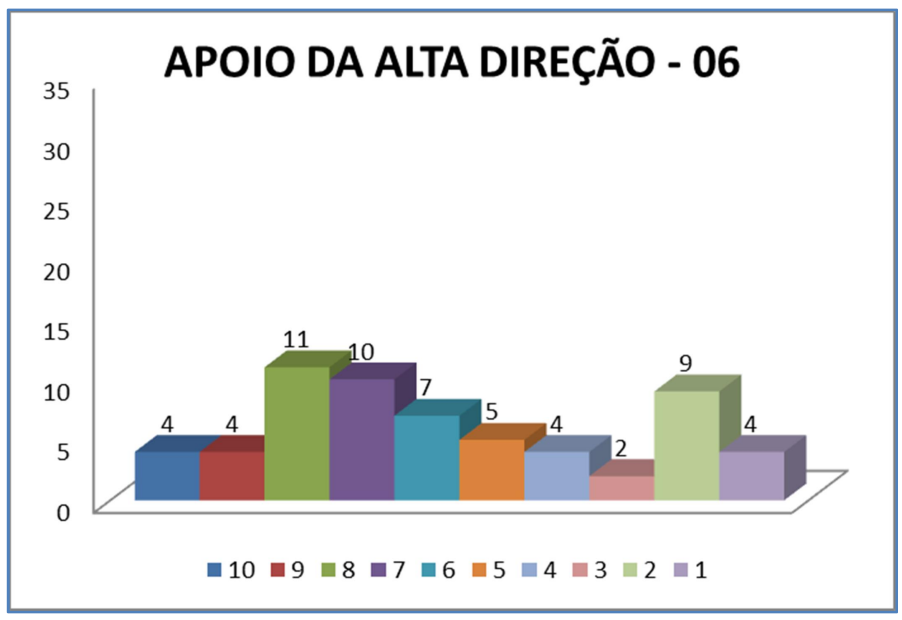

Gráfico 27 - Distribuição de notas de ACEITAÇÃO DE CLIENTES

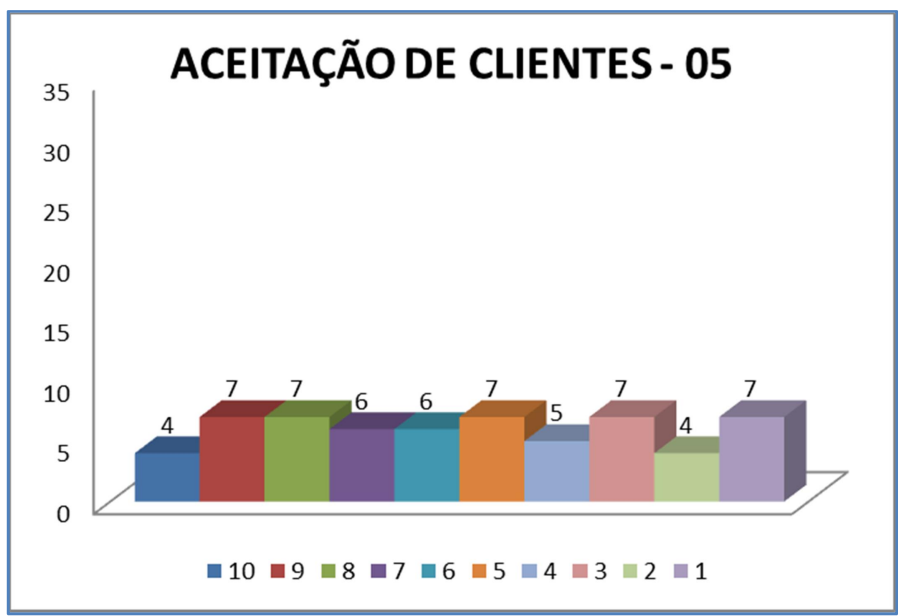


Gráfico 28 - Distribuição de notas de COMUNICAÇÃO

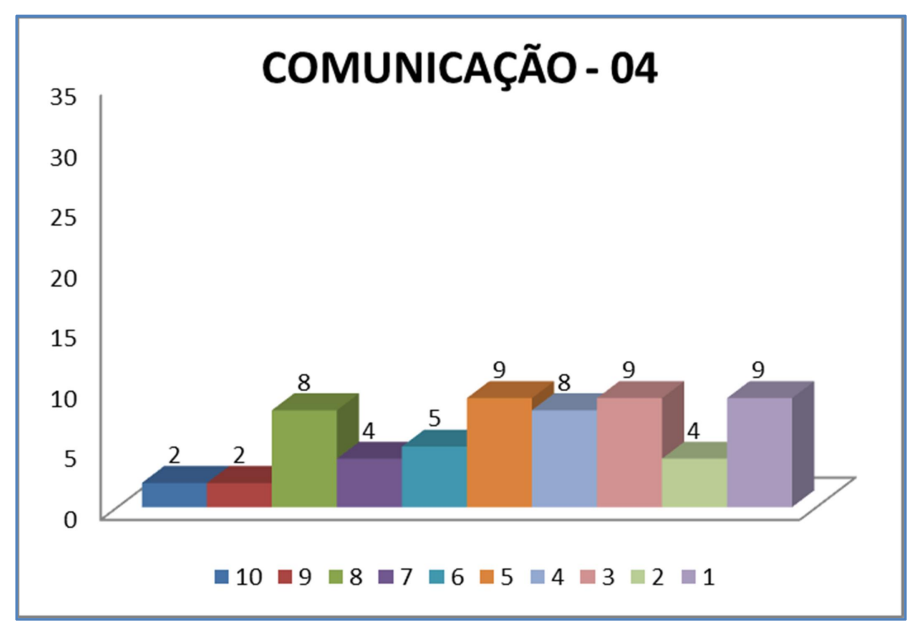

Gráfico 29 - Distribuição de notas de ATIVIDADES TÉCNICAS

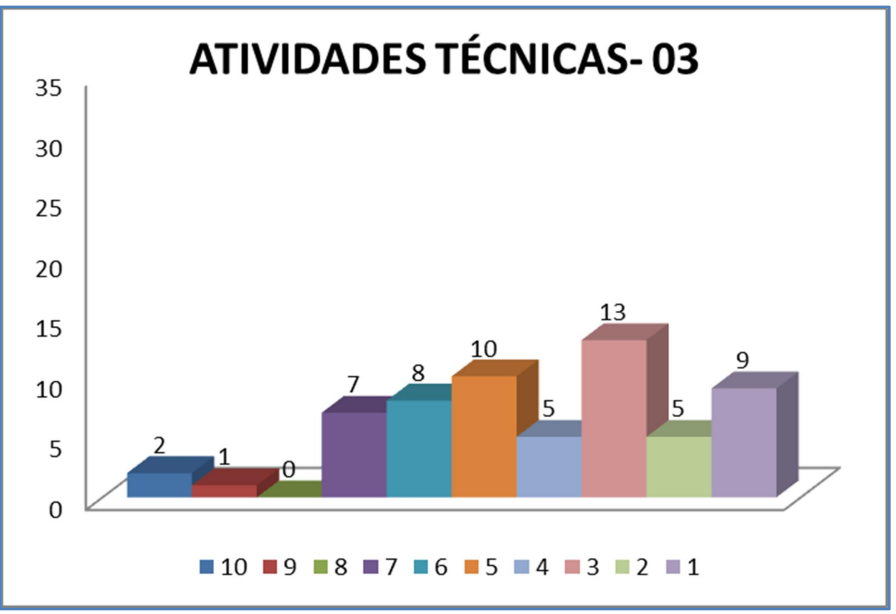

Gráfico 30 - Distribuição de notas de ACOMPANHAMENTO E FEEDBACK

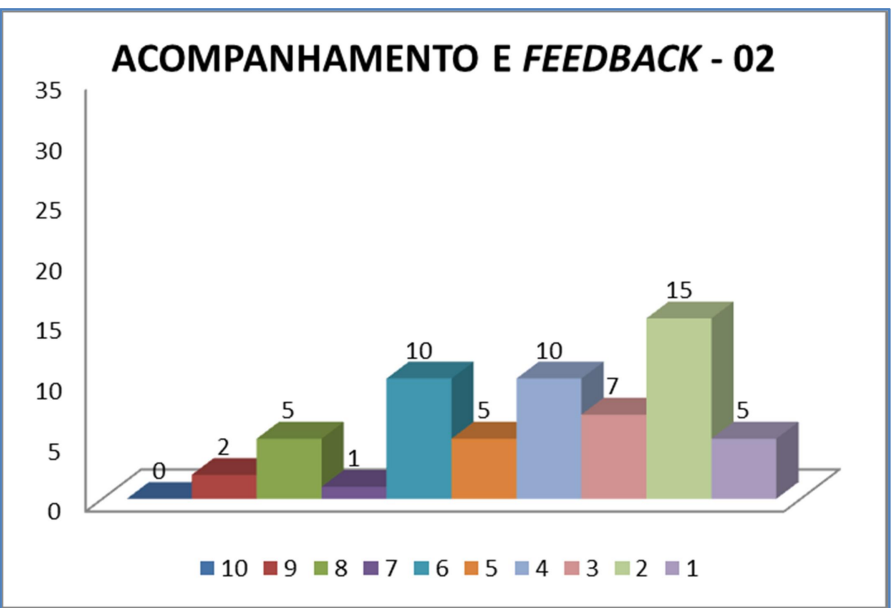


Gráfico 31 - Distribuição de notas de SOLUÇÃO DE PROBLEMAS

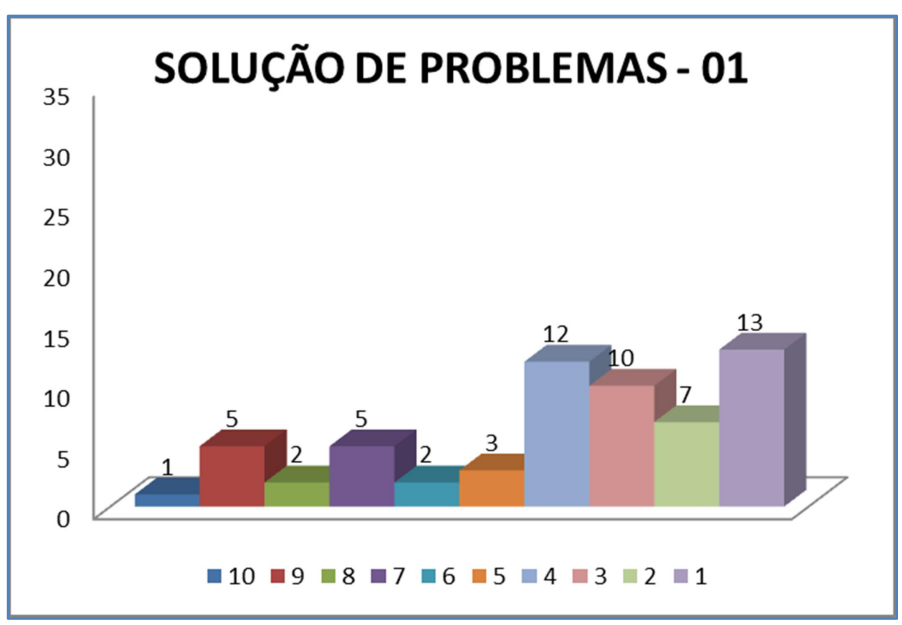

Observa-se que, a menos do fator Missão, que teve claramente indicação de o mais importante dos fatores, todos os demais, mostraram distribuições que dificultam sua classificação, mostrando apenas tendências. Desta forma, a ponderação das notas atribuídas, conforme explicado anteriormente, ajuda na tentativa de uma classificação mais objetiva.

Os resultados da priorização geral dos fatores críticos de sucesso para a execução do projeto mostraram a seguinte classificação (vide Tabela 24):

i. Missão

ii. Planejamento e Cronograma

iii. Consulta a Clientes

iv. Pessoal

v. Apoio da Alta Direção

vi. Aceitação de Clientes

vii. Comunicação

viii. Atividades Técnicas

ix. Acompanhamento e Feedback

x. Solução de Problemas com 478 pontos;

com 400 pontos;

com 373 pontos;

com 357 pontos;

com 345 pontos;

com 328 pontos;

com 281 pontos;

com 254 pontos;

com 246 pontos;

com 238 pontos. 
Tabela 24 - Priorização dos Fatores Críticos de Sucesso (FCS)

\begin{tabular}{|c|l|c|}
\hline \multirow{2}{*}{ NOTAS } & \multirow{2}{*}{$\begin{array}{c}\text { FATORES CRÍTICOS DE SUCESSO } \\
\text { PARA A EXECUÇÃO DE PROJETO }\end{array}$} & $\begin{array}{c}\text { TOTAL } \\
\text { (Entrevistados = 60) }\end{array}$ \\
\cline { 3 - 3 } & número de pontos \\
\hline 10 & MISSÃO & 478 \\
\hline 8 & $\begin{array}{l}\text { PLANEJAMENTO E } \\
\text { CRONOGRAMA }\end{array}$ & 400 \\
\hline 7 & CONSULTA A CLIENTES & 373 \\
\hline 6 & APOIO DA ALTA DIREÇÃO & 357 \\
\hline 5 & ACEITAÇÃO DE CLIENTES & 345 \\
\hline 4 & COMUNICAÇÃO & 281 \\
\hline 3 & ATIVIDADES TÉCNICAS & 254 \\
\hline 2 & $\begin{array}{l}\text { ACOMPANHAMENTO E } \\
\text { FEEDBACK }\end{array}$ & 246 \\
\hline 1 & SOLUÇÃO DE PROBLEMAS & 238 \\
\hline
\end{tabular}

Do cruzamento destes resultados com o referencial teórico no qual esta dissertação se baseia, observa-se que a priorização dos FCS indicada, segue relativamente o fluxo (e não prioridades) indicado no Modelo de Dez-Fatores de Implantação do Projeto (SLEVIN; PINTO, 1986), lembrando que o fluxo relaciona 7 fatores sequenciais (Missão, Apoio da Alta Direção, Planejamento e Cronograma, Consulta ao Cliente, Pessoal, Atividades Técnicas e Aceitação do Cliente) e 3 fatores simultâneos (Comunicação, Acompanhamento e Feedback e Solução de Problemas).

O fator Apoio da Alta Direção (segundo no fluxo teórico) aparece posicionado na quinta prioridade, o que indica aparentemente que, nesta empresa, o apoio da alta direção é efetivo e, portanto, sentido como menos necessário pelos entrevistados. Da mesma forma, o fator Atividades Técnicas deve ser bem realizado na empresa, visto que aparece como última prioridade entre os 7 fatores do fluxo teórico.

Os fatores Comunicação, Acompanhamento e Feedback e Solução de Problemas, que são relacionados no modelo como ocorrendo simultaneamente ao fluxo dos demais 7 fatores, aparecem entre as últimas prioridades da Tabela 24, também demonstrando que aparentemente estas ações são bem realizadas no gerencimento de projetos pela empresa. 
Da mesma forma que nos itens anteriores, de modo a se verificar se as prioridades dos FCS aqui encontradas tem influência do perfil do entrevistado ou mesmo da característica do projeto executado, foram feitas as seguintes estratificações:

- Priorização dos FCS em função do perfil do entrevistado: (i) Nível Hierárquico; (ii) Área Funcional; (iii) Tempo de Experiência Profissional; (iv) Participação no Projeto;

- Priorização dos FCS em função das características dos projetos: (i) Novidade; (ii) Tecnologia; (iii) Complexidade; (iv) Tempo.

A seguir encontram-se todas as estratificações com seus respectivos resultados.

\subsubsection{Priorização dos FCS em Função do Perfil do Entrevistado}

A estratificação da priorização dos fatores críticos de sucesso (FCS) em função dos níveis hierárquicos dos entrevistados resultou na Tabela 25, onde cada cor representa um FCS.

Tabela 25 - Priorização dos FCS em função do Nível Hierárquico

\begin{tabular}{|c|c|c|c|c|c|}
\hline \multirow[t]{2}{*}{ NOTAS } & \multirow{2}{*}{$\begin{array}{l}\text { FATORES CRÍTICOS DE SUCESSO } \\
\text { PARA A EXECUÇÃO DE PROJETO }\end{array}$} & $\begin{array}{c}\text { TOTAL } \\
(\text { Entrevistados }=60)\end{array}$ & $\begin{array}{l}\text { G-I } \\
(7)\end{array}$ & $\begin{array}{l}\text { G-II } \\
(19)\end{array}$ & $\begin{array}{c}\text { G-III } \\
(34)\end{array}$ \\
\hline & & \multicolumn{4}{|c|}{ número de pontos } \\
\hline 10 & MISSÃO & 478 & 58 & 153 & 267 \\
\hline 9 & $\begin{array}{l}\text { PLANEJAMENTO E } \\
\text { CRONOGRAMA } \\
\end{array}$ & 400 & 52 & 132 & 238 \\
\hline 8 & CONSULTA A CLIENTES & 373 & 47 & 123 & 208 \\
\hline 7 & PESSOAL & 357 & 40 & 117 & 201 \\
\hline 6 & APOIO DA ALTA DIREÇÃO & 345 & 39 & 111 & 194 \\
\hline 5 & ACEITAÇÃO DE CLIENTES & 328 & 39 & 90 & 186 \\
\hline 4 & COMUNICAÇÃO & 281 & 38 & 90 & 175 \\
\hline 3 & ATIVIDADES TÉCNICAS & 254 & 28 & 86 & 146 \\
\hline 2 & $\begin{array}{l}\text { ACOMPANHAMENTO E } \\
F E E D B A C K\end{array}$ & 246 & 26 & 78 & 135 \\
\hline 1 & SOLUÇÃO DE PROBLEMAS & 238 & 18 & 65 & 120 \\
\hline
\end{tabular}


Interessante notar desta Tabela 25 que o grupo G-I prioriza a Aceitação de Clientes e a Consulta a Clientes imediatamente em seguida ao de Missão, enquanto o G-II sinaliza a importância do Consulta a Clientes maior que Planejamento e Cronograma e o G-III o Apoio da Alta Direção logo após Missão e Planejamento e Cronograma e Consulta a Clientes.

Aparentemente as diferenças de priorização se dão em função das respectivas necessidades dos diferentes grupos. Logicamente o grupo G-I coloca o Apoio da Alta Direção como o segundo menos importante dos fatores críticos de sucesso, só a frente de Solução de Problemas. Das mesma forma, enquanto Acompanhamento e Feedback é o quarto mais importante para o G-I, ele é o oitavo para o G-II e o menos importante para o G-III.

Assim é que o resultado geral é uma ponderação dos 3 grupos em função da quantidade de participantes de cada um, mas que representa aproximadamente uma distribuição hierárquica comum nas empresas.

Estratificando-se a priorização dos FCS, agora em função das áreas funcionais dos entrevistados, tem-se a Tabela 26.

Tabela 26 - Priorização dos FCS em função da Área Funcional

\begin{tabular}{|c|c|c|c|c|c|c|}
\hline \multirow[t]{2}{*}{ NOTAS } & \multirow{2}{*}{$\begin{array}{l}\text { FATORES CRÍTICOS DE SUCESSO } \\
\text { PARA A EXECUÇÃO DE PROJETO }\end{array}$} & $\begin{array}{c}\text { TOTAL } \\
(\text { Entrevistados }=60)\end{array}$ & $\begin{array}{c}\mathrm{D} \\
(40) \\
\end{array}$ & $\begin{array}{c}\mathrm{I} \\
(12) \\
\end{array}$ & $\begin{array}{l}\mathrm{V} \\
(4) \\
\end{array}$ & \multirow[t]{2}{*}{$\begin{array}{r}\mathrm{T} \\
(4) \\
\end{array}$} \\
\hline & & \multicolumn{4}{|c|}{ número de pontos } & \\
\hline 10 & MISSÃO & 478 & 319 & 94 & 30 & 35 \\
\hline 9 & $\begin{array}{l}\text { PLANEJAMENTO E } \\
\text { CRONOGRAMA } \\
\end{array}$ & 400 & 270 & 77 & 29 & 30 \\
\hline 8 & CONSULTA A CLIENTES & 373 & 258 & 76 & 27 & 30 \\
\hline 7 & PESSOAL & 357 & 237 & 75 & 25 & 28 \\
\hline 6 & APOIO DA ALTA DIREÇÃO & 345 & 225 & 70 & 25 & 25 \\
\hline 5 & ACEITAÇÃO DE CLIENTES & 328 & 204 & 67 & 21 & 19 \\
\hline 4 & COMUNICAÇÃO & 281 & 202 & 58 & 18 & 16 \\
\hline 3 & ATIVIDADES TÉCNICAS & 254 & 171 & 57 & 17 & 13 \\
\hline 2 & $\begin{array}{l}\text { ACOMPANHAMENTO E } \\
F E E D B A C K\end{array}$ & 246 & 164 & 50 & 15 & 13 \\
\hline 1 & SOLUÇÃO DE PROBLEMAS & 238 & 150 & 36 & 13 & 11 \\
\hline
\end{tabular}


Desta Tabela 26 pode-se observar que há um menor distanciamento entre as prioridades dos grupos e do total dos entrevistados. No entanto, pode-se inferir que os fatores críticos de sucesso também são as maiores necessidades de cada área estratificada. Interessante notar por exempo que o grupo V é o que atribui aos fatores de Aceitação de Clientes e Consulta a Clientes a menor relevância relativa, talvez justamente por estar mais próximo dos clientes no seu trabalho diário. Em contrapartida, parece necessitar de mais informações do detalhamento do projeto, quando classifica o fator Comunicação como terceiro mais importante, após apenas dos fatores Missão e Planejamento e Cronograma.

No entanto, há que se considerar a quantidade de respondentes de cada segmento e assim relativizar os resultados encontrados. O maior grupo estratificado, o grupo D, influencia fortemente os resultados totais, sendo que somente os fatores Pessoal e Apoio da Alta direção aparecem com classificação inversa do total de entrevistados, por terem os demais grupos priorizado diferentemente este fatores.

Buscando-se a estratificação da priorização dos FCS em função do tempo de experiência profissional dos entrevistados, forma-se a seguinte Tabela 27:

Tabela 27 - Priorização dos FCS em função do Tempo de Experiência Profissional

\begin{tabular}{|c|c|c|c|c|c|}
\hline \multirow[t]{2}{*}{ NOTAS } & \multirow{2}{*}{$\begin{array}{l}\text { FATORES CRÍTICOS DE SUCESSO } \\
\text { PARA A EXECUÇÃO DE PROJETO }\end{array}$} & $\begin{array}{c}\text { TOTAL } \\
(\text { Entrevistados }=60)\end{array}$ & $\begin{array}{l}>20 \\
(24)\end{array}$ & $\begin{array}{c}10 \text { e } 20 \\
(29)\end{array}$ & $\begin{array}{l}<10 \\
(7)\end{array}$ \\
\hline & & \multicolumn{4}{|c|}{ número de pontos } \\
\hline 10 & MISSÃO & 478 & 183 & 242 & 53 \\
\hline 9 & $\begin{array}{l}\text { PLANEJAMENTO E } \\
\text { CRONOGRAMA } \\
\end{array}$ & 400 & 165 & 196 & 50 \\
\hline 8 & CONSULTA A CLIENTES & 373 & 155 & 184 & 49 \\
\hline 7 & PESSOAL & 357 & 145 & 176 & 47 \\
\hline 6 & APOIO DA ALTA DIREÇÃO & 345 & 134 & 161 & 42 \\
\hline 5 & ACEITAÇÃO DE CLIENTES & 328 & 126 & 143 & 40 \\
\hline 4 & COMUNICAÇÃO & 281 & 119 & 131 & 32 \\
\hline 3 & ATIVIDADES TÉCNICAS & 254 & 103 & 124 & 27 \\
\hline 2 & $\begin{array}{l}\text { ACOMPANHAMENTO E } \\
F E E D B A C K\end{array}$ & 246 & 103 & 120 & 25 \\
\hline 1 & SOLUÇÃO DE PROBLEMAS & 238 & 87 & 118 & 20 \\
\hline
\end{tabular}


Desta Tabela 27, pode-se inferir novamente que as diferentes priorizações ocorrem em função das diferentes necessidades, neste caso, consequência da experiência adquirida. Assim é que os grupos com mais de 10 anos de experiência profissional, valorizam o fator Consulta a Clientes com prioridade bem diferente do grupo com menos de 10 anos.

Por fim, a estratificação da priorização dos FCS em função da participação do entrevistado nos projetos forma a seguinte Tabela 28:

Tabela 28 - Priorização dos FCS em função da Participação no Projeto

\begin{tabular}{|c|c|c|c|c|c|}
\hline \multirow[t]{2}{*}{ NOTAS } & \multirow{2}{*}{$\begin{array}{l}\text { FATORES CRÍTICOS DE SUCESSO } \\
\text { PARA A EXECUÇÃO DE PROJETO }\end{array}$} & $\begin{array}{c}\text { TOTAL } \\
(\text { Entrevistados }=60)\end{array}$ & $\begin{array}{l}\text { COMITE } \\
(11) \\
\end{array}$ & $\begin{array}{c}\text { GERENTE } \\
(42) \\
\end{array}$ & $\begin{array}{c}\text { PARTIC } \\
(7) \\
\end{array}$ \\
\hline & & \multicolumn{4}{|c|}{ número de pontos } \\
\hline 10 & MISSÃO & 478 & 92 & 319 & 67 \\
\hline 9 & $\begin{array}{l}\text { PLANEJAMENTO E } \\
\text { CRONOGRAMA } \\
\end{array}$ & 400 & 77 & 271 & 56 \\
\hline 8 & CONSULTA A CLIENTES & 373 & 73 & 261 & 44 \\
\hline 7 & PESSOAL & 357 & 73 & 245 & 43 \\
\hline 6 & APOIO DA ALTA DIREÇÃO & 345 & 64 & 241 & 38 \\
\hline 5 & ACEITAÇÃO DE CLIENTES & 328 & 56 & 226 & 35 \\
\hline 4 & COMUNICAÇÃO & 281 & 53 & 194 & 34 \\
\hline 3 & ATIVIDADES TÉCNICAS & 254 & 47 & 188 & 29 \\
\hline 2 & $\begin{array}{l}\text { ACOMPANHAMENTO E } \\
F E E D B A C K\end{array}$ & 246 & 37 & 183 & 22 \\
\hline 1 & SOLUÇÃO DE PROBLEMAS & 238 & 33 & 182 & 17 \\
\hline
\end{tabular}

Esta Tabela 28 é a que mostra mais homogeneidade de todas as anteriores, com as percepções dos diferentes grupos formando um desenho bem semelhante ao do resultado total. Aparentemente as maiores execções são a do Apoio da Alta Direção em geral e o fator Consulta a Clientes no grupo Participantes, que talvez seja também influenciado pela função exercida (geralmente os cargos Comite e Gerente costumam ser ocupados por pessoas mais experientes do que os Participantes). 


\subsubsection{Priorização dos FCS em Função das Características dos Projetos}

A estratificação da priorização dos FCS em função da novidade dos veículos em relação ao mercado resultou na seguinte Tabela 29:

Tabela 29 - Priorização dos FCS em função da Novidade

\begin{tabular}{|c|c|c|c|c|c|}
\hline \multirow[t]{2}{*}{ NOTAS } & \multirow{2}{*}{$\begin{array}{l}\text { FATORES CRÍTICOS DE SUCESSO } \\
\text { PARA A EXECUÇÃO DE PROJETO }\end{array}$} & $\begin{array}{c}\text { TOTAL } \\
(\text { Entrevistados }=60)\end{array}$ & $\begin{array}{c}\mathrm{I} \\
29\end{array}$ & $\begin{array}{c}\mathrm{S} \\
25\end{array}$ & $\begin{array}{l}\mathrm{F} \\
8\end{array}$ \\
\hline & & \multicolumn{4}{|c|}{ número de pontos } \\
\hline 10 & MISSÃO & 478 & 229 & 178 & 71 \\
\hline 9 & $\begin{array}{l}\text { PLANEJAMENTO E } \\
\text { CRONOGRAMA } \\
\end{array}$ & 400 & 198 & 150 & 53 \\
\hline 8 & CONSULTA A CLIENTES & 373 & 182 & 149 & 51 \\
\hline 7 & PESSOAL & 357 & 172 & 139 & 46 \\
\hline 6 & APOIO DA ALTA DIREÇÃO & 345 & 168 & 131 & 45 \\
\hline 5 & ACEITAÇÃO DE CLIENTES & 328 & 160 & 130 & 45 \\
\hline 4 & COMUNICAÇÃO & 281 & 137 & 116 & 36 \\
\hline 3 & ATIVIDADES TÉCNICAS & 254 & 120 & 97 & 33 \\
\hline 2 & $\begin{array}{l}\text { ACOMPANHAMENTO E } \\
F E E D B A C K\end{array}$ & 246 & 116 & 89 & 31 \\
\hline 1 & SOLUCCÃO DE PROBLEMAS & 238 & 113 & 86 & 29 \\
\hline
\end{tabular}

Esta Tabela 29 mostra um relativo desalinhamento de prioridades de FCS em função da novidade dos produtos em relação ao mercado, apesar de algumas inversões de prioridade terem valores bem próximos. No entanto, se considerar-se que os FCS são priorizados em função das maiores necessidades verificadas, pode-se entender porque produtos inéditos apresentam o fator Pessoal como o terceiro mais importante e um produto facelift apresenta a aceitação do cliente como o último fator crítico de sucesso. Desta forma pode-se observar que diferentes tipos de produtos requerem diferentes prioridades entre os fatores críticos de sucesso relacionados. 
Estratificando-se a priorização dos FCS, agora em função em função da tecnologia dos veículos ou dos seus principais sistemas importantes, tem-se a seguinte Tabela 30 comparativa:

Tabela 30 - Priorização dos FCS em função da Tecnologia

\begin{tabular}{|c|c|c|c|c|c|}
\hline \multirow[t]{2}{*}{ NOTAS } & \multirow{2}{*}{$\begin{array}{l}\text { FATORES CRÍTICOS DE SUCESSO } \\
\text { PARA A EXECUÇÃO DE PROJETO }\end{array}$} & $\begin{array}{c}\text { TOTAL } \\
(\text { Entrevistados }=60)\end{array}$ & $\begin{array}{c}\text { A } \\
16 \\
\end{array}$ & $\begin{array}{l}\mathrm{M} \\
37 \\
\end{array}$ & $\begin{array}{l}B \\
7 \\
\end{array}$ \\
\hline & & \multicolumn{4}{|c|}{ número de pontos } \\
\hline 10 & MISSÃO & 478 & 142 & 284 & 54 \\
\hline 9 & $\begin{array}{l}\text { PLANEJAMENTO E } \\
\text { CRONOGRAMA } \\
\end{array}$ & 400 & 111 & 244 & 52 \\
\hline 8 & CONSULTA A CLIENTES & 373 & 95 & 235 & 48 \\
\hline 7 & PESSOAL & 357 & 90 & 222 & 45 \\
\hline 6 & APOIO DA ALTA DIREÇÃO & 345 & 84 & 214 & 41 \\
\hline 5 & ACEITAÇÃO DE CLIENTES & 328 & 83 & 214 & 40 \\
\hline 4 & COMUNICAÇÃO & 281 & 81 & 165 & 31 \\
\hline 3 & ATIVIDADES TÉCNICAS & 254 & 72 & 161 & 30 \\
\hline 2 & $\begin{array}{l}\text { ACOMPANHAMENTO E } \\
F E E D B A C K\end{array}$ & 246 & 67 & 152 & 27 \\
\hline 1 & SOLUÇÃO DE PROBLEMAS & 238 & 55 & 144 & 17 \\
\hline
\end{tabular}

Mesmo mostrando um perfil de desalinhamento de prioridade menor do que a estratificação anterior, pode-se inferir também desta Tabela 30 que as prioridades variam em função da diferença de necessidade, no caso a diferença de tecnologias de produtos ou sistemas importantes. Assim é que produtos de mais alta tecnologia parecem ser tratados com mais sigilo e portanto não se prioriza a consulta a clientes, enquanto produtos de baixa tecnologia chegam a ter este fator como o de maior prioridade. Da mesma forma, produtos de maior tecnologia requerem uma prioridade maior do fator Pessoal do que os demais produtos de média e baixa tecnologia.

Buscando-se a estratificação da priorização dos FCS em função da complexidade do fornecimento dos principais sistemas importantes, forma-se a seguinte Tabela 31: 
Tabela 31 - Priorização dos FCS em função da Complexidade

\begin{tabular}{|c|c|c|c|c|c|}
\hline \multirow[t]{2}{*}{ NOTAS } & \multirow{2}{*}{$\begin{array}{l}\text { FATORES CRÍTICOS DE SUCESSO } \\
\text { PARA A EXECUÇÃO DE PROJETO }\end{array}$} & $\begin{array}{c}\text { TOTAL } \\
(\text { Entrevistados }=60)\end{array}$ & $\begin{array}{r}\text { A } \\
36\end{array}$ & $\begin{array}{l}M \\
17\end{array}$ & $\begin{array}{l}\text { B } \\
7\end{array}$ \\
\hline & & \multicolumn{4}{|c|}{ número de pontos } \\
\hline 10 & MISSÃO & 478 & 298 & 142 & 52 \\
\hline 9 & $\begin{array}{l}\text { PLANEJAMENTO E } \\
\text { CRONOGRAMA } \\
\end{array}$ & 400 & 249 & 114 & 41 \\
\hline 8 & CONSULTA A CLIENTES & 373 & 237 & 113 & 40 \\
\hline 7 & PESSOAL & 357 & 209 & 101 & 39 \\
\hline 6 & APOIO DA ALTA DIREÇÃO & 345 & 206 & 99 & 38 \\
\hline 5 & ACEITAÇÃO DE CLIENTES & 328 & 191 & 94 & 38 \\
\hline 4 & COMUNICAÇÃO & 281 & 163 & 84 & 37 \\
\hline 3 & ATIVIDADES TÉCNICAS & 254 & 146 & 64 & 37 \\
\hline 2 & $\begin{array}{l}\text { ACOMPANHAMENTO E } \\
F E E D B A C K\end{array}$ & 246 & 142 & 64 & 36 \\
\hline 1 & SOLUÇÃO DE PROBLEMAS & 238 & 139 & 60 & 27 \\
\hline
\end{tabular}

Desta Tabela 31 percebe-se que há uma maior alinhamento entre os estratos e o resultado geral, a menos do estrato de Baixa Complexidade. No entanto, observa-se que neste estrato as pontuações dos FCS são muito próximas entre si (entre 36 e 41pontos) a menos dos dois extremos, o que não possibilita uma análise mais afirmativa. Aparentemente, a priorização dos FCS não depende, pelo menos não fortemente, da complexidade do fornecimento.

Por fim, estratificando-se a priorização pessoal, agora em função do tempo disponível para o desenvolvimento dos projetos, tem-se a seguinte Tabela 32: 
Tabela 32 - Priorização dos FCS em função do Tempo

\begin{tabular}{|c|c|c|c|c|c|}
\hline \multirow[t]{2}{*}{ NOTAS } & \multirow{2}{*}{$\begin{array}{l}\text { FATORES CRÍTICOS DE SUCESSO } \\
\text { PARA A EXECUÇÃO DE PROJETO }\end{array}$} & $\begin{array}{c}\text { TOTAL } \\
(\text { Entrevistados }=60)\end{array}$ & $\begin{array}{c}\mathrm{U} \\
22\end{array}$ & $\begin{array}{c}\mathrm{C} \\
23\end{array}$ & $\begin{array}{l}\mathrm{N} \\
14\end{array}$ \\
\hline & & \multicolumn{4}{|c|}{ número de pontos } \\
\hline 10 & MISSÃO & 478 & 190 & 171 & 107 \\
\hline 9 & $\begin{array}{l}\text { PLANEJAMENTO E } \\
\text { CRONOGRAMA } \\
\end{array}$ & 400 & 162 & 153 & 87 \\
\hline 8 & CONSULTA A CLIENTES & 373 & 161 & 136 & 86 \\
\hline 7 & PESSOAL & 357 & 147 & 133 & 80 \\
\hline 6 & APOIO DA ALTA DIREÇÃO & 345 & 146 & 124 & 75 \\
\hline 5 & ACEITAÇÃO DE CLIENTES & 328 & 129 & 118 & 69 \\
\hline 4 & COMUNICAÇÃO & 281 & 126 & 114 & 61 \\
\hline 3 & ATIVIDADES TÉCNICAS & 254 & 91 & 109 & 55 \\
\hline 2 & $\begin{array}{l}\text { ACOMPANHAMENTO E } \\
F E E D B A C K\end{array}$ & 246 & 85 & 106 & 54 \\
\hline 1 & SOLUÇÃO DE PROBLEMAS & 238 & 83 & 91 & 41 \\
\hline
\end{tabular}

Desta Tabela 32, aparentemente pode-se afirmar que a priorização dos FCS não depende do tempo requerido para o desenvolvimento do projeto, visto que é a tabela que apresenta o maior alinhamento entre os resultados gerais e os estratos.

Curiosamente nota-se apenas uma grande diferença entre os fatores Comunicação e Solução de Problemas que aparecem "trocados" na priorização em função do estrato Crítico, apesar de ambos os fatores ocorrerem simultaneamento e em harmonia com o fluxo conforme a teoria. 


\section{SÍNTESE E CONCLUSÕES}

Pode-se afirmar que o objetivo principal deste trabalho, pesquisar a importância dos Fatores Críticos de Sucesso (FCS) para a execução do Processo de Gerenciamento do Desenvolvimento de Produtos e a importância dos Critérios de Avaliação de Sucesso dos Resultados de Projetos em uma empresa tradicional da indústria automobilística brasileira de veículos comerciais foi abordado no estudo de caso da montadora selecionada e as principais questões de pesquisa formuladas foram analisadas conforme descrito a seguir.

Da análise dos resultados da pesquisa, apresentados no capítulo anterior, frente à teoria apresentada e levando-se em conta as perguntas de pesquisa originais e subsequentes ao estudo, pode-se destacar a seguinte síntese dos resultados e principais conclusões:

\section{- Qual o perfil do participante de processos de gerenciamento de projetos de desenvolvimento de veículos comerciais brasileiros?}

Conforme detalhado no item 4.1, verifica-se na empresa pesquisada que as pessoas que participaram de processos de gerenciamento de projetos de desenvolvimento de produto e que responderam ao questionário têm o seguinte perfil:

i. são preponderantemente do gênero masculino;

ii. têm função executiva

iii. a maioria trabalha na área funcional de Desenvolvimento de Produtos

iv. são pessoas com grande experiência profissional (aproximadamente $90 \%$ mais de 10 anos de experiência e $40 \%$ com mais de 20 anos de experiência);

v. trabalharam em projetos principalmente na função de Gerente / Líder de Projeto e Comitê de Direção / Decisão de Projeto (respectiva e aproximadamente 70\% e 20\%).

Visto esta empresa pesquisada ser uma das tradicionais montadoras de veículos comerciais brasileiras, poder-se-ia inferir que o perfil geral no Brasil dos grupos de desenvolvimento de projetos seja de alguma forma semelhante a este, com equipes predominamente masculinas e grande capacidade e experiência profissional, guardadas as limitações do estudo tratar-se de um estudo de caso em uma montadora. 


\section{- Quais as características de projeto de desenvolvimento de veículos comerciais brasileiros?}

Conforme detalhado no item 4.2, os respondentes desta pesquisa participaram de projetos de veículos comerciais da montadora com as seguintes principais características:

i. a grande maioria dos produtos desenvolvidos (aproximadamente 90\%) foi inédita em relação ao mercado ou sucessora de uma linha atual;

ii. os veículos desenvolvidos ou seus principais sistemas importantes (cabine, quadro, motor, transmissão, eixos, direção, suspensão e freios) apresentaram em sua maioria alta e média tecnologia (respectiva e aproximadamente $25 \%$ desenvolvidas durante o projeto e $60 \%$ recém-desenvolvidas);

iii. a complexidade de fornecimento dos principais sistemas importantes dos veículos foi considerada alta ou média (aproximadamente 90\% dos veículos desenvolvidos têm os principais sistemas importantes fornecidos por empresas que não a própria montadora);

iv. o tempo disponível para o desenvolvimento dos projetos foi considerado em sua maioria (aproximadamente 75\%) como urgente (determinado por uma janela de oportunidade como uma licitação) ou crítico (determinado por uma legislação).

Mais uma vez, visto sua representatividade (líder) no mercado nacional, esta montadora poderia ser considerada exemplo das empresas automobilísticas brasileiras que desenvolvem veículos comerciais. Portanto, poder-se-ia dizer que os veículos comerciais brasileiros mostram-se inovadores, de alta e média tecnologia, com fornecimento complexo de sistemas importantes, desenvolvidos em relativo curto espaço de tempo e adequados às aplicações de países em desenvolvimento e, em geral, diferentes dos produtos de suas matrizes localizadas em países desenvolvidos, aqui também observadas as limitações do estudo de caso. 
- Quais são os critérios de avaliação do resultado mais importantes de um projeto bem sucedido de veículos comerciais brasileiros? A percepção dos participantes de times de projetos sobre a hierarquia destes critérios é semelhante à que eles pensam ser a valorizada pela empresa em que trabalham?

Conforme detalhado no item 4.3, esta pesquisa propiciou uma comparação entre a opinião pessoal dos entrevistados sobre a importância dos critérios de avaliação de resultados de um projeto bem sucedido, frente ao que pensam ser a prioridade adotada pela montadora. Além disto, a estratificação desta comparação em função dos perfis dos entrevistados e também das características dos projetos, possibilitou observações e conclusões abordadas na sequência.

Os critérios de avaliação de sucesso que foram utilizados para as priorizações pelos entrevistados foram adaptados do Modelo Diamante de Shenhar e Dvir (2010), conforme a seguinte descrição:

i. Eficiência: cronograma e orçamento do projeto conforme planejado inicialmente;

ii. Clientes (Impacto no Cliente): satisfação dos clientes e usuários com o escopo do produto;

iii. Equipe (Impacto na Equipe): satisfação e desenvolvimento pessoal dos participantes do projeto;

iv. Viabilidade (Sucesso Comercial e Direto): resultados financeiros e mercadológicos da empresa com o projeto;

v. Sustentabilidade (Preparação para o Futuro): como o projeto contribui para o desenvolvimento de novas competências que preparam adequadamente a empresa para oportunidades futuras.

Enquanto a teoria indica um caráter dinâmico de priorização dos critérios de sucesso de um projeto ao longo do tempo, do curto para o longo prazo na ordem de Eficiência / Clientes / Equipe / Viabilidade / Sustentabilidade, a pesquisa demonstrou que os entrevistados priorizam estes critérios na sequência Clientes / Viabilidade / Eficiência / Equipe / Sustentabilidade e afirmam que sua empresa adota a sequência Viabilidade / Clientes / Eficiência / Sustentabilidade / Equipe. 
Quadro 2 - Critérios de Avaliação de Resultados - Resultados da Pesquisa e Fluxo teórico

\begin{tabular}{|c|c|c|c|c|c|}
\hline Opiniões: & \multicolumn{2}{|c|}{ Mais importante } & \multicolumn{2}{|c|}{ (Importância) } & Menos importante \\
\hline "Empresa" & Viabilidade & Clientes & Eficiência & Sustentabilidade & Equipe \\
\hline "Pessoal”" & Clientes & Viabilidade & Eficiência & Equipe & Sustentabilidade \\
\hline & Efici & & $\mathrm{Eq}$ & Vic & Sust \\
\hline Teórico & Curto & & (Período d & mpo) & Longo \\
\hline
\end{tabular}

Fonte: Autor

Percebe-se do Quadro 2 que os respondentes priorizaram um critério de mais longo prazo como Viabilidade, a frente de outros de curto e médio prazo como Eficiência e Equipe e consideram que sua empresa adota este mesmo critério como o mais importante de todos. Isto indica que os respondentes são profissionais experientes, confirmando o perfil levantado, e que observam a importância de critérios que garantam o longo prazo da empresa em que trabalham.

Da estratificação "pessoal x empresa" destas respostas, segundo os perfis dos entrevistados quanto ao (i) nível hierárquico, (ii) área funcional de atuação, (iii) tempo de experiência profissional e (iv) tipo de participação nos projetos, observa-se principalmente que:

(i) Quanto ao nível hierárquico, enquanto na avaliação pessoal, observam-se diferenças de prioridades entre os diferentes níveis hierárquicos, na avaliação sobre o que a empresa adota os resultados são totalmente homogêneos. O resultado mais interessante desta estratificação foi a observação que o nível hierárquico mais alto (G-I: presidente / vice-presidente / diretor adjunto), em princípio os executivos representantes da empresa, enxergam que a empresa tem critérios diferentes dos seus próprios.

(ii) $\mathrm{O}$ resultado mais interessante da estratificação por área funcional de atuação foi a observação que as pessoas que trabalham em Vendas acreditam que a empresa dá menos importância ao critério Clientes talvez numa "reclamação" indireta. Por serem a maioria dos entrevistados, as pessoas que trabalham na área de Desenvolvimento de Produto influenciam os resultados gerais tanto pessoal quanto em relação à opinião da empresa sem, no entanto, distorcê-los exageradamente. 
(iii) O resultado mais interessante da estratificação por tempo de experiência profissional foi a observação que os resultados observados foram praticamente homogêneos em relação aos resultados gerais, tanto para a avaliação pessoal quanto para o que a empresa adota.

(iv) Quanto ao tipo de participação no projeto, enquanto nas avaliações pessoais há certa harmonia entre as respostas, nas avaliações sobre o que a empresa adota, observam-se priorizações diferentes em relação ao critério Eficiência sendo que o grupo de participantes, mais operacional, acredita ser este o critério mais importante adotado pela empresa enquanto o resultado geral o posiciona na terceira prioridade. Talvez aqui, estes participantes acreditem na importância que a empresa dá à necessidade que estas pessoas tenham um bom desempenho durante a execução dos projetos.

Da estratificação pessoal x empresa segundo a caracterização dos projetos quanto à (i) novidade em relação ao mercado, (ii) tecnologia dos veículos ou de seus principais sistemas importantes, (iii) complexidade de fornecimento dos sistemas importantes e (iv) tempo disponível para o desenvolvimento do projeto, a pesquisa demonstrou que:

(i) Aparentemente, a novidade em relação ao mercado não influencia a priorização dos critérios de sucesso do projeto nem na avaliação pessoal nem na avaliação empresa;

(ii) e (iii) $\mathrm{O}$ critério de Eficiência é mais priorizado na avaliação pessoal quando se trata de produtos de baixa tecnologia e baixa complexidade de fornecimento de sistemas importantes. No entanto, isto paradoxalmente não é confirmado na avaliação empresa.

(iv) Em relação ao tempo para desenvolvimento de projeto, percebe-se da avaliação pessoal que os entrevistados priorizaram a Equipe mais importante que a Sustentabilidade, exceto para projetos críticos, aqui provavelmente pela alusão ao cumprimento de legislações contida na definição da característica. Já na avaliação sobre o que consideram a empresa adotar como prioridade, a estratificação apresenta resultados uniformes, com a Sustentabilidade mais importante que a Equipe.

De uma forma geral, na estratificação (opinião da) empresa, estranhamente a priorização para todas as diferentes características de projetos consideradas acima é uniforme e igual à geral, o que contradiz a teoria que afirma que "para projetos de baixo risco, o cumprimento das restrições de recursos é mais critico e relevante que para projetos de risco maior" (SHENHAR; DVIR, 2010, p. 43). 


\section{- Quais são os Fatores Críticos de Sucesso (FCS) mais importantes para a execução do processo de desenvolvimento de veículos comerciais brasileiros?}

Conforme descrito no item 4.4, os fatores críticos de sucesso que foram utilizados para as priorizações pelos entrevistados foram adaptados do Modelo de Processo de Dez-Fatores de Implantação de Projeto, de Pinto e Slevin (1987), conforme a seguinte descrição:

i. Missão - objetivos do projeto claramente definidos desde o inicio;

ii. Apoio da Alta Direção - suporte da alta direção em prover os recursos necessários, autoridade e poder para o sucesso da implantação;

iii. Planejamento e Cronograma - existência de plano detalhado, incluindo cronograma, milestones, necessidades de mão de obra, etc., para a execução integral do projeto;

iv. Consulta a Clientes - consulta a clientes no início do projeto e informação sobre o seu progresso, inclusive decisões sobre inclusão de suas sugestões;

v. Pessoal - qualificação e quantidade de pessoas adequadas à realização do projeto;

vi. Atividades Técnicas - recursos tecnológicos adequados à realização do projeto;

vii. Aceitação do Cliente - verificação da aceitação e disposição de utilização do produto em sua última versão pelos potenciais clientes e usuários;

viii. Acompanhamento e Feedback - monitoração de todos os aspectos importantes ao progresso do projeto por meio de revisões periódicas planejadas;

ix. Comunicação - disposição de informações por meio de canais e formatos adequados a todos os participantes do projeto;

x. Solução de Problemas - capacidade e agilidade de gerenciamento de crises e desvios de projeto, utilizando todos os recursos humanos e tecnológicos necessários. 
Em resposta à questão principal desta pesquisa, os entrevistados priorizaram os FCS, segundo suas opiniões pessoais, na sequência Missão / Planejamento e Cronograma / Consulta a Clientes / Pessoal / Apoio da Alta Direção / Aceitação dos Clientes / Comunicação / Atividades Técnicas / Acompanhamento e Feedback / Solução de Problemas.

Observando-se a priorização encontrada na pesquisa verifica-se que ela é muito semelhante à do fluxo do modelo teórico, que representa a sua sequência no tempo (e não suas prioridades).

Os FCS Comunicação, Solução de Problemas e Acompanhamento e Feedback, são considerados entre os menos importantes da sequência pesquisada e são fatores que na teoria acontecem simultaneamente e em harmonia aos demais sete FCS. Isolando-se estes três FCS do modelo de Dez-Fatores tem-se:

Quadro 3 - Fatores Críticos de Sucesso - Resultados da Pesquisa e Modelo Teórico

\begin{tabular}{|c|c|c|c|c|c|c|c|}
\hline \multirow[b]{2}{*}{$\begin{array}{c}\text { Resultado } \\
\text { da } \\
\text { Pesquisa }\end{array}$} & \multicolumn{2}{|c|}{ Mais importante } & \multicolumn{3}{|c|}{ (Importância) } & \multicolumn{2}{|c|}{ Menos importante } \\
\hline & Missão & $\begin{array}{l}\text { Planejamento } \\
\text { Cronograma }\end{array}$ & $\begin{array}{l}\text { Consulta a } \\
\text { Clientes }\end{array}$ & Pessoal & $\begin{array}{c}\text { Apoio da } \\
\text { Alta Direção }\end{array}$ & $\begin{array}{c}\text { Aceitação } \\
\text { dos } \\
\text { Clientes }\end{array}$ & $\begin{array}{c}\text { Atividades } \\
\text { Técnicas }\end{array}$ \\
\hline $\begin{array}{c}\text { Teoria } \\
\text { Modelo } \\
\text { Dez-fatores }\end{array}$ & Missão & $\begin{array}{c}\text { Apoio da } \\
\text { Alta Direção }\end{array}$ & $\begin{array}{l}\text { Planejamento } \\
\text { Cronograma }\end{array}$ & $\begin{array}{l}\text { Consulta a } \\
\text { Clientes }\end{array}$ & Pessoal & $\begin{array}{l}\text { Atividades } \\
\text { Técnicas }\end{array}$ & $\begin{array}{c}\text { Aceitação } \\
\text { dos } \\
\text { Clientes }\end{array}$ \\
\hline & Início & & $(\mathrm{Se}$ & ência no ter & & & Fim \\
\hline
\end{tabular}

Fonte: Autor

Observa-se do Quadro 3 que o critério Apoio da Alta Direção aparece classificado numa posição de menor prioridade, indicando provavelmente que, na empresa pesquisada, a Direção apoia naturalmente os projetos realizados e, por esta razão, os entrevistados não o veem como um FCS tão importante. Da mesma forma, o fator Atividades Técnicas, classificado inclusive após o fator Comunicação, indica a existência rotineira de recursos tecnológicos adequados e suficientes para a execução dos projetos.

Da estratificação destas respostas, segundo os perfis dos entrevistados quanto ao (i) nível hierárquico, (ii) área funcional de atuação, (iii) tempo de experiência profissional e (iv) tipo de participação nos projetos, a pesquisa demonstrou que em geral, a priorização dos fatores críticos de sucesso por ser considerada uma função das maiores necessidades dos grupos estratificados, ou seja, necessidades prioritárias que as pessoas sentem não ter domínio. Como exemplos desta afirmação tem-se que: 
(i) O grupo de altos executivos enxerga o Apoio da Alta Direção como a nona prioridade entre os dez fatores, enquanto o de menor hierarquia enxerga o mesmo fator na terceira posição;

(ii) O grupo de Vendas prioriza o FCS de Consulta a Clientes, apenas na sétima posição enquanto o grupo de processos de suporte o coloca na segunda prioridade e o pessoal de Desenvolvimento na terceira prioridade;

(iii) Os menos experientes classificam o FCS Apoio da Alta direção na segunda prioridade, enquanto os demais o enxergam como o quinto mais importante. De forma semelhante, o FCS Consulta a Clientes é o segundo mais importante para os mais experientes e sétimo para os mais novos;

(iv) Mesmo na estratificação pela participação no projeto que é a mais homogênea em relação ao resultado geral, os fatores de Apoio da Alta direção e Consulta a Clientes parecem ser função da necessidade dos subgrupos de classificação.

Da estratificação segundo a caracterização dos projetos, quanto à (i) novidade em relação ao mercado, (ii) tecnologia dos veículos ou de seus principais sistemas importantes, (iii) complexidade de fornecimento dos sistemas importantes e (iv) tempo disponível para o desenvolvimento do projeto, a pesquisa demonstrou que os resultados estratificados são relativamente homogêneos em relação ao geral. Mesmo assim, há alguns FCS que se mostram mais ou menos importantes (que requerem mais cuidados) em função de uma ou outra característica específica do projeto, como por exemplo:

(i) Produtos inéditos no mercado, naturalmente apresentam o FCS Pessoal como o terceiro mais importante, enquanto Aceitação do Cliente aparece na última colocação para produtos facelift;

(ii) Produtos de Alta Tecnologia também apresentam o FCS Pessoal na mesma terceira prioridade, enquanto o Consulta a Clientes aparece como primeira prioridade em produtos de baixa tecnologia; 


\subsection{Limitações da Pesquisa}

Evidentemente esta pesquisa coloca conclusões que devem ser relativizadas em função de uma série de limitações inerentes às características da empresa pesquisada, ao método de pesquisa, aos perfis profissionais dos entrevistados, aos projetos considerados pelos respondentes e outros.

Assim é que se pode relacionar como principais exemplos de limitações da pesquisa e de suas conclusões:

O ambiente de crise econômica atualmente vivido, após um grande ciclo de progresso de desenvolvimento de produtos, pode ter eventualmente influenciado os respondentes, criando vieses desconhecidos sobre o teor das respostas, visto que o tema pesquisado é justamente sobre parâmetros de sucesso.

O fato do questionário de pesquisa ser enviado e preenchido por mídia eletrônica e, portanto não permitir a interação entre o pesquisador e os entrevistados, com a consequente perda de oportunidades de coleta de impressões e percepções pela observação direta do pesquisador durante as respostas. Além disto, os entrevistados podem ter uma falsa interpretação sobre o que de fato é perguntado, a exemplo dos dois casos em que respostas tiveram que ser desconsideradas pelo incorreto preenchimento do formulário. Além disto, seria o formato deste questionário o responsável por quatro de sete executivos da empresa afirmarem prioridades pessoais de critérios de sucesso de resultado de projeto diferentes do que acreditam a empresa valorizar?

O fato do questionário solicitar ao respondente pensar em um "projeto bem sucedido do qual participou" limita o universo de projetos da montadora aos casos de sucesso.

A maioria dos pesquisados atua funcionalmente na área de Desenvolvimento de Produtos da empresa, apesar de haver sido solicitada a distribuição dos questionários pelas diversas áreas da empresa. Isto, apesar de ser uma característica da empresa pesquisada, certamente dá um viés de "visão de Engenharia" às respostas gerais. 


\subsection{Contribuições para a Academia, para as Empresas, para a Sociedade}

Como contribuições para a Academia do presente estudo registradas nesta dissertação, confirmam-se praticamente as teorias sobre parâmetros de sucesso em gerenciamento de projetos, mais especificamente sobre os cinco (5) critérios de avaliação de sucesso de resultados de projetos propostos no Modelo Diamante de Shenhar e Dvir assim como sobre os Fatores Críticos de Sucesso amplamente estudados por Pinto e Slevin e considerados no Modelo de Processo de Dez Fatores de Implantação de Projeto.

Para as empresas, esta dissertação é uma oportunidade dos profissionais de desenvolvimento de veículos comerciais, e mesmo de outras áreas que se utilizam de ferramentas de gestão de projetos, terem informações e esclarecimentos teóricos sobre impressões vividas no cotidiano de suas empresas e nem sempre bem fundamentas conceitualmente.

Para a Sociedade, a ligação proposta pelo Mestrado Profissional entre as áreas de Pesquisa Universitária com as áreas de Negócios de Empresas, sejam privadas, mistas ou públicas, no sentido de aproximar os diferentes ambientes e ampliar o universo com mais informação e produtividade de forma a se conquistar um aperfeiçoamento das instituições sociais de forma constante e sustentável.

De forma a dar maior publicidade aos resultados desta pesquisa, foi também elaborado Relato Técnico e também feitas apresentações a interessados com seus principais resultados, conforme sugestão do Programa de Mestrado Profissional em Empreendedorismo (MPE) da Faculdade de Contabilidade, Economia e Administração da Universidade de São Paulo (FEAUSP).

\subsection{Sugestões de Estudos Futuros}

Com base nos resultados desta dissertação, percebem-se oportunidades de outros novos estudos sobre o tema parâmetros de sucesso no gerenciamento de desenvolvimento de produtos em empresas brasileiras, ou mesmo outros temas observados com diferente potencial de especificidade e abrangência de investigação. 
Assim é que uma primeira sugestão para estudos futuros pode ser a possibilidade de avaliar se as percepções e opiniões dos altos executivos dirigentes de empresas brasileiras refletem na realidade a cultura vivida na empresa por eles dirigida.

Outra sugestão é investigar mais profundamente, na prática da realidade brasileira, se "o cumprimento das restrições dos recursos" é realmente mais crítico e relevante para projetos de risco mais baixo, conforme acreditam Shenhar e Dvir (2010, p. 43), visto que se verificou um aparente paradoxo nesta pesquisa.

Naturalmente sugere-se ainda estender e replicar esta pesquisa a outras montadoras tradicionais ou novas no mercado brasileiro, de forma qualitativa e quantitativa, buscando formatar o cenário automobilístico nacional em relação a parâmetros de sucesso em gerenciamento de projetos de veículos comerciais brasileiros. 


\section{REFERÊNCIAS}

ANFAVEA. ANFAVEA - 60 Anos - Anuário da Indústria Automobilística Brasileira. Associação Nacional dos Fabricantes de Veículos Automotores. São Paulo. 2016a. Disponível em: http://www.anfavea.com.br/anuario2016/anuario2016.zip.

ANFAVEA. Carta da ANFAVEA. Associação Nacional dos Fabricantes de Veículos Automotores. SP. 2016b. Disponível em: http://www.anfavea.com.br/carta.html.

ANFAVEA. Estatísticas - Séries Temporais. Associação Nacional dos Fabricantes de Veículos Automotores. SP. 2016c. Disponível em: http://www.anfavea.com.br/tabelasnovo.html.

ATKINSON, R. Project management: cost, time and quality, two best guesses and a phenomenon, it's time to accept other succes criteria. International Journal of Project Management, v. 17, n. 6, p. 337-342, 1999.

BACCARINI, D. The Concept of Project Complexity: A Review. International Journal of Project Management, v. 14, n. 4, p. 210-204, 1996.

BACCARINI, D. The Logical Framework for Defining Project Success. Project Management Journal, v. 30, n. 4, p. 25-32, 1999.

BANNERMAN, P. L. Defining Project Success - A Multi-Level Framework. Proceedings of the Project Management Institute Research Conference, Varsovia: Project Management Institute, 13 a 16 Jul. 2008.

BARCLAY, C.; OSEI-BRYSON, K.-M. Project performance development framework: An approach for developing performance criteria \& measures for information systems (IS) projects. Int. J. Production Economics, v. 124, p. 272-292, 2010.

BELLASSI, W.; TUKEL, O. I. A new frameworlk for determining critical success/ failures factors in projects. International Journal of Project Management, v. 14, n. 3, p. 141-151, 1996.

CAPES/MEC. Coordenação de Aperfeiçoamento de Pessoal de Nível Superior (CAPES) Fundação do Ministério da Educação (MEC). Portal de Periódicos, 2014. Disponivel em: $<$ http://www-periodicos-capes-gov- 
br.ez67.periodicos.capes.gov.br/index.php?option=com_phome>.

em: $2014 / 2015 / 2016$.

CARVAlHO, M. M.; RABECHINI JR., R. Fundamentos em Gestão de Projetos Construindo Competências para Gerenciar Projetos. São Paulo: Atlas, 2011.

CPG-FEA-USP. Comissão de Pós-Graduação da Faculdade de Economia, Administração e Contabilidade da Universidade de São Paulo. Manual Para Formatação e Edição de Dissertações e Teses, São Paulo, Novembro 2008. Disponivel em: $<$ http://www.fea.usp.br/media/fck/File/ManualTesesdez2008\%281\%29.pdf>.

DAIMLER. Daimler / Investor Relations / News / Capital Market Releases. Daimler Trucks - A True “Global Player", 17 Setembro 2012. Disponivel em: $<\mathrm{http}: / / \mathrm{www}$.daimler.com/dccom/0-5-7171-1-1533528-1-0-0-0-0-0-9296-0-0-0-0-0-0-00.html>. Acesso em: Maio 2014.

DAIMLER. Daimler / Company / Tradition / Company History. Beginnings of the Automobile - The Predecessor Companies (1886-1920), 2015. Disponivel em: $<$ http://www.daimler.com/company/tradition/company-history/1886-1920.html >. Acesso em: Março 2015.

DANIEL, D. R. Management Information Crisis. Harvard Business Review, p. 111-121, Sep. 1961.

DE WITT, A. Measurement of Project Success. Journal of Project Management, v. 6, n. 3, Aug. 1988.

EFQM. European Fondation for Quality Management. EFQM Model in Action, 2015-a. Disponivel em: <http://www.efqm.org/efqm-model/efqm-model-in-action-0>. Acesso em: Abril 2015.

EFQM. European Foundation for Quality Management. EFQM Processes, Products \& Services, 2015-b. Disponivel em: <http://www.efqm.org/efqm-model/efqm-model-inaction/processes-products-services>. Acesso em: Março 2015.

ELSEVIER. SD. ScienceDirect, 2014. Disponivel em: <http://www.sciencedirect.com/>. Acesso em: 2014/2015/2016. 
EMPRAD USP. Encontro dos Mestrados Profissionais de Administração. You Tube, 2014a. Disponivel em: $<$ https://www.youtube.com/watch?v=6XjKAJsnCtc $>$.

EMPRAD USP. Diferença entre Mestrado Profissional vs Mestrado Acadêmico. You Tube, 2014b. Disponivel em: < https://www.youtube.com/watch?v=gJZmImWQ1XI>.

FEA/USP. EMPRAD. Encontro dos Mestrados Profissionais em Administração, 2014. Disponivel em: <http://www.emprad.org.br/>. Acesso em: 2014/2015/2016.

FNQ. Fundação Nacional da Qualidade. Modêlo de Excelência da Gestão (MEG), Junho 2014. Disponivel em: <http://www.fnq.org.br/avalie-se/metodologia-meg/modelo-deexcelencia-da-gestao>. Acesso em: Junho 2014.

FORTUNE, J.; WHITE, D. Framing of Project Critical Success Factors by a System Model. International Journal of Project Management, v. 24, p. 53-65, 2006.

GERALDI, J.; ADBRECHT, G. On faith, fact, and interaction in projects. Project Management Journal, v. 38, n. 1, p. 32-43, Mar. 2007.

GOOGLE. Google. Google Acadêmico, 2014. Disponivel em: $<$ https://scholar.google.com.br/>. Acesso em: 2014/2015/2016.

GUERRA, J. H. L. O modelo de integração de sistemas da indústria aeronáutica: fatores motivadores. Gestão e Produção, São Carlos, v. 18, n. 2, p. 251-264, 2011.

IBAMA. Instituto Brasileiro do Meio Ambiente e Recursos Naturais Renováveis. Proconve / Promot - Programa de Controle de Poluição de Ar por Veículos Automotores, Março 2016. Disponivel em: $<$ http://www.ibama.gov.br/phocadownload/category/4?download=4792\%3Amanualportugues $>$.

IPMA. Individual Competence Baseline (ICB4). 4th. ed. Zurich: IPMA - International Project Management Association, 2015a. disponível em http://products.ipma.ch/wpcontent/uploads/2015/09/IPMA-ICB4.pdf.

IPMA. International Project Management Association. IPMA, 2015b. Disponivel em: $<$ http://www.ipma.world/>. Acesso em: Setembro 2014. 
JUSE. Japanese Union of Scientists and Engineers. The Deming Prize, 2015. Disponivel em: $<$ http://www.juse.or.jp/deming_en/>. Acesso em: Março 2015.

KERZNER, H. Gestão de Projetos - As Melhores Práticas. 2a. ed. Porto Alegre: Bookman, 2006.

KERZNER, H. Gerenciamento de Projetos - Uma Abordagem Sistêmica para Planejamento, Programação e Controle. 1 ${ }^{\mathrm{a}}$. ed. São Paulo: Edgard Blucher, 2011.

KOTABE, M.; HELSEN, K. Administração de Marketing Global. 1 ${ }^{\mathrm{a}}$. ed. São Paulo: Atlas, 2000.

LEWIS, J. P. The project Manager's Desk Reference. Chicago: Irwin, 1995.

MARCONI, M. D. A.; LAKATOS, E. M. Fundamentos da Metodologia Científica. $7^{\mathrm{a}}$. ed. São Paulo: Atlas, 2010.

MARCONI, M. D. A.; LAKATOS, E. M. Metodologia Científica. 6a . ed. São Paulo: Atlas, 2011.

MARTINS, G. D. A.; THEÓPHILO, C. R. Metodologia da Investigação Científica para Ciências Sociais Aplicadas. 2a . ed. São Paulo: Atlas, 2009.

MAXIMIANO, A. C. A. Administração de Projetos - Como Transformar Ideias em Resultados. 5a. ed. São Paulo: Atlas, 2014.

MDIC. Ministério do Desenvolvimento, Indústria e Comércio Exterior. Sistema de Acompanhamento do INOVAR-AUTO, Março 2016. Disponivel em: $<$ http://inovarauto.mdic.gov.br/InovarAuto/public/login.jspx?_adf.ctrl-state=6k12zjded_19>.

NIST. National Institute of Standards and Technology. Baldrige Performance Excellence Program, 2014. Disponivel em: <http://nist.gov/baldrige/index.cfm>. Acesso em: Junho 2014.

OGC. Gerenciando Projetos de Sucesso com Prince2 TM. London: OFFICE OF GOVERNMENT COMMERCE (OGC-TSO), 2011.

PINTO, J. K.; KHARBANDA, O. P. Successful Project Managers - Leading Your Team to Success. 1st. ed. New York: Van Nostrand Reinhold, 1995. 
PINTO, J. K.; KHARBANDA, O. P. How to Fail in Project Management (without Really Trying). Business Horizons, v. 39, n. 4, p. 45-53, July-August 1996.

PINTO, J. K.; MANTEL JR., S. J. The Causes of Project Failures. IEEE Transactions on Engineering Management, v. 37, n. 4, p. 269-276, Nov. 1990.

PINTO, J. K.; MILLET, I. Chapter 4 - Critical Success Factor in Information System Projects. In: PINTO, J. K.; IDO, M. Successful Information System Implementation. 2nd. ed. Newton Square: Project Management Institute, 1999.

PINTO, J. K.; PRESCOTT, J. E. Variation in Critical Success Factors Over the STages in the Project Life Cycle. Journal of Management, v. 14, n. 1, p. 5-18, 1988.

PINTO, J. K.; PRESCOTT, J. E. Planning and Tactical Factors In The Project Implementation Process. Journal of Managemente Studies, p. 305-328, May 1990.

PINTO, J. K.; SLEVIN, D. P. Critical Factors In Success Project Implementation. IEEE Transactions on Engeneering Management, v. EM-34, n. 1, p. 22-27, Feb. 1987.

PINTO, J. K.; SLEVIN, D. P. Critical Success Factors Across The Project Life. Project Management Journal, p. 67-75, Jun. 1988a.

PINTO, J. K.; SLEVIN, D. P. Project Success: Definitions and Measurements Techniques. Project Management Journal, v. XIX, p. 67-73, Feb. 1988b.

PINTO, J. K.; SLEVIN, D. P. Critical Success Factors in R\&D Projects. Research Technology Management, p. 31-35, Jan. 1989.

PINTO, J. K.; SLEVIN, D. P. Chapter 13 - Project Critical Success Factors: The project Implementation Profile. In: CLELAND, D. I.; GAREIS, R. Global Project Managment Handbook - Planning, Organizing and Controlling International Projects. 2nd. ed. New York: McGRAW-HILL, 2006.

PMI. Um Guia do Conjunto de Conhecimentos em Gerenciamento de Projetos (Guia PMBOK®). $3^{\text {a }}$. ed. Newtonwn Square: Project Management Institute, Inc., 2004.

PMI. Project Managment Institute. Project Management Institute (PMI), 2014a. Disponivel em: <www.pmi.org>. Acesso em: Setembro 2014. 
PMI. Um Guia do Conjunto do Conhecimentos em Gerenciamento de Projetos (Guia PMBOK®). 5a . ed. São Paulo: Saraiva, 2014b.

PRADO, D. Gerenciamento de Portfólios, Programas e Projetos nas Organizações. Nova Lima: INDG Tecnologia e Serviços Ltda., 2004. (Série Gerência de Projetos - Vol. 1).

PROQUEST. ProQuest. Produtos e Serviços, 2015. Disponivel em: $<$ http://www.proquest.com/LATAM-PT/pt-products-services/>. Acesso em: 2015/2016.

PWC. Top Suppliers. Supplement to Automotive News (Sponsored by PwC), p. 15, June 15, 2015. disponível em: https://www.autonews.com/assets/PDF/CA100044612.PDF.

REMINGTON, K.; ZOLIN, R.; TURNER, R. A Model of Project Complexity Distinguishing Dimensions of Complexity from Severity. Proceedings of 9th International Research Network of Project Management, Berlim: QUT Digital Repository, 11-13 Oct. 2009.

RESEARCH GATE. Research Gate. Home Feed, 2014. Disponivel em: $<$ https://www.researchgate.net/home>. Acesso em: 2014/2015/2016.

ROCKART, J. F. Chief executives define their own data needs. Harvard Business Review, v. 57, n. 2, p. 81-93, Mar./Apr. 1979.

SÃO PAULO. Início / Conheça SP/ História / República / Indústria Automobilística. Portal do Governo do Estado de São Paulo, 2014. Disponivel em: $<$ http://www.saopaulo.sp.gov.br/conhecasp/historia_republica-industria-automobilistica $>$. Acesso em: Maio 2014.

SCHULTZ, R. L.; SLEVIN, D. P.; PINTO, J. K. Strategy and Tatics in a Process Model of Project Implementation. Interfaces, p. 33-46, May-Jun 1987.

SHENHAR, A. J.; DVIR, D. Reinventando Gerenciamento de Projetos - A Abordagem Diamante ao Crescimento e Inovação Bem-Sucedidos. São Paulo: M. Books, 2010.

SIBI USP. SIBi USP. Sistema Integrado de Bibliotecas da Universidade de São Paulo, 2014. Disponivel em: <http://www.sibi.usp.br/>. Acesso em: 2014/2015/2016. 
SIBI/USP. Biblioteca Digital USP. Diretrizes para apresentação de dissertações e teses da USP - documento eletrônico e impresso - Parte I (ABNT), São Paulo, 2009. Disponivel em:

$<$ http://www.teses.usp.br/index.php?option=com_content\&view=article\&id=52\&Itemid=67 $>$.

SINDIPEÇAS. Sindicato Nacional da Indústria de Componentes para Veículos Automotores. Institucional, 2016. Disponivel em: <http://www.sindipecas.org.br/areaatuacao/?a=institucional\#.VxOYx0dyxZI>. Acesso em: Abril 2016.

SLEVIN, D. P.; PINTO, J. K. The Project Implementation Profile: New Tool for Projects Managers. Project Management Journal, p. 57-70, Sep. 1986.

SLEVIN, D. P.; PINTO, J. K. Balancing Strategy and Tactics in Project Implementation. Sloan Management Review, p. 33-41, Sep. 1987.

STATISTA. The Statistics Portal. The leading global automotive suppliers in 2015, 2016.

Disponivel em: <http:/www.statista.com/statistics/199703/10-leading-global-automotiveoriginal-equipment-suppliers/>. Acesso em: abr. 2016.

TATIKONDA, M. V.; ROSENTHAL, S. R. Technology Novelty, Project Complexity, and Product Development Project Execution Success: A Deeper Look at Task Uncertainty in Product Innovation. IEEE Transactions on Engineering Management, v. 47, n. 4, p. 74-87, Feb. 2000.

THOMSON REUTERS. Pesquisa. Web of Science (TM), 2014. Disponivel em: $<$ http://apps.webofknowledge.com/UA_GeneralSearch_input.do?product=UA\&search_mode $=$ GeneralSearch\&SID=3DXNzLS3C8d76syQUDH\&preferencesSaved $=>$. Acesso em: $2014 / 2015 / 2016$.

UK.GOV. Cabinet Office - GOV.UK. Best Management Practice Portfolio, 2016. Disponivel em: <https://www.gov.uk/government/publications/best-management-practiceportfolio/about-the-office-of-government-commerce>. Acesso em: Abril 2016.

UNICAMP. Sistema de Bibliotecas da Universidade Estadual de Campinas (SBU UNICAMP). Biblioteca Digital da UNICAMP, 2014. Disponivel em: $<$ http://www.bibliotecadigital.unicamp.br/>. Acesso em: 2014/2015/2016. 
WESTERVELD, E. Project Excellence Model(R): linking sucess criterias and critical success factors. International Journal of Project Management, v. 21, p. 411-418, 2003.

YIN, R. K. Estudo de Caso - Planejamento e Métodos. 4ª . ed. Porto Alegre: Bookman, 2010 .

YUGUE, R. T. Contribuição ao Estudo dos Processos de Gerenciamento e da Complexidade dos Projetos. Dissertação (Mestrado em Administração) - Programa de PósGraduação em Administração, Faculdade de Economia, Administração e Contabilidade da Universidade de São Paulo. São Paulo. 2011. 


\section{APÊNDICES}

APÊNDICE 1 - Questionário de Pesquisa Enviado por Correio Eletrônico

APÊNDICE 2 - Tabela de Respostas da Pesquisa 


\section{Pesquisa sobre Parâmetros de Sucesso em Gerenciamento de Projetos Brasileiros de Desenvolvimento de Veículos Comerciais}

*Obrigatório

\section{Termo de Consentimento Livre e Esclarecido}

Olá.

Meu nome é Paschoal Federico Neto e estou cursando atualmente o Mestrado Profissional em Empreendedorismo (MPE) da Faculdade de Economia, Administração e Contabilidade da Universidade de São Paulo (FEA-USP).

O objeto de minha dissertação de mestrado é o estudo sobre Parâmetros de Sucesso na Gestão de Projetos Brasileiros de Desenvolvimento de Veículos Comerciais (Caminhões e Ônibus).

Meu orientador é o Prof. Dr. Antonio Cesar Amaru Maximiano.

A pesquisa será feita por meio de um formulário online. Serão convidados a participar profissionais de gerenciamento de projetos.

As informações desta pesquisa serão confidenciais e divulgadas apenas em eventos ou publicações científicas, não havendo identificação dos participantes, sendo assegurado o sigilo sobre sua identidade (cláusula de confidencialidade).

E-mail para contato: paschoalfederico@usp.br

Li e concordo com os termos do Termo de Consentimento Livre e Esclarecido e minha participação é inteiramente voluntária. 


\title{
1. Dados Profissionais do Entrevistado
}

\author{
- Gênero * \\ Masculino \\ Feminino
}

- Ocupação / Função Hierárquica *

Presidente / Vice-Presidente / Diretor Pleno

Diretor Adjunto / Gerente Sênior

Gerente / Supervisor

Mestre / Especialista

- Sua atividade funcional na organização está relacionada ao processo de: *

Desenvolvimento de Produtos

Industrialização / Planejamento / Produção de Produtos

Vendas / Pós-Vendas / Marketing / Serviços

RH / Compras / Finanças / Controladoria

Outro:

- Tempo de Experiência Profissional relacionado à sua participação no gerenciamento de projetos de novos produtos: *
menos que 10 anos
de 11 a 20 anos
mais que 20 anos

- Sua participação no Gerenciamento de Projetos de Novos Produtos se deu através do exercício de: *

Comitê de Direção / Decisão do Projeto

Gerente / Lider de Projeto

Outro:

- Informe seu nome (opcional, recomendado para esclarecimento de dúvidas):

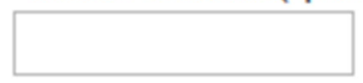

- Informe seu e-mail de contato (opcional, recomendado para esclarecimento de dúvidas):

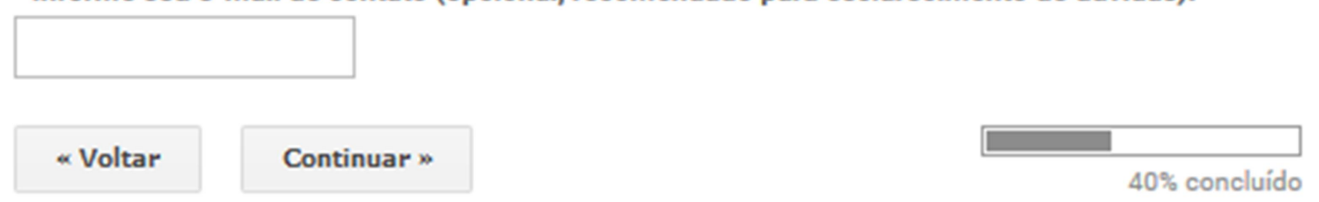




\section{Dados do Projeto de Veículo Comercial Desenvolvido}

Pense em um projeto brasileiro bem sucedido de veículo comercial (caminhão ou ônibus) do qual você tenha participado.

Informe o nome do veiculo desenvolvido (opcional)

Responda agora as perguntas de 3 a 5 sobre este projeto bem sucedido em que você participou.

\section{Caracterização do Projeto}

Caracterize esse projeto bem sucedido, baseado nas seguintes principais dimensões: (escolha apenas uma alternativa para cada dimensão)

NOVIDADE do veículo em relação ao mercado: *

Facelift: extensões e melhorias de produtos existentes

Sucessor: novas gerações de linhas de produtos existentes

Inédito: novos conceitos de veículo ou de sistemas veiculares importantes (Cabine / Quadro / Motor / Transmissão / Eixos / Direção / Suspensão / Freios)

TECNOLOGIA do veiculo ou de sistema veicular importante do veiculo: *

Baixa: veículo não apresenta novas tecnologias (por ex: nacionalizações)

Média: veiculo apresenta novas tecnologias recém-existentes

Alta: veiculo apresenta tecnologias desenvolvidas durante o projeto

COMPLEXIDADE referente aos tipos de fornecimento de sistemas veiculares importantes: *

Baixa: sistemas fornecidos por sua própria empresa

Média: sistemas fornecidos por empresas pertencentes à mesma holding proprietária de sua empresa

Alta: sistemas fornecidos por empresas sem qualquer vínculo com sua empresa

TEMPO disponivel para desenvolvimento do veículo: *

Normal: determinados normalmente pela empresa

Crítico: determinado por uma legislação especifica conhecida

Urgente: determinado por uma janela de oportunidade (ex: nova licitação) 
4. Classificação dos critérios de sucesso do resultado do projeto

Considere os seguintes critérios de sucesso de um projeto bem sucedido:

- EFICIÊNCIA:

cronograma e orçamento do projeto conforme planejado;

- CLIENTES:

satisfação dos clientes e usuários com o escopo do produto;

-EQUIPE:

satisfação e desenvolvimento pessoal dos participantes do projeto;

- VIABILIDADE:

resultados financeiros e mercadológicos;

- SUSTENTABILIDADE:

desenvolvimento de novas competências que preparam a empresa para oportunidades futuras.

4.1. Classifique os critérios de sucesso desse projeto SEGUNDO A SUA OPINIÃO SOBRE O GRAU DE IMPORTÂNCIA *

Os critérios devem ser classificados com avaliações distintas (sem repetição de valores)

\begin{tabular}{lccccc} 
& EFICIÊNCIA & CLIENTES & EQUIPE & VIABILIDADE & SUSTENTABILIDADE \\
\hline $\begin{array}{l}\text { Mais importante } \\
05\end{array}$ & 0 & 0 & 0 & 0 & 0 \\
\hline 04 & 0 & 0 & 0 & 0 & 0 \\
\hline 03 & 0 & 0 & 0 & 0 & 0 \\
\hline 02 & 0 & 0 & 0 & 0 & 0 \\
\hline $\begin{array}{l}01 \text { - Menos } \\
\text { importante }\end{array}$ & 0 & 0 & 0 & 0 & 0 \\
\hline
\end{tabular}

4.2. Classifique os critérios de sucesso desse projeto SEGUNDO O SEU ENTENDIMENTO SOBRE $O$ GRAU DE IMPORTÂNCIA ADOTADO POR SUA EMPRESA *

Os critérios devem ser classificados com avaliações distintas (sem repetição de valores)

\begin{tabular}{|c|c|c|c|c|c|}
\hline & EFICIÊNCIA & CLIENTES & EQUIPE & VIABILIDADE & SUSTENTABILIDADE \\
\hline $\begin{array}{l}\text { Mais importante } \\
05\end{array}$ & 0 & 0 & 0 & 0 & 0 \\
\hline 04 & 0 & 0 & 0 & 0 & 0 \\
\hline 03 & 0 & 0 & 0 & 0 & 0 \\
\hline 02 & 0 & 0 & 0 & 0 & 0 \\
\hline $\begin{array}{l}01 \text { - Menos } \\
\text { importante }\end{array}$ & 0 & 0 & 0 & 0 & 0 \\
\hline$\propto$ Voltar & Continuar * & & & & \\
\hline
\end{tabular}




\section{Classificação dos fatores críticos para a execução bem sucedida do projeto}

Considere os seguintes fatores críticos de sucesso (FCS) de gerenciamento de projetos:

- MISSÃO

objetivos do projeto claramente definidos desde o início;

- APOIO DA ALTA DIREÇÃO

suporte da alta direção em prover os recursos necessários e autoridade / poder para o sucesso da implementação;

- PLANEJAMENTO / CRONOGRAMA

Existência de plano detalhado (incluindo cronograma, "milestones", necessidades de mão de obra, etc.) para a execução integral do projeto;

- CONSULTA A CLIENTES

consulta a clientes no início do projeto e informação sobre o seu progresso (inclusive decisões sobre inclusão de sugestões);

- PESSOAL

qualificação e quantidade de pessoas adequadas à realização do projeto;

- ATIVIDADES TÉCNICAS

recursos tecnológicos adequados à realização do projeto;

- ACEITAÇÃO DO CLIENTE

verificação da aceitação e disposição de utilização do produto em sua última versão pelos potencias clientes e usuários;

- ACOMPANHAMENTO E "FEEDBACK"

monitoração de todos os aspectos importantes ao progresso do projeto através de revisões periódicas planejadas;

- COMUNICAÇÃO

disposição de informações através de canais e formatos adequados a todos os participantes do projeto;

- SOLUÇÃO DE PROBLEMAS

capacidade e agilidade de gerenciamento de crises e desvios de projeto, utilizando todos os recursos humanos e tecnológicos necessários.

\section{CLASSIFIQUE O FATOR MAIS IMPORTANTE COMO 10 E O MENOS IMPORTANTE COMO 01 *}

Cada valor deve ser atribuido a apenas um fator distinto (sem repetição de valores)

\begin{tabular}{|c|c|c|c|c|c|c|c|c|c|c|}
\hline & 10 & 09 & 08 & 07 & 06 & 05 & 04 & 8 & 02 & 01 \\
\hline MISSÃO & 0 & 0 & 0 & 0 & 0 & 0 & 0 & 0 & 0 & 0 \\
\hline \multirow{3}{*}{$\begin{array}{l}\text { APOIO DA ALTA } \\
\text { DIREÇÃAO } \\
\text { PLANEJAMENTO E } \\
\text { CRONOGRAMA } \\
\text { CONSULTAA } \\
\text { CLIENTES }\end{array}$} & 0 & 0 & 0 & 0 & 0 & 0 & 0 & 0 & 0 & 0 \\
\hline & 0 & 0 & 0 & 0 & 0 & 0 & 0 & 0 & 0 & 0 \\
\hline & 0 & 0 & 0 & 0 & 0 & $\mathrm{O}$ & $\mathrm{O}$ & 0 & O & 0 \\
\hline PESSOAL & 0 & 0 & 0 & 0 & 0 & 0 & 0 & 0 & 0 & 0 \\
\hline \multirow{3}{*}{$\begin{array}{l}\text { ATIVIDADES } \\
\text { TÉCNICAS } \\
\text { ACEITAC̆ÃO DO } \\
\text { CLIENTE } \\
\text { ACOMPANHAMENTO } \\
\text { E "FEEDBACK" }\end{array}$} & 0 & 0 & 0 & 0 & 0 & 0 & 0 & 0 & 0 & 0 \\
\hline & 0 & 0 & 0 & 0 & 0 & 0 & 0 & 0 & 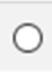 & 0 \\
\hline & 0 & 0 & 0 & 0 & 0 & 0 & 0 & 0 & 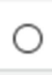 & 0 \\
\hline COMUNICAÇÃO & 0 & 0 & 0 & 0 & 0 & 0 & 0 & 0 & 0 & 0 \\
\hline $\begin{array}{l}\text { SOLUÇÃOO DE } \\
\text { PROBLEMAS }\end{array}$ & 0 & 0 & 0 & 0 & 0 & 0 & 0 & 0 & 0 & 0 \\
\hline
\end{tabular}

Muito obrigado por sua colaboração.

$$
\text { « Voltar Enviar }
$$

Nunca envie senhas pelo Formulários Google. 


\section{Pesquisa sobre Parâmetros de Sucesso em Gerenciamento de Projetos Brasileiros de Desenvolvimento de Veículos Comerciais}

Sua resposta foi registrada. Muito obrigado por sua colaboração.

Caso tenha interesse em receber posteriormente o resultado da pesquisa, envie-me um e-mail no endereço paschoalfederico@usp.br 


\section{APÊNDICE 2 - Tabela de Respostas da Pesquisa}

\section{Dados Profissionais dos Entrevistados}

\begin{tabular}{|c|c|c|c|c|c|c|c|c|c|c|}
\hline Data e Hora & & Gêne & Hierárquica & & Área de Atuação & & Tempo & & Participação no Gerenciamen & \\
\hline 16/1/2016 09:13 & ok & M & Diretor Adjunto / Geren & 3 & Vendas / Pós-Vendas / Marketing & & Mais de 20 anos & 3 & |Comitê de Direção / Decisão & \\
\hline 8/1/2016 00:45 & ok & M & Gerente / Supenvisor & 4 & Desenvolvimento de Produtos & 1 & Entre 10 e 20 anos & 2 & Gerente / Líder de Projeto & 2 \\
\hline 11/1/2016 14:43 & ok & M & Gerente / Supenvisor & 4 & Desenvolvimento de Produtos & 1 & Menos de 10 anos & 1 & Gerente / Líder de Projeto & 2 \\
\hline 13/1/2016 19:16 & ok & M & Serente Sênior & 3 & RH / Compras / Finanças / Cont & 4 & Entre 10 e 20 anos & 2 & Gerente / Líder de Projeto & 2 \\
\hline 13/1/2016 19:44 & ok & $\mathrm{F}$ & Gerente / Supervisor & 4 & Desenvolvimento de Produtos & 1 & Menos de 10 anos & 1 & área de PMO & 3 \\
\hline 13/1/2016 21:08 & ok & M & Gerente Sênior & 3 & Desenvolvimento de Produtos & 1 & Entre 10 e 20 anos & 2 & Gerente / Líder de Projeto & 2 \\
\hline 13/1/2016 21:13 & ok & M & erente / Supen & 4 & Industrialização / Planejamento & 2 & Entre 10 e 20 anos & 2 & Gerente / Líder de Projeto & 2 \\
\hline 14/1/2016 04:39 & ok & M & Gerente / Supervisor & 4 & Desenvolvimento de Produtos & 1 & Menos de 10 anos & 1 & Gerente / Líder de Projeto & 2 \\
\hline 14/1/2016 07:40 & ok & M & Gerente / Supervisor & 4 & Desenvolvimento de Produtos & 1 & Mais de 20 anos & 3 & Gerente / Líder de Projeto & 2 \\
\hline 14/1/2016 07:47 & ok & M & Gerente / Supervisor & 4 & Desenvolvimento de Produtos & 1 & Entre 10 e 20 anos & 2 & Gerente / Líder de Projeto & 2 \\
\hline 14/1/2016 07:57 & ok & M & Gerente Sênior & 3 & Desenvolvimento de Produtos & 1 & Mais de 20 anos & 3 & Comitê de Direção / Decisão & 1 \\
\hline 14/1/2016 08:27 & ok & M & Gerente / Supenvisor & 4 & Desenvolvimento de Produtos & 1 & Mais de 20 anos & 3 & Participante como Gerente d & 3 \\
\hline 14/1/2016 08:28 & ok & $\mathrm{F}$ & Gerente / Supervisor & 4 & Industrialização / Planejamento & 2 & Mais de 20 anos & 3 & Gerente / Líder de Projeto & 2 \\
\hline 14/1/2016 08:33 & ok & M & Gerente / Supervisor & 4 & Vendas / Pós-Vendas / Marketir & 3 & Entre 10 e 20 anos & 2 & Gerente / Líder de Projeto & 2 \\
\hline 14/1/2016 08:35 & ok & M & Gerente / Supenvisor & 4 & Desenvolvimento de Produtos & 1 & Menos de 10 anos & 1 & Gerente / Líder de Projeto & 2 \\
\hline 14/1/2016 08:48 & ok & M & Gerente / Supervisor & 4 & Desenvolvimento de Produtos & 1 & Mais de 20 anos & 3 & Gerente / Líder de Projeto & 2 \\
\hline 14/1/2016 09:42 & ok & M & Gerente / Super & 4 & Vendas / Pós-Vendas / Marketir & 3 & Entre 10 e 20 anos & 2 & Gerente / Líder de Projeto & 2 \\
\hline 14/1/2016 10:24 & ok & M & Gerente Sênior & 3 & Desenvolvimento de Produtos & 1 & Entre 10 e 20 anos & 2 & Gerente / Líder de Projeto & 2 \\
\hline 14/1/2016 11:00 & ok & M & Gerente Sênior & 3 & Desenvolvimento de Produtos & 1 & Entre 10 e 20 anos & 2 & Gerente / Líder de Projeto & 2 \\
\hline 14/1/2016 11:40 & ok & M & Gerente Sênior & 3 & RH / Compras / Finanças / Cont & 4 & Mais de 20 anos & 3 & Comitê de Direção / Decisão & 1 \\
\hline 14/1/2016 11:58 & ok & M & Gerente Sênior & 3 & Industrialização / Planejamento & 2 & Mais de 20 anos & 3 & Gerente / Líder de Projeto & 2 \\
\hline 14/1/2016 11:59 & ok & M & Gerente / Supervisor & 4 & Desenvolvimento de Produtos & 1 & Mais de 20 anos & 3 & Comitê de Direção / Decisão & 1 \\
\hline 14/1/2016 12:33 & ok & M & iretor & 1 & Qualidade & 2 & Mais de 20 anos & 3 & / Líder de Projeto & 2 \\
\hline $14 / 1 / 201612: 47$ & ok & M & Presidente / Diretor & 1 & Desenvolvimento de Produtos & 1 & Entre 10 e 20 anos & 2 & Comitê de Direção / Decisão & 1 \\
\hline $14 / 1 / 201614: 28$ & ok & M & Presidente / Diretor & 1 & Industrialização / Planejamento & 2 & Mais de 20 anos & 3 & Gerente / Líder de Projeto & 2 \\
\hline 14/1/2016 17:22 & ok & M & Sênior & 3 & Industrialização / Planejamento & 2 & Entre 10 e 20 ano & 2 & Gerente / Líder de Projeto & 2 \\
\hline 14/1/2016 17:57 & ok & M & Gerente / Supervisor & 4 & Industrialização / Planejamento & 2 & Mais de 20 anos & 3 & Gerente / Líder de Projeto & 2 \\
\hline 14/1/2016 18:09 & ok & M & Gerente Sênior & 3 & Industrialização / Planejamento & 2 & Entre 10 e 20 anos & 2 & Gerente / Líder de Projeto & 2 \\
\hline $15 / 1 / 2$ & ok & M & Gerente Sênior & 3 & Dese & 1 & anos & 2 & ojeto & 2 \\
\hline 15/1/2016 13:17 & ok & M & Gerente / Supervisor & 4 & Desenvolvimento de Produtos & 1 & Mais de 20 anos & 3 & Gerente / Líder de Projeto & 2 \\
\hline 15/1/2016 15:05 & ok & M & Gerente Sênior & 3 & Desenvolvimento de Produtos & 1 & Mais de 20 anos & 3 & Comite e Gerente de projetos & 1 \\
\hline $16 / 1 / 2$ & ok & M & Gerente / Super & 4 & Des & 1 & M & 3 & Ger & 2 \\
\hline 16/1/2016 23:34 & ok & M & Gerente Sênior & 3 & Desenvolvimento de Produtos & 1 & Entre 10 e 20 anos & 2 & Comitê de Direção / Decisão & 1 \\
\hline 18/1/2016 09:13 & ok & M & or & 1 & RH / Compras / Finanças / Cont & 4 & Mais de 20 anos & 3 & Comitê de Direção / Decisão & 1 \\
\hline 18/1/2016 09:58 & ok & M & Gerente / Supervisor & 4 & Desenvolvimento de Produtos & 1 & Entre 10 e 20 ano & 2 & Gerente / Líder de Projeto & 2 \\
\hline 18/1/2016 14:00 & ok & $\mathrm{F}$ & Gerente Sênior & 3 & Industrialização / Planejamento & 2 & Mais de 20 anos & 3 & Comitê de Direção / Decisão & 1 \\
\hline 18/1/2016 14:26 & ok & M & & 1 & Head Bus LA & 2 & Mais de 20 anos & 3 & comite de direção e como ge & 1 \\
\hline 18/1/2016 16:28 & ok & M & Gerente / Supenvisor & 4 & Desenvolvimento de Produtos & 1 & Entre 10 e 20 anos & 2 & Especialista tecnico & 3 \\
\hline 18/1/2016 17:34 & ok & M & Gerente Sênior & 3 & RH / Compras / Finanças / Cont & 4 & Entre 10 e 20 anos & 2 & Gerente / Líder de Projeto & 2 \\
\hline 18/1/2016 23:09 & ok & M & a & 5 & Desenvolvimento de Produtos & 1 & Menos de 10 anos & 1 & Gerente / Líder de Projeto & 2 \\
\hline 19/1/2016 06:44 & ok & M & Gerente / Supervisor & 4 & Desenvolvimento de Produtos & 1 & Entre 10 e 20 anos & 2 & Gerente / Líder de Projeto & 2 \\
\hline $20 / 1 / 201618: 56$ & ok & M & Gerente / Supervisor & 4 & Desenvolvimento de Produtos & 1 & Entre 10 e 20 anos & 2 & Gerente / Líder de Projeto & 2 \\
\hline 21/1/2016 09:07 & ok & M & Gerente / Super & 4 & Desenvolvimento de Produtos & 1 & Mais de 20 anos & 3 & Gerente / Líder de Projeto & 2 \\
\hline 22/1/2016 20:01 & ok & M & Gerente Sênior & 3 & Desenvolvimento de Produtos & 1 & Mais de 20 anos & 3 & Gerente / Líder de Projeto & 2 \\
\hline 24/1/2016 13:07 & ok & M & Presic & 1 & Desenvolvimento de Produtos & 1 & Entre 10 e 20 anos & 2 & Gerente / Líder de Projeto & 2 \\
\hline 24/1/2016 20:01 & ok & M & Gerente / Supervisor & 4 & Desenvolvimento de Produtos & 1 & 20 anos & 2 & Gerente / Líder de Projeto & 2 \\
\hline 25/1/2016 11:43 & ok & M & Gerente / Supervisor & 4 & Desenvolvimento de Produtos & 1 & Mais de 20 anos & 3 & Gerente / Líder de Projeto & 2 \\
\hline 25/1/2016 11:53 & ok & M & sor & 4 & Desenvolvimento de Produtos & 1 & Entre 10 e 20 anos & 2 & Gerente / Líder de Projeto & 2 \\
\hline 25/1/2016 14:13 & ok & $\mathrm{M}$ & Gerente / Supervisor & 4 & Desenvolvimento de Produtos & 1 & Menos de 10 anos & 1 & Gerente / Líder de Projeto & 2 \\
\hline 25/1/2016 15:04 & ok & M & Gerente / Supervisor & 4 & Desenvolvimento de Produtos & 1 & Mais de 20 anos & 3 & Gerente / Líder de Projeto & 2 \\
\hline $26 / 1 / 201611: 57$ & ok & M & visor & 4 & Desenvolvimento de Produtos & 1 & Mais de 20 anos & 3 & Gerente / Líder de Projeto & 2 \\
\hline $26 / 1 / 201616: 23$ & ok & M & Gerente / Supervisor & 4 & Vendas / Pós-Vendas / Marketir & 3 & Mais de 20 anos & 3 & Tanto como gerente quanto $c$ & 3 \\
\hline 26/1/2016 22:45 & ok & M & Gerente Sênior & 3 & Desenvolvimento de Produtos & 1 & Entre 10 e 20 anos & 2 & Gerente / Líder de Projeto & 2 \\
\hline 27/1/2016 13:59 & ok & M & Ger & 4 & Desenvolvimento de Produtos & 1 & Entre 10 e 20 anos & 2 & Participante & 3 \\
\hline 28/1/2016 15:36 & ok & M & Gerente / Supervisor & 4 & Desenvolvimento de Produtos & 1 & Entre 10 e 20 anos & 2 & Gerente / Lider & 2 \\
\hline 29/1/2016 10:51 & ok & M & Gerente / Supervisor & 4 & Desenvolvimento de Produtos & 1 & Entre 10 e 20 anos & 2 & & 3 \\
\hline 4/2/2016 20:16 & ok & M & Gerente Sênior & 3 & Vendas / Pós-Vendas / Marketir & 3 & Entre 10 e 20 anos & 2 & Comitê de Direção / Decisão & 1 \\
\hline $22 / 2 / 201607: 21$ & ok & M & Gerente / Supenvisor & 4 & Desenvolvimento de Produtos & 1 & Entre 10 e 20 anos & 2 & Gerente / Líder de Projeto & 2 \\
\hline 22/2/2016 07:38 & ok & M & Gerente / Supen & 4 & Cost Engineering & 2 & Menos de 10 anos & 1 & Grupo de Trabalho & 3 \\
\hline 22/2/2016 11:06 & ok & M & Gerente Sênior & 3 & Desenvolvimento de Produtos & 1 & Entre 10 e 20 anos & 2 & Gerente / Líder de Projeto & 2 \\
\hline $25 / 2 / 201616: 27$ & ok & M & Gerente Sênior & 1 & Desenvolvimento de Produtos & 1 & Mais de 20 anos & 3 & Comitê de Direção / Decisão & 1 \\
\hline 29/2/2016 00:24 & ok & M & or & 3 & ejamento & 2 & $\mathrm{Ma}$ & 3 & Gerent & 2 \\
\hline
\end{tabular}




\section{Caracterização do Projeto}

\begin{tabular}{|c|c|c|c|c|c|c|c|c|}
\hline Data e Hora & NOVIDADE & & TECNOLOGIA & & COMPLEXD & & TEMPO & $1-$ \\
\hline 16/1/2016 09:13 & Sucessor & 2 & Alta & 1 & Alta & 1 & Crítico & 2 \\
\hline 8/1/2016 00:45 & Inédito & 1 & Alta & 1 & Alta & 1 & Urgente & 1 \\
\hline 11/1/2016 14:43 & Facelift & 3 & Média & 2 & Média & 2 & Urgente & 1 \\
\hline 13/1/2016 19:16 & Sucessor & 2 & Baixa & 3 & Alta & 1 & Crítico & 2 \\
\hline 13/1/2016 19:44 & Sucessor & 2 & Alta & 1 & Alta & 1 & Urgente & 1 \\
\hline 13/1/2016 21:08 & Inédito & 1 & Média & 2 & Alta & 1 & Urgente & 1 \\
\hline 13/1/2016 21:13 & Inédito & 1 & Média & 2 & Média & 2 & Urgente & 1 \\
\hline 14/1/2016 04:39 & Sucessor & 2 & Média & 2 & Alta & 1 & Urgente & 1 \\
\hline 14/1/2016 07:40 & Sucessor & 2 & Alta & 1 & Alta & 1 & Urgente & 1 \\
\hline 14/1/2016 07:47 & Inédito & 1 & Média & 2 & Alta & 1 & Crítico & 2 \\
\hline 14/1/2016 07:57 & Inédito & 1 & Alta & 1 & Alta & 1 & Normal & 3 \\
\hline 14/1/2016 08:27 & Facelift & 3 & Média & 2 & Alta & 1 & Normal & 3 \\
\hline 14/1/2016 08:28 & Inédito & 1 & Média & 2 & Alta & 1 & Crítico & 2 \\
\hline 14/1/2016 08:33 & Sucessor & 2 & Média & 2 & Alta & 1 & Crítico & 2 \\
\hline 14/1/2016 08:35 & Facelift & 3 & Baixa & 3 & Alta & 1 & Urgente & 1 \\
\hline 14/1/2016 08:48 & Inédito & 1 & Média & 2 & Baixa & 3 & Urgente & 1 \\
\hline 14/1/2016 09:42 & Inédito & 1 & Média & 2 & Baixa & 3 & Normal & 3 \\
\hline 14/1/2016 10:24 & Sucessor & 2 & Alta & 1 & Média & 2 & Normal & 3 \\
\hline 14/1/2016 11:00 & Inédito & 1 & Média & 2 & Alta & 1 & Crítico & 2 \\
\hline 14/1/2016 11:40 & Sucessor & 2 & Média & 2 & Alta & 1 & Urgente & 1 \\
\hline 14/1/2016 11:58 & Facelift & 3 & Baixa & 3 & Baixa & 3 & Urgente & 1 \\
\hline 14/1/2016 11:59 & Inédito & 1 & Média & 2 & Alta & 1 & Crítico & 2 \\
\hline 14/1/2016 12:33 & Inédito & 1 & Média & 2 & Alta & 1 & Urgente & 1 \\
\hline 14/1/2016 12:47 & Sucessor & 2 & Alta & 1 & Média & 2 & Crítico & 2 \\
\hline $14 / 1 / 201614: 28$ & Sucessor & 2 & Média & 2 & Alta & 1 & Crítico & 2 \\
\hline 14/1/2016 17:22 & Inédito & 1 & Média & 2 & Alta & 1 & Crítico & 2 \\
\hline 14/1/2016 17:57 & Inédito & 1 & Média & 2 & Média & 2 & Normal & 3 \\
\hline 14/1/2016 18:09 & Sucessor & 2 & Alta & 1 & Alta & 1 & Urgente & 1 \\
\hline 15/1/2016 10:48 & Facelift & 3 & Média & 2 & Alta & 1 & Crítico & 2 \\
\hline 15/1/2016 13:17 & Sucessor & 2 & Média & 2 & Média & 2 & Crítico & 2 \\
\hline 15/1/2016 15:05 & Inédito & 1 & Alta & 1 & Alta & 1 & Crítico & 2 \\
\hline 16/1/2016 17:46 & Inédito & 1 & Média & 2 & Alta & 1 & Crítico & 2 \\
\hline 16/1/2016 23:34 & Facelift & 3 & Baixa & 3 & Média & 2 & Urgente & 1 \\
\hline 18/1/2016 09:13 & Sucessor & 2 & Baixa & 3 & Baixa & 3 & Crítico & 2 \\
\hline 18/1/2016 09:58 & Sucessor & 2 & Média & 2 & Alta & 1 & Urgente & 1 \\
\hline 18/1/2016 14:00 & Inédito & 1 & Média & 2 & Média & 2 & Urgente & 1 \\
\hline 18/1/2016 14:26 & Inédito & 1 & Média & 2 & Alta & 1 & Normal & 3 \\
\hline 18/1/2016 16:28 & Sucessor & 2 & Alta & 1 & Alta & 1 & Normal & 3 \\
\hline 18/1/2016 17:34 & Sucessor & 2 & Média & 2 & Alta & 1 & Crítico & 2 \\
\hline 18/1/2016 23:09 & Inédito & 1 & Baixa & 3 & Baixa & 3 & Urgente & 1 \\
\hline 19/1/2016 06:44 & Facelift & 3 & Média & 2 & Baixa & 3 & Crítico & 2 \\
\hline $20 / 1 / 2016$ 18:56 & Inédito & 1 & Média & 2 & Média & 2 & Normal & 3 \\
\hline 21/1/2016 09:07 & Sucessor & 2 & Média & 2 & Média & 2 & Normal & 3 \\
\hline 22/1/2016 20:01 & Sucessor & 2 & Alta & 1 & Média & 2 & Crítico & 2 \\
\hline 24/1/2016 13:07 & Inédito & 1 & Alta & 1 & Alta & 1 & Crítico & 2 \\
\hline 24/1/2016 20:01 & Sucessor & 2 & Média & 2 & Alta & 1 & Crítico & 2 \\
\hline 25/1/2016 11:43 & Inédito & 1 & Alta & 1 & Alta & 1 & Urgente & 1 \\
\hline 25/1/2016 11:53 & Sucessor & 2 & Alta & 1 & Média & 2 & Normal & 3 \\
\hline $25 / 1 / 201614: 13$ & Sucessor & 2 & Baixa & 3 & Alta & 1 & Urgente & 1 \\
\hline 25/1/2016 15:04 & Inédito & 1 & Média & 2 & Média & 2 & Crítico & 2 \\
\hline $26 / 1 / 2016$ 11:57 & Sucessor & 2 & Média & 2 & Média & 2 & Normal & 3 \\
\hline 26/1/2016 16:23 & Inédito & 1 & Alta & 1 & Alta & 1 & Crítico & 2 \\
\hline $26 / 1 / 201622: 45$ & Inédito & 1 & Alta & 1 & Alta & 1 & Crítico & 2 \\
\hline 27/1/2016 13:59 & Facelift & 3 & Média & 2 & Média & 2 & Urgente & 1 \\
\hline 28/1/2016 15:36 & Sucessor & 2 & Alta & 1 & Média & 2 & Normal & 1 \\
\hline $29 / 1 / 2016$ 10:51 & Inédito & 1 & Média & 2 & Média & 2 & Urgente & 1 \\
\hline 4/2/2016 20:16 & Inédito & 1 & Média & 2 & Alta & 1 & Normal & 3 \\
\hline 22/2/2016 07:21 & Sucessor & 2 & Média & 2 & Alta & 1 & Crítico & 2 \\
\hline 22/2/2016 07:38 & Inédito & 1 & Média & 2 & Média & 2 & Crítico & 2 \\
\hline $22 / 2 / 2016$ 11:06 & Inédito & 1 & Média & 2 & Baixa & 3 & Urgente & 1 \\
\hline 25/2/2016 16:27 & Inédito & 1 & Média & 2 & Alta & 1 & Urgente & 1 \\
\hline 29/2/2016 00:24 & Sucessor & 2 & Média & 2 & Alta & 1 & Normal & 3 \\
\hline
\end{tabular}




\section{Classificação dos Critérios de Sucesso do Resultado do Projeto}

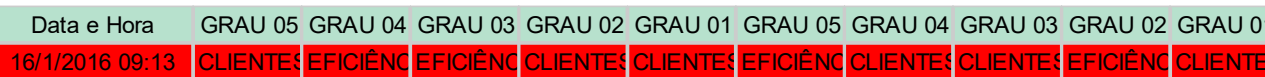

8/1/2016 00:45 CLIENTE@ VIABILIDA EFICIÊNC EQUIPE SUSTENT VIABILID\& EFICIÊNC CLIENTE؟ SUSTENT EQUIPE 11/1/2016 14:43 VIABILIDA EFICIÊNC CLIENTE؟ SUSTENT EQUIPE CLIENTE؟ VIABILID\& SUSTENT EFICIÊNC EQUIPE 13/1/2016 19:16 CLIENTE؟EFICIÊNC EQUIPE VIABILIDA SUSTENT CLIENTE EFICIÊNC EQUIPE VIABILID\& SUSTEN7 13/1/2016 19:44 CLIENTE؟ VIABILIDA EQUIPE SUSTEN7 EFICIÊNC EFICIÊNC VIABILIDA SUSTENT CLIENTES EQUIPE 13/1/2016 21:08 CLIENTE؟ VIABILIDf EQUIPE SUSTEN7 EFICIÊNC VIABILID\& EFICIÊNC CLIENTE@ SUSTENT EQUIPE 13/1/2016 21:13 CLIENTE@EQUIPE EFICIÊNC VIABILIDA SUSTENT CLIENTE@ EQUIPE EFICIÊNC VIABILID\& SUSTEN7 14/1/2016 04:39 CLIENTE@EFICIÊNC EQUIPE VIABILID/SUSTENT CLIENTEৎ EFICIÊNC EQUIPE VIABILID\& SUSTENT 14/1/2016 07:40 VIABILIDA CLIENTE`EFICIÊNC SUSTEN7 EQUIPE VIABILID/ CLIENTEৎ EFICIÊNC SUSTENT EQUIPE 14/1/2016 07:47 CLIENTE؟EFICIÊNC VIABILIDA EQUIPE SUSTENT EFICIÊNC VIABILID\& CLIENTE؟ SUSTENT EQUIPE 14/1/2016 07:57 CLIENTE@ VIABILIDA SUSTENT EQUIPE EFICIÊNC VIABILID\& SUSTENT CLIENTE EFICIÊNC EQUIPE 14/1/2016 08:27 CLIENTE؟EFICIÊNC VIABILIDA EQUIPE SUSTENT CLIENTE@EFICIÊNC VIABILIDA SUSTENT EQUIPE 14/1/2016 08:28 SUSTENT CLIENTE؟EQUIPE VIABILID/ EFICIÊNC SUSTENT VIABILID\& CLIENTE@ EFICIÊNC EQUIPE 14/1/2016 08:33 CLIENTE؟EFICIÊNC VIABILIDA EQUIPE SUSTENT VIABILID\& EFICIÊNC CLIENTE؟EQUIPE SUSTENT 14/1/2016 08:35 EQUIPE VIABILIDA EFICIÊNC CLIENTE@ SUSTENT VIABILID\& CLIENTE@ SUSTENT EQUIPE EFICIÊNC 14/1/2016 08:48 EFICIÊNC EQUIPE CLIENTE؟SUSTEN7 VIABILIDA CLIENTE@ VIABILID\& EFICIÊNC SUSTENT EQUIPE 14/1/2016 09:42 CLIENTE؟EQUIPE EFICIÊNC VIABILID/SUSTENT EQUIPE CLIENTEৎ VIABILIDf EFICIÊNC SUSTENT 14/1/2016 10:24 VIABILIDA SUSTENT CLIENTE@ EFICIÊNC EQUIPE VIABILID\& SUSTENT CLIENTE@ EFICIÊNC EQUIPE 14/1/2016 11:00 CLIENTE@EQUIPE VIABILIDA EFICIÊNC SUSTENT CLIENTE@ VIABILID\& EQUIPE EFICIÊNC SUSTENT 14/1/2016 11:40 CLIENTE؟SUSTENT VIABILIDA EQUIPE EFICIÊNC EFICIÊNC CLIENTEৎ VIABILIDA SUSTENT EQUIPE 14/1/2016 11:58 CLIENTE؟VIABILID\& EFICIÊNC SUSTEN7 EQUIPE CLIENTE؟VIABILID\& EFICIÊNC SUSTENT EQUIPE 14/1/2016 11:59 VIABILIDA EFICIÊNC EQUIPE CLIENTE؟SUSTENT VIABILID\& EFICIÊNC EQUIPE CLIENTE؟ SUSTENT 14/1/2016 12:33 CLIENTE؟ VIABILID\& EFICIÊNC SUSTENT EQUIPE CLIENTE؟ VIABILID\& EFICIÊNC SUSTEN7 EQUIPE 14/1/2016 12:47 CLIENTE@EQUIPE EFICIÊNC VIABILIDA SUSTENT EFICIÊNC CLIENTEৎ VIABILIDA SUSTENT EQUIPE 14/1/2016 14:28 CLIENTE@ VIABILIDA EFICIÊNC EQUIPE SUSTENT CLIENTE@ VIABILID\& EFICIÊNC EQUIPE SUSTENT 14/1/2016 17:22 EFICIÊNC CLIENTE@ VIABILIDA EQUIPE SUSTENT EFICIÊNC CLIENTE@ VIABILIDA SUSTENT EQUIPE 14/1/2016 17:57 SUSTENT CLIENTEৎEFICIÊNC EQUIPE VIABILID\& SUSTENT VIABILID\& CLIENTEৎEFICIÊNC EQUIPE 14/1/2016 18:09 CLIENTE؟ EFICIÊNC SUSTENT VIABILIDf EQUIPE CLIENTE؟ EFICIÊNC SUSTENT VIABILID/ EQUIPE 15/1/2016 10:48 CLIENTE؟VIABILIDf SUSTENT EQUIPE EFICIÊNC VIABILIDf CLIENTES EFICIÊNC SUSTENT EQUIPE 15/1/2016 13:17 VIABILIDA CLIENTE@ EFICIÊNC SUSTENT EQUIPE VIABILID\& CLIENTE@ EFICIÊNC SUSTENT EQUIPE 15/1/2016 15:05 CLIENTE@VIABILIDf EFICIÊNC SUSTEN7 EQUIPE CLIENTE@ VIABILID\& EFICIÊNC SUSTENT EQUIPE 16/1/2016 17:46 SUSTENT VIABILID/ EQUIPE CLIENTEৎEFICIÊNC VIABILID\& SUSTENT CLIENTEৎEQUIPE EFICIÊNC 16/1/2016 23:34 CLIENTE@ EFICIÊNC VIABILIDA EQUIPE SUSTENT CLIENTEৎ EFICIÊNC VIABILIDf EQUIPE SUSTENT 18/1/2016 09:13 CLIENTE؟EFICIÊNC VIABILIDA SUSTEN7 EQUIPE CLIENTE؟ VIABILIDf EFICIÊNC SUSTENT EQUIPE 18/1/2016 09:58 EQUIPE EFICIÊNC CLIENTE؟ SUSTENT VIABILIDA VIABILID\& EFICIÊNC CLIENTESEQUIPE SUSTENT 18/1/2016 14:00 CLIENTE؟ VIABILIDf EFICIÊNC SUSTEN7 EQUIPE VIABILID\& CLIENTE؟ EFICIÊNC SUSTENT EQUIPE 18/1/2016 14:26 EFICIÊNC EQUIPE VIABILIDA SUSTENT CLIENTEৎ EFICIÊNC VIABILID\& CLIENTE؟ SUSTENT EQUIPE 18/1/2016 16:28 CLIENTE؟ VIABILIDf EFICIÊNC EQUIPE SUSTENT VIABILIDf CLIENTE؟ EFICIÊNC SUSTENT EQUIPE 18/1/2016 17:34 CLIENTE؟ VIABILID/ SUSTENT EQUIPE EFICIÊNC VIABILID/ CLIENTEৎ EFICIÊNC SUSTENT EQUIPE 18/1/2016 23:09 EFICIÊNC SUSTENT CLIENTE〔 VIABILIDf EQUIPE VIABILID\& CLIENTE؟EFICIÊNC SUSTENT EQUIPE 19/1/2016 06:44 EFICIÊNC VIABILID/ SUSTENT CLIENTEৎEQUIPE EFICIÊNC VIABILID\& SUSTENT CLIENTEৎ EQUIPE 20/1/2016 18:56 EQUIPE EFICIÊNC CLIENTE` VIABILIDA SUSTENT VIABILID\& EFICIÊNC CLIENTE؟EQUIPE SUSTENT 21/1/2016 09:07 CLIENTE@VIABILID\& EQUIPE EFICIÊNC SUSTENT VIABILID\& EFICIÊNC CLIENTE؟EQUIPE SUSTEN7 22/1/2016 20:01 CLIENTE؟EFICIÊNC VIABILIDA SUSTEN7 EQUIPE VIABILID\& CLIENTES EFICIÊNC SUSTENT EQUIPE 24/1/2016 13:07 VIABILIDA CLIENTE؟ EFICIÊNC SUSTENT EQUIPE VIABILID\& CLIENTE؟ EFICIÊNC SUSTENT EQUIPE 24/1/2016 20:01 EFICIÊNC CLIENTE@ VIABILIDA SUSTENT EQUIPE EFICIÊNC CLIENTE@ VIABILIDf SUSTENT EQUIPE 25/1/2016 11:43 EFICIÊNC CLIENTE؟ SUSTENT EQUIPE VIABILIDf EFICIÊNC SUSTENT CLIENTE؟ VIABILID\& EQUIPE 25/1/2016 11:53 CLIENTE@EQUIPE SUSTENT VIABILIDA EFICIÊNC VIABILID\& CLIENTES EFICIÊNC SUSTENT EQUIPE 25/1/2016 14:13 CLIENTE؟EFICIÊNC VIABILIDf EQUIPE SUSTENT VIABILID\& EFICIENNC CLIENTE؟EQUIPE SUSTENT 25/1/2016 15:04 CLIENTE@VIABILID\& EQUIPE SUSTENTEFICIÊNC SUSTENT VIABILID\& CLIENTE@EQUIPE EFICIÊNC 26/1/2016 11:57 VIABILIDA CLIENTEৎ EFICIÊNC SUSTENT EQUIPE VIABILID\& EFICIÊNC CLIENTE؟ SUSTENT EQUIPE 26/1/2016 16:23 VIABILIDA SUSTENT EFICIÊNC CLIENTE؟EQUIPE SUSTEN7 EFICIÊNC VIABILIDA CLIENTE؟ EQUIPE 26/1/2016 22:45 CLIENTE؟VIABILIDA EFICIÊNC SUSTEN7 EQUIPE CLIENTE؟ VIABILID\& SUSTENT EFICIÊNC EQUIPE 27/1/2016 13:59 CLIENTE؟VIABILIDA EQUIPE EFICIÊNC SUSTENT VIABILID\& CLIENTEৎEFICIENNC EQUIPE SUSTENT 28/1/2016 15:36 EQUIPE EFICIÊNC CLIENTE@ SUSTEN7 VIABILIDA CLIENTE@ SUSTENT VIABILIDA EFICIÊNC EQUIPE 29/1/2016 10:51 CLIENTE؟VIABILIDA EFICIÊNC EQUIPE SUSTENT EFICIÊNC CLIENTEৎ VIABILIDA EQUIPE SUSTENT 4/2/2016 20:16 CLIENTE@ VIABILID\& EFICIÊNC SUSTEN7 EQUIPE VIABILID\& EFICIÊNC SUSTENT CLIENTE؟EQUIPE 22/2/2016 07:21 CLIENTE؟ VIABILIDf EFICIÊNC SUSTENT EQUIPE VIABILIDf CLIENTE؟ EFICIÊNC SUSTENT EQUIPE 22/2/2016 07:38 EFICIÊNC SUSTENT CLIENTE؟ VIABILIDf EQUIPE EFICIÊNC CLIENTE؟ VIABILIDA SUSTENT EQUIPE 22/2/2016 11:06 VIABILIDA EFICIÊNC CLIENTE؟ EQUIPE SUSTENT VIABILID/ SUSTENT EFICIÊNC CLIENTEৎ EQUIPE 25/2/2016 16:27 VIABILIDA CLIENTE〔 EQUIPE EFICIÊNC SUSTENT VIABILID\& EFICIÊNC CLIENTE؟ SUSTENT EQUIPE 29/2/2016 00:24 CLIENTE؟ VIABILIDA EQUIPE SUSTENTEFICIÊNC VIABILIDf CLIENTE؟ SUSTENT EFICIÊNC EQUIPE 
Classificação dos Fatores Críticos de Sucesso (FCS) para a Execução do Projeto

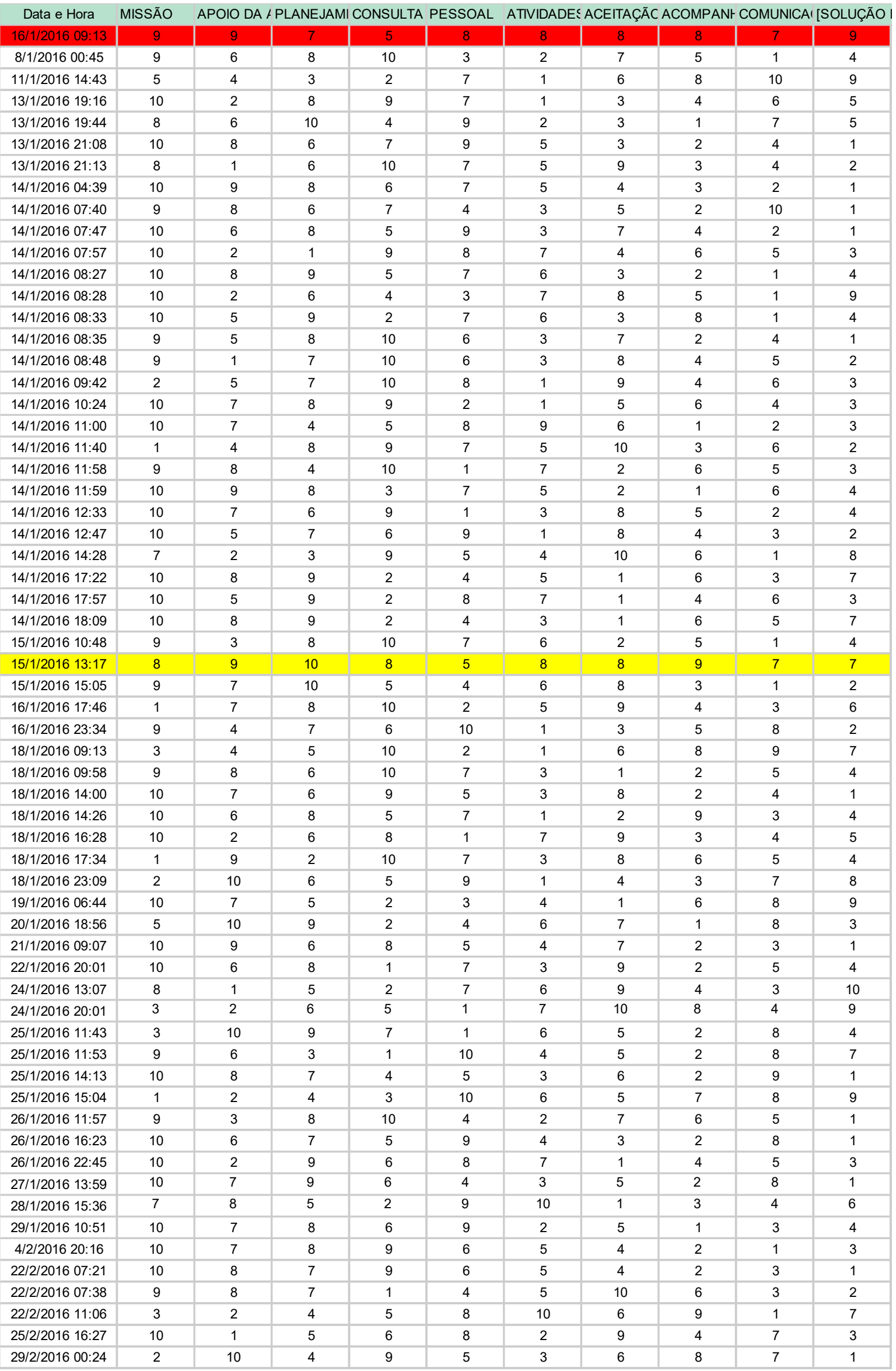

